Aus dem Institut für Neuro- und Sinnesphysiologie

(Prof. Dr. rer nat. S. Rizzoli)

der Medizinischen Fakultät der Universität Göttingen

\title{
Auswirkungen von Dimerisierung auf die Signalgebung der Serotonin- Rezeptoren 2A, 2B und 2C
}

\author{
INAUGURAL-DISSERTATION \\ zur Erlangung des Doktorgrades \\ der Medizinischen Fakultät der \\ Georg-August-Universität zu Göttingen
}

vorgelegt von

Meike Thode

aus

Heide

Göttingen 2021 
Dekan:

\section{Betreuungsausschuss}

Betreuer:

Ko-Betreuer:

\section{Prüfungskommission}

Referent:

Ko-Referent:

Drittreferent:

Datum der mündlichen Prüfung: 09.11.2021
PD Dr. phil. nat. M. Niebert

Prof. Dr. med. M. Oppermann

PD Dr. phil. nat. M. Niebert

Prof. Dr. Martin Oppermann

Prof. Dr. Ralf Dressel 
Hiermit erkläre ich, die Dissertation mit dem Titel "Auswirkungen von Dimerisierung auf die Signalgebung der Serotonin-Rezeptoren $2 \mathrm{~A}, 2 \mathrm{~B}$ und $2 \mathrm{C}$ " eigenständig angefertigt und keine anderen als die von mir angegebenen Quellen und Hilfsmittel verwendet zu haben.

Göttingen, den 


\section{Inhaltsverzeichnis}

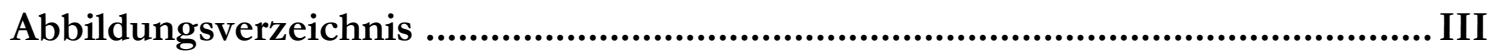

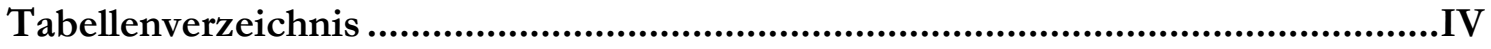

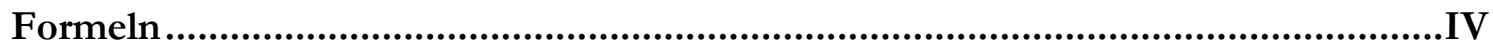

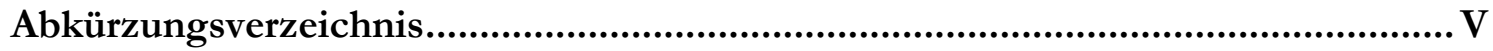

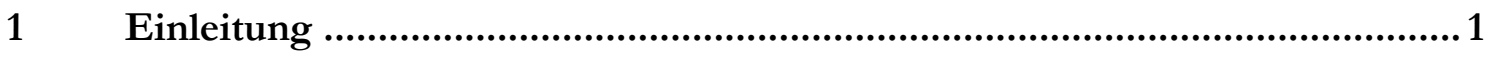

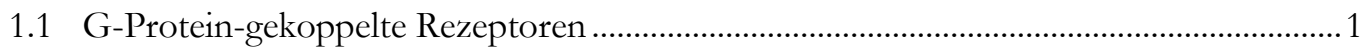

1.1.1 G-Proteine

1.1.2 Aktivierung der GPCRs .............................................................................

1.1.3 Desensibilisierung der GPCRs........................................................................

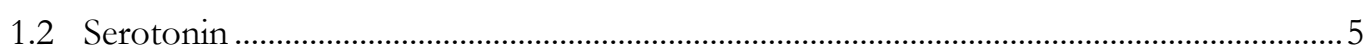

1.2.1 Die Entdeckung des Serotonins ..........................................................................

1.2.2 Serotonin im menschlichen Körper.................................................................

1.2.3 Serotoninungleichgewicht und damit assoziierte Erkrankungen.............................

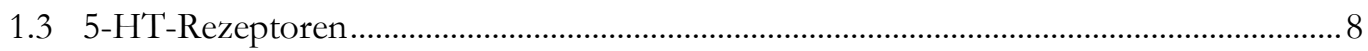

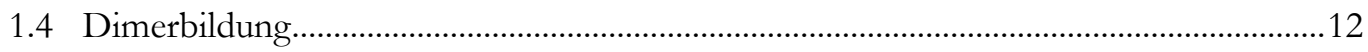

1.4.1 Auswirkungen der Dimerisierung....................................................................13

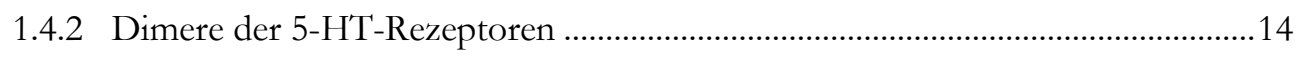

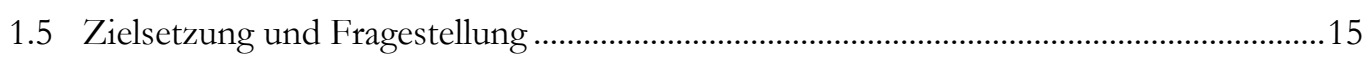

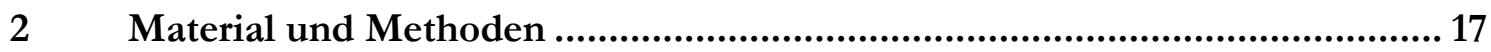

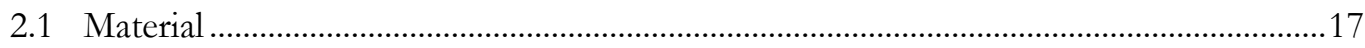

2.1.1 Biologische Materialien (Zellen, Vektoren, Antikörper, Enzyme, Bakterienstämme) ................................................................................................2

2.1.2 Verbrauchsmaterialien, Geräte und Software........................................................21

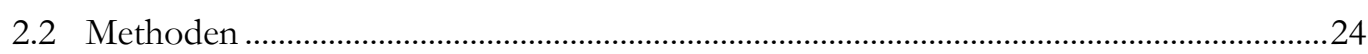

2.2.1 Forcierte Dimerisierung …………………………………………………...24

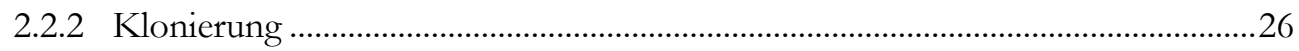

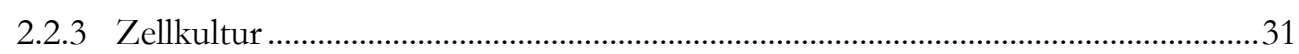

2.2.4 Liposomale Transfektion...................................................................................

2.2.5 Durchflusszytometrie .......................................................................................

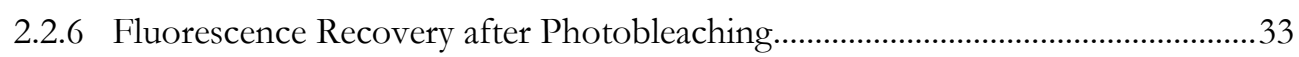

2.2.7 Single Particle Tracking........................................................................................

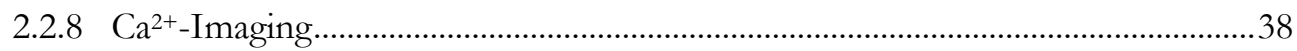

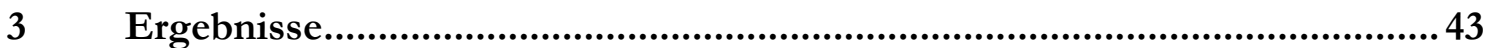

3.1 Rezeptorexpression....................................................................................................4

3.2 Single Particle Tracking................................................................................................4

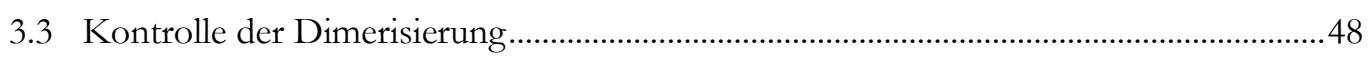

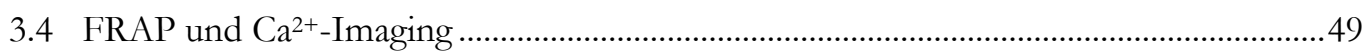




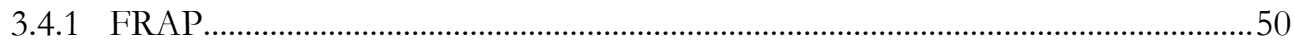

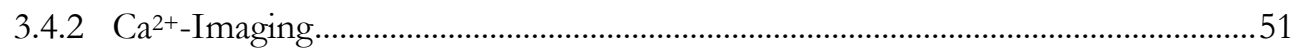

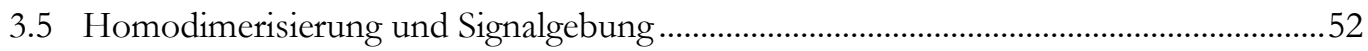

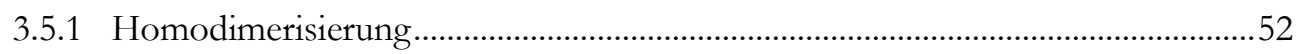

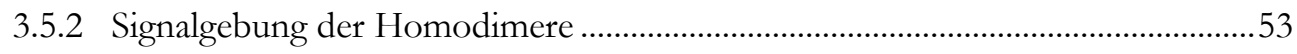

3.5.3 Zusammenfassung Homodimere ........................................................................54

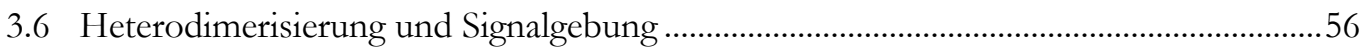

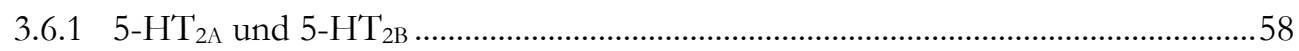

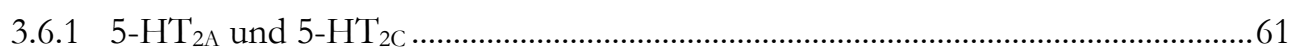

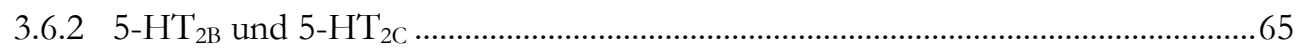

$4 \quad$ Diskussion und Ausblick ...........................................................6 68

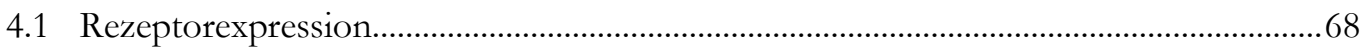

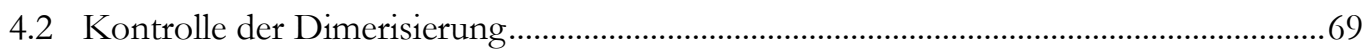

4.3 Dimerisierung und ihre Auswirkungen auf die Signalgebung.........................................71

4.3.1 Interpretation der Ergebnisse hinsichtlich der Homodimerisierung und ihrer Auswirkungen auf die Signalgebung........................................................... 73

4.3.2 Interpretation der Ergebnisse hinsichtlich der Heterodimerisierung und ihrer Auswirkungen auf die Signalgebung.......................................................... 77

4.3.3 Zusammenfassung: Dimerisierung und ihr Einfluss auf die Signalgebung ........81

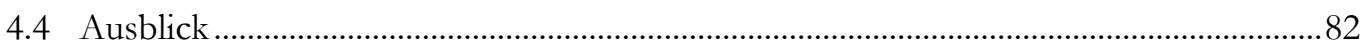

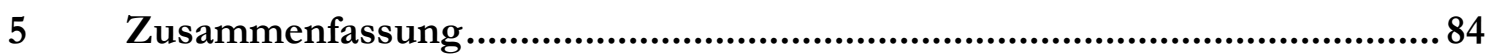

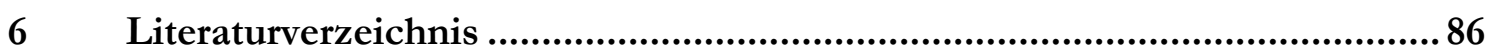




\section{Abbildungsverzeichnis}

Abbildung 1: Aktivierung des $\mathrm{G}_{\mathrm{q}^{-}}$gekoppelten Rezeptors durch einen Agonisten...........................4

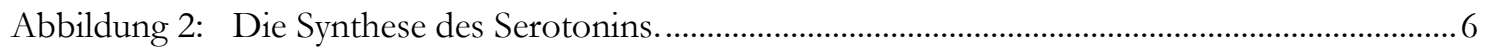

Abbildung 3: Die menschlichen 5-HT-Rezeptoren........................................................................... 9

Abbildung 4: Immunhistochemischer Nachweis der Ko-Expression von SerotoninRezeptoren 5- $\mathrm{HT}_{2 \mathrm{~A}}$ und 5-HT $2 \mathrm{C}$ am Nucleus arcuatus des Mäusehirns. ....................11

Abbildung 5: Schematische Darstellung der forcierten Dimerisierung für die Rezeptoren

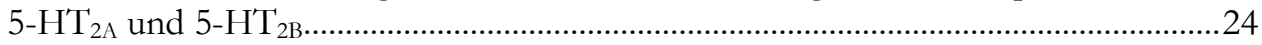

Abbildung 6: IgG-Antikörper und Nanobody mit Molekülgrößen................................................25

Abbildung 7: Die DNA-Fragmente 5-HT $2 \mathrm{C}$ und GFP bzw. NB mit den jeweiligen Primern, mit denen sie für die Fusions-PCR verlängert wurden. ..............................................26

Abbildung 8: Darstellung der HiFi-Assembly.................................................................................30

Abbildung 9: FRAP an einer Zelle mit 5-HT $2 \mathrm{~A}-$ Rezeptoren gekoppelt mit GFP..........................36

Abbildung 10: $\mathrm{Ca}^{2+}$-Signal der mit 5- $\mathrm{HT}_{2 \mathrm{~A}^{-}}$und GCaMP6s-DNA transfizierten Zellen nach

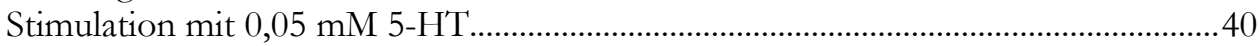

Abbildung 11: $\mathrm{Ca}^{2+}$-Reaktionskurven für die 5-HT-Stimulation der Rezeptoren 5-HT2A, 5-

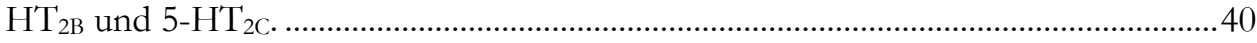

Abbildung 12: Kurve des Calcium-Signals einer Zelle mit 5-HT $2 \mathrm{~A}-$ Rezeptor nach Stimulation mit 5-HT.

Abbildung 13: Expressionsrate der transfizierten Rezeptoren und die dazugehörige Signalgebung...

Abbildung 14: Histogramm der FACS-Analyse an Zellen mit transfiziertem Rezeptor 2A mit steigender Menge der transfizierten cDNA

Abbildung 15: Histogramm der FACS-Analyse nach Transfektion von Rezeptor 2A bzw. den ko-exprimierten Rezeptoren 2A und 2B. ..............................................................46

Abbildung 16: Das SPT des Rezeptors 5-HT 2B, fluoreszent markiert mit quantum dots.....................47

Abbildung 17: Neuroblastomzellen mit fluoreszenten Proteinen mit bzw. ohne Nanobodygekoppelten Rezeptor.

Abbildung 18: Ergebnisse der FRAP für die Oberflächenproteine CD28 und CD86.

Abbildung 19: Diffusionskoeffizienten der nicht forcierten und forciert dimerisierten Homodimere 2A, 2B und 2C und deren Signalgebungen.

Abbildung 20: $\mathrm{Ca}^{2+}$-Signal des Rezeptors $2 \mathrm{~B}$ im nicht forcierten und forciert dimerisierten Zustand nach Stimulation mit 5-HT.

Abbildung 21: Die 5-HT2-Rezeptor-Agonisten und ihre Wirkung auf die verschiedenen 5- $\mathrm{HT}_{2}$-Rezeptoren.

Abbildung 22: Die Diffusionskoeffizienten und Signalkurven der Rezeptoren 2A/2B.....................58

Abbildung 23: $\mathrm{Ca}^{2+}$-Signal der Rezeptoren 2A/2B im nicht forcierten und forciert dimerisierten Zustand nach Stimulation mit BW723c86 Hydrochlorid.

Abbildung 24: Die Diffusionskoeffizienten und Signalkurven der Rezeptoren 2A/2C.

Abbildung 25: $\mathrm{Ca}^{2+}$-Signal der Rezeptoren 2A/2C im nicht forcierten und forciert dimerisierten Zustand nach Stimulation mit TCB-2

Abbildung 26: $\mathrm{Ca}^{2+}$-Signal der Rezeptoren 2A/2C im nicht forcierten und forciert dimerisierten Zustand nach Stimulation mit WAY629 Hydrochlorid.

Abbildung 27: Die Diffusionskoeffizienten und Signalkurven der Rezeptoren 2B/2C.

Abbildung 28: $\mathrm{Ca}^{2+}$-Signal der Rezeptoren 2B/2C im nicht forcierten und forciert dimerisierten Zustand nach Stimulation mit BW723c86 Hydrochlorid.

Abbildung 29: $\mathrm{Ca}^{2+}$-Signal der Rezeptoren 2B/2C im nicht forcierten und forciert dimerisierten Zustand nach Stimulation mit WAY629 Hydrochlorid. 


\section{Tabellenverzeichnis}

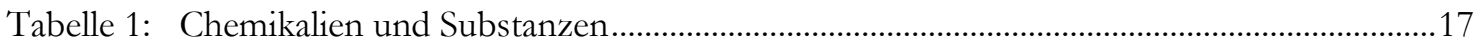

Tabelle 2: Lösungen, Puffer und Medien ........................................................................................18

Tabelle 3: Ansatz SOC(Super optimal broth with catabolite repression)-Medium ........................................19

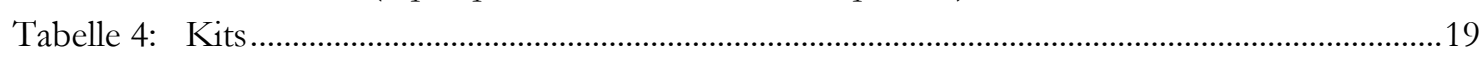

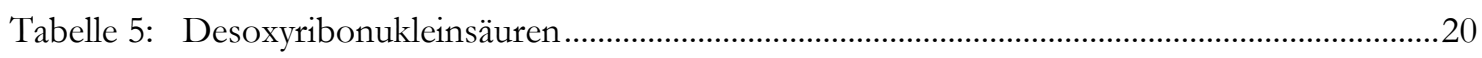

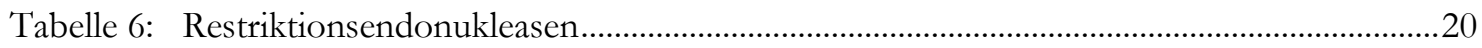

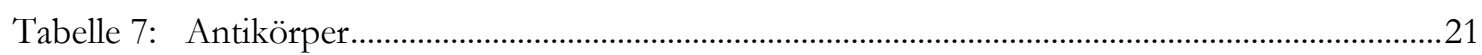

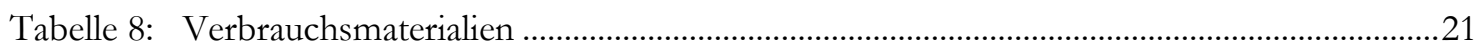

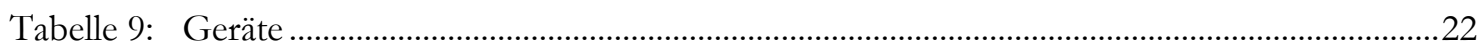

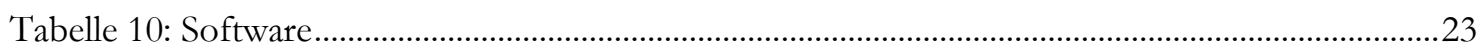

Tabelle 11: Primer für die PCR der 5-HT 2C-Rezeptor-DNA bzw. GFP oder NB-DNA. ..................27

Tabelle 12: Primersequenzen für die PCR der DNA-Fragmente für die Gibson-Assembly.............29

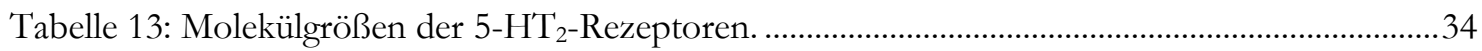

Tabelle 14: 5-HT ${ }_{2}$-Rezeptor-Agonisten mit ihren Strukturformeln und Ki-Werten.............................41

Tabelle 15: Übersicht über die Homo- und Heterodimerbildung der 5- $\mathrm{HT}_{2}$-Rezeptoren und die jeweiligen Auswirkungen der Dimerisierung auf die Signalgebung..............................81

\section{Formeln}

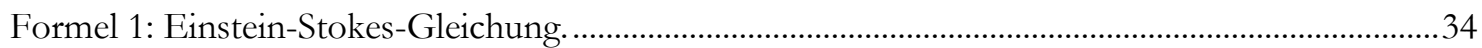

Formel 2: Berechnung des Diffusionskoeffizienten D nach Soumpasis...............................................36 


\section{Abkürzungsverzeichnis}

(e)GFP (enhanced) green fluorescent protein

5-HT 5-Hydroxytryptamin

a. E.

arbiträre Einheiten

AADC

aromatische Aminosäure Decarboxylase

AT

Angiotensin

AUC

area under the curve

BRET

Biolumineszenz-Resonanzenergietransfer

CA

Cornu ammonis

cAMP

cyclic adenosine monophosphate

cDNA

complementary deoxyribonucleic acid

CFP

cyan fluorescent protein

D

Diffusionskoeffizient

DAG

Diacylglycerin

DMEM

Dulbecco's modified eagle's medium

dNTP

Desoxynukleotidtriphosphat

$\mathrm{EC}_{50}$

effective concentration

ER

Endoplasmatisches Retikulum

FACS

fluorescence-activated cell sorting

FCS

fluorescence correlation spectroscopy

FRAP

fluorescence recovery after photobleaching

FRET

Förster-Resonanzenergietransfer

GABA

$\gamma$-aminobutyric acid

GbR

$\gamma$-Aminobuttersäure(B)-Rezeptor

GDP

Guanosindiphosphat

GPCR

G-protein-coupled receptor

GRK

G-Protein-gekoppelte Rezeptor-Kinasen 


$\begin{array}{ll}\text { GTP } & \text { Guanosintriphosphat } \\ \mathrm{IP}_{3} & \text { Inositol-1,4,5-trisphosphat }\end{array}$

LB-Medium Nährmedium zur Kultivierung von Bakterien nach Giuseppe Bertani (engl. lysogeny broth)

LSM laser scanning microscope

NB Nanobody

OD optische Dichte

PCR polymerase chain reaction

$\mathrm{PIP}_{2} \quad$ Phosphatidylinositol-4,5-bisphosphat

PKA Proteinkinase A

PKC Proteinkinase C

PLC Phospholipase C

QD quantum dot

RFP red fluorescent protein

ROI region of interest

SNR signal-to-noise ratio

SOB super optimal broth

SOC super optimal broth with catabolite repression

SPT single particle tracking

TAE Tris Acetat-EDTA

TIRF total internal reflection

TPH Tryptophan-Hydroxylase

TSB Soja-Casein-Pepton-Medium (engl. tryptic soy broth)

YFP yellow fluorescent protein

ZNS zentrales Nervensystem 


\section{Einleitung}

Lange Zeit galt für G-Protein-gekoppelte Rezeptoren (G-protein-coupled receptors, GPCRs) die Hypothese: ,Ein Ligand, ein Rezeptor, ein G-Protein'. So wurde die Funktionalität von GPCRs als Monomer in Studien belegt (Bourne 1997). Jedoch zeigen mittlerweile immer mehr Studien, dass einige der GPCRs dazu neigen, sich zu Dimeren oder größeren Oligomeren zusammenzuschließen (Milligan 2001; Gurevich und Gurevich 2008a). Dies konnte auch für verschiedene Serotonin-Rezeptoren gezeigt werden, welche eine Untergruppe der GPCRs darstellen (Pellissier et al. 2011; Renner et al. 2012; Herrick-Davis 2013).

Dimere können fakultativ vorliegen, was bedeutet, dass der Rezeptor sowohl als Mono- als auch als Dimer vorliegt und in beiden Zuständen funktionsfähig ist. Fakultative Dimere sind häufig dynamisch und wechseln zwischen mono- und dimerer Konfiguration, wobei die Dauer der Dimerisierung von den Bindungspartnern abhängig ist. Bei den sogenannten obligaten Dimeren hingegen ist die Dimerbildung essenziell für ihre Funktion. Sie liegen stets als Dimer vor und sind in der Regel als Monomer nicht oder kaum funktionsfähig (Kasai und Kusumi 2014).

Bis heute ist bei den meisten Rezeptoren unklar, ob und welche Auswirkungen das Vorliegen als Dimer auf die Signalgebung hat. Besonders hinsichtlich solcher Rezeptoren, die kurzzeitig oder nur zum Teil dimerisieren, gestaltet sich eine Messung der Unterschiede in der Signalgebung schwierig, da Mono- und Dimere in einem Equilibrium gleichzeitig existieren und so die Signalgebung nicht eindeutig einem Mono- oder Dimer zugeordnet werden kann.

Ziel dieser Arbeit war es, verschiedene Serotoninrezeptoren hinsichtlich ihrer Dimerbildung zu untersuchen und zu analysieren, ob diese einen Einfluss auf die Signalgebung der Rezeptoren hat. Um das oben beschriebene Messproblem zu lösen, wurde ein neues System getestet, welches die Rezeptoren in ein Dimer zwingt. Durch die Forcierung eines physiologischerweise dynamisch dimerisierenden Rezeptors in ein konstantes Dimer konnten Auswirkungen der Dimerisierung auf die Signalgebung eindeutiger gemessen und zugeordnet werden.

\section{$1.1 \quad$ G-Protein-gekoppelte Rezeptoren}

Nach Ähnlichkeiten ihrer Sequenzen und Funktionen werden die GPCRs in sechs Gruppen eingeteilt: In Klasse A, welche mit $80 \%$ den größten Teil der GPCRs beinhaltet, finden sich Rhodopsin-ähnliche Rezeptoren. Die anderen Klassen enthalten Sekretin-ähnliche Rezeptoren (Klasse B), metabotrope Glutamatrezeptoren (Klasse C), Pheromon-Rezeptoren (Klasse D), cAMP(yclic adenosine monophosphate)-Rezeptoren (Klasse E) und Frizzled/Smoothened 
Rezeptoren (Klasse F) (Davies et al. 2007; Hu et al. 2017). Die 5-HT ${ }_{2}$-Rezeptoren gehören zu der Klasse A der GPCRs.

Die GPCRs stellen mit über 1.000 bekannten Rezeptorstrukturen die größte Superfamilie der Membranrezeptoren und damit einen wichtigen Angriffspunkt für verschiedene Pharmaka dar. Die Stimulation der GPCR ist durch verschiedenste Stimuli möglich: So können u. a. sowohl Hormone als auch Neurotransmitter, Photonen, Proteine oder Ionen als Liganden am GPCR agieren (Davies et al. 2007; Wacker et al. 2017).

GPCRs werden auch als heptahelikale Rezeptoren bezeichnet, da sie charakteristischerweise aus sieben Transmembran-Domänen bestehen, welche durch drei intrazelluläre (intracellular loops 1-3 = IL1-IL3) und drei extrazelluläre Schleifen (extracellular loops 1-3 = EL1-EL3) verbunden sind. Die Rezeptorstruktur endet extrazellulär im hochvariablen Aminoterminus, welcher je nach GPCR aus 10 bis zu 600 Aminosäuren bestehen kann. Intrazellulär endet der Rezeptor im Carboxyterminus (Gurevich und Gurevich 2008b).

\subsubsection{G-Proteine}

Die GPCRs sind an G-Proteine gekoppelt. Diese bestehen typischerweise aus einer $G_{\alpha^{-}}, G_{\beta^{-}}$ und $G_{\gamma}$-Untereinheit und sind damit heterotrimer (Gurevich und Gurevich 2008b). Im inaktiven Zustand ist Guanosindiphosphat (GDP) an die $\mathrm{G}_{\alpha}$-Untereinheit des G-Proteins gebunden.

Je nach Effekt ihrer $\alpha$-Untereinheit werden die G-Proteine in verschiedene Gruppen eingeteilt: $G_{s}, G_{i}, G_{q}$ und $G_{12}$. Die $G_{\alpha s}-$ Untereinheit stimuliert die zelluläre Adenylatzyklase und erhöht dadurch den cAMP-Spiegel. Die $\mathrm{G}_{\alpha \mathrm{i}}$ Untereinheit hingegen inhibiert die Adenylatzyklase und senkt somit den cAMP-Spiegel. Die $\mathrm{G}_{\alpha \mathrm{q}}$-Untereinheit sorgt hauptsächlich für die Aktivierung der Phospholipase C, welche einen Anstieg des intrazellulären $\mathrm{Ca}^{2+}$-Spiegels und eine Aktivierung der Proteinkinase $C$ bewirkt. $G_{\alpha 12}$ ist in die Aktivierung der Rho-GTPasen involviert, welche u. a. eine Veränderung der Gentranskription und des Zytoskeletts bewirken können (Kozasa et al. 2011).

Die 5-HT-Rezeptoren können je nach Gruppe an verschiedene GPCRs binden (siehe Abbildung 3). Im Folgenden wird der Fokus auf die $G_{q^{-}}$gekoppelten Proteine gelegt, da die hier betrachteten 5- $\mathrm{HT}_{2}$-Rezeptoren an diese binden.

\subsubsection{Aktivierung der GPCRs}

Durch die Bindung eines Agonisten wird ein GPCR in den aktiven Zustand überführt. Große Liganden wie Peptidhormone und Proteine binden häufig an den Aminoterminus, während 
kleinere Liganden an Segmente der Transmembrandomänen binden können (Kobilka 2007; Gurevich und Gurevich 2008b). An den Carboxyterminus sowie an weitere intrazelluläre Bestandteile des GPCRs binden Effektoren wie G-Proteine, Kinasen und Arrestine (Venkatakrishnan et al. 2013). Ob bei Stimulation bereits ein G-Protein an den Rezeptor gebunden ist, wird in zwei Modellen diskutiert: dem ,collision coupling'-Modell oder dem ,precoupling'-Modell. Während lange Zeit das, collision coupling'-Modell angenommen wurde, bei welchem der Rezeptor aufgrund des ,fluid-mosaic-Modells der Zellmembran durch die Membran diffundiert und gelegentlich auf ein G-Protein stößt und dieses ggf. aktiviert, deutet mittlerweile vieles darauf hin, dass GPCRs häufig schon an ein G-Protein gebunden sind, wenn sie aktiviert werden (precoupling-Modell) (Ferré 2015).

Welches G-Protein durch den Rezeptor gebunden wird, bestimmen die intrazellulären Anteile der Transmembrandomänen und der Carboxyterminus. Für die Bindung eines $G_{\mathrm{q}}$-Proteins sind eine kurze Schleife der dritten intrazellulären Transmembrandomäne und ein langer Carboxyterminus vonnöten. Für ein $\mathrm{G}_{\mathrm{i}}$-Protein verhält es sich genau gegenteilig und ein $\mathrm{G}_{\mathrm{s}}$-Protein benötigt einen langen Carboxyterminus mit vielen Serin- und Threonin-Resten, um sich an den Rezeptor zu lagern (Hollmann et al. 2005).

Bei Stimulation wird das GDP, welches an die $\alpha$-Untereinheit des G-Proteins gebunden ist, durch die Katalysator-Aktivität des Rezeptor-/G-Protein-Komplexes durch Guanosintriphosphat (GTP) ersetzt. Der Austausch der Nukleosidphosphate bewirkt eine Konformationsänderung des G-Proteins, wodurch das G-Protein zum einen von dem Rezeptor dissoziiert und zum anderen die Affinität der $G_{\alpha}$-Untereinheit zu der $G_{\beta / \gamma}$-Untereinheit geringer wird und diese dadurch dissoziieren (Wess 1997). Im dissoziierten Zustand bewirken beide Untereinheiten jeweils die Aktivierung bestimmter Effektoren. Während die Konformation der $G_{\alpha}$-Untereinheit derart verändert wird, dass sie eine 20- bis 100-fach stärkere Affinität zu ihren Effektoren erlangt, ändert die $G_{\beta / \gamma}$ Untereinheit ihre Konformation nicht. Dennoch gehen auch von dieser Untereinheit Effekte aus. Wahrscheinlich ist dies dadurch zu begründen, dass die $\mathrm{G}_{\alpha}-$ Untereinheit im trimeren Zustand eine Hemmung der $G_{\beta / \gamma}$-Untereinheit bewirkt, welche im dissoziierten Zustand wegfällt.

Durch die GTPase-Aktivität der $\mathrm{G}_{\alpha}$-Untereinheit wird schließlich das gebundene GTP zu GDP dephosphoryliert, die $G_{\alpha^{-}}$und die $G_{\beta / \gamma^{-}}$Untereinheit reassoziieren und der aktive Zustand des G-Proteins ist damit beendet (Hamm 1998). Ein aktivierter Rezeptor kann an mehrere G-Proteine binden, wodurch das Signal amplifiziert wird (Simon et al. 1991). Wird ein $G_{q^{-}}$Protein stimuliert, so aktiviert es die Phospholipase C (PLC). Diese wiederum katalysiert die Hydrolysierung des membranständigen Phosphatidylinositol-4,5-bisphosphat $\left(\mathrm{PIP}_{2}\right)$ in die sekundären 
Botenstoffe Diacylglycerin (DAG) und Inositol-1,4,5-trisphosphat (IP3) (Berridge 1984). Das $\mathrm{IP}_{3}$ setzt $\mathrm{Ca}^{2+}$ aus intrazellulären Speichern frei und das DAG aktiviert zusammen mit $\mathrm{Ca}^{2+}-$ Ionen die Proteinkinase C (PKC), welche als sekundärer Botenstoff durch die Phosphorylierung terminaler Zielproteine den Stoffwechsel der Zelle beeinflusst (Rhee und Choi 1992) (siehe Abbildung 1).

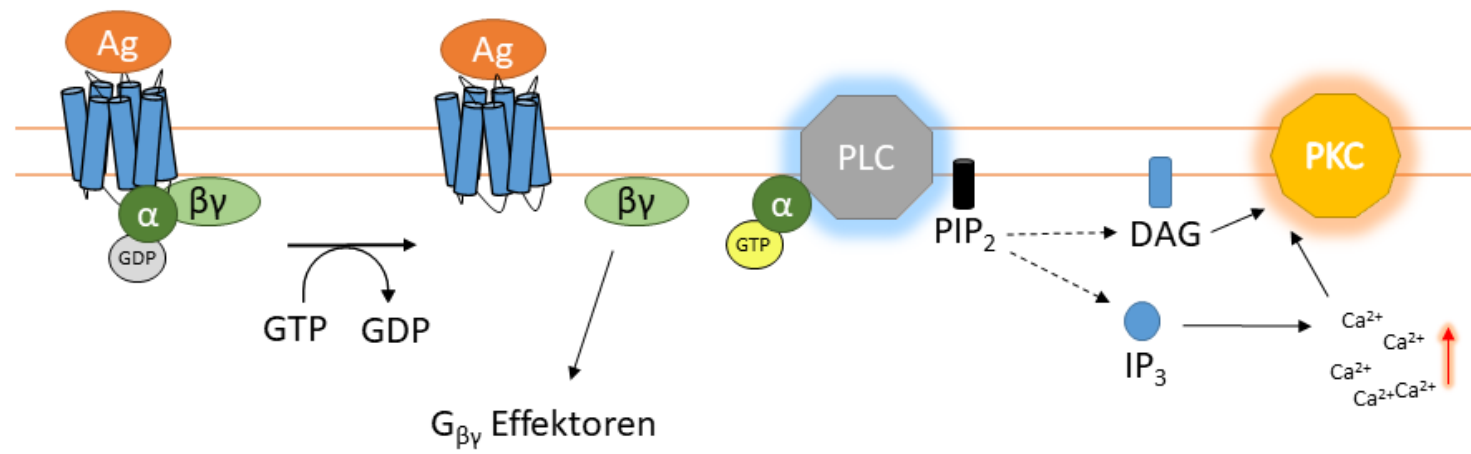

Abbildung 1: Aktivierung des $\mathrm{G}_{\mathrm{q}}$-gekoppelten Rezeptors durch einen Agonisten (Ag). Bei Aktivierung wird das GDP der $\alpha$-Untereinheit durch GTP ersetzt, die $\beta / \gamma$ - und $\alpha$-Untereinheit dissoziieren und diffundieren von dem Rezeptor weg. Während durch die $\beta / \gamma$-Untereinheit weitere Effektoren aktiviert werden, bewirkt die $\alpha$-Untereinheit eine Aktivierung der PLC. Durch die PLC wird das membranständige $\mathrm{PIP}_{2}$ in DAG und $\mathrm{IP}_{3}$ gespalten. $\mathrm{IP}_{3}$ bewirkt eine $\mathrm{Ca}^{2+}$-Freisetzung. Durch DAG und $\mathrm{Ca}^{2+}$ wird die PKC aktiviert, welche durch eine Phosphorylierung weitere Signale vermittelt. Basierend auf Berridge (1984) und Rhee und Choi (1992).

\subsubsection{Desensibilisierung der GPCRs}

Um ein überschießendes Zellsignal zu vermeiden, folgt nach der Aktivierung eine Desensibilisierung der Rezeptoren. Dabei kann der Rezeptor in der Zellmembran verbleiben oder internalisiert werden.

Die Proteinkinase A (PKA), welche durch das $\mathrm{G}_{\mathrm{s}}$-Protein aktiviert wird, und die Proteinkinase $\mathrm{C}$, deren Aktivierung durch das $\mathrm{G}_{\mathrm{q}}$-Protein erfolgt, können als negativer Feedback-Mechanismus wirken, indem sie den GPCR phosphorylieren. Dadurch wird die Konformation des Rezeptors dahingehend geändert, dass er kein G-Protein mehr binden kann und so kein Signal fortleitet.

Auch kann die Desensibilisierung durch G-Protein-gekoppelte-Rezeptor-Kinasen (GRK) erfolgen, die den Rezeptor an Serin- und Threonin-Resten der zytoplasmatischen Domäne phosphorylieren (Rajagopal und Shenoy 2018). An die phosphorylierten Rezeptoren bindet Arrestin mit hoher Affinität, welches zum einen die Interaktion mit G-Proteinen verhindert und zum anderen die Bindung der Rezeptoren an Clathrin vermittelt (Lefkowitz 1998; Koppen und 
Jakobs 2004). Clathrin ist ein an der Bildung von Vesikeln beteiligtes Protein, welches durch sogenannte Stachelsaumbläschen (,coated pits") die Rezeptorinternalisierung vermittelt. Auch in Membranregionen, an denen kein Clathrin gebunden ist, können die Rezeptoren durch sogenannte Caveolae internalisiert werden. Internalisierte GPCRs können entweder dephosphoryliert und zur Zellmembran zurück transportiert oder durch Lysosomen abgebaut werden (Brink et al. 2004).

\subsection{Serotonin}

\subsubsection{Die Entdeckung des Serotonins}

Der Neurotransmitter Serotonin (5-Hydroxytryptamin, 5-HT) wurde erstmals 1868 von den Physiologen Carl Ludwig und Alexander Schmidt beschrieben. Sie beobachteten, dass im Muskel eines Hundes eine Vasokonstriktion stattfand, wenn dieser von defibriniertem Blut durchströmt wurde. Aufgrund dieser Beobachtung postulierten sie das Vorhandensein einer vasokonstriktorischen Substanz im Blut (Ludwig und Schmidt 1868). 1937 wurde von Maffo Vialli und Vittorio Erspamer eine Substanz aus der Magenschleimhaut von Kaninchen extrahiert, welche eine Kontraktion der glatten Muskulatur des Darms von Mäusen und Ratten und des Uterus von Ratten bewirkte. Diese Substanz wurde Enteramin genannt (Erspamer 1940). Maurice Rapport, Arda Green und Irvine Page isolierten 1948 eine Substanz, welche sie aufgrund ihres Vorkommens im Serum und ihrer vasokonstriktorischen Wirkung Serotonin nannten (Rapport et al. 1948). Im Jahre 1952 wurde die Struktur des Serotonins (5-Hydroxytryptamin) entschlüsselt und festgestellt, dass es mit dem Enteramin identisch ist (Erspamer und Asero 1952).

\subsubsection{Serotonin im menschlichen Körper}

Die Synthese des Serotonins ist in Abbildung 2 dargestellt. Als Ausgangssubstanz für die Synthese dient die essenzielle Aminosäure Tryptophan, welche durch die Tryptophan-Hydroxylase (TPH) zu 5-Hydroxytryptophan hydroxyliert wird. In einem weiteren Schritt wird 5-Hydroxytryptophan durch die Aromatische-Aminosäure-Decarboxylase (AADC) decarboxyliert und damit in 5-Hydroxytryptamin (Serotonin) umgewandelt. Der geschwindigkeitsbegrenzende Schritt in der Serotoninsynthese ist die Aktivität der TPH (El-Merahbi et al. 2015). 


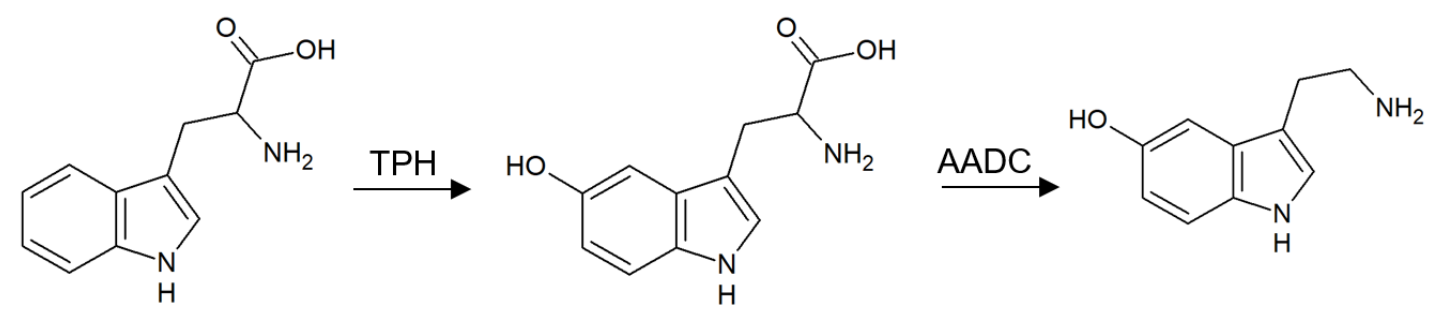

Tryptophan

5-Hydroxytryptophan

5-Hydroxytryptamin

Abbildung 2: Die Synthese des Serotonins. Tryptophan wird durch die TPH zu 5-Hydroxytryptophan hydroxyliert. 5-Hydroxytryptophan wird durch die AADC zu 5-Hydroxytryptamin (Serotonin) decarboxyliert. Nach El-Merahbi et al. 2015.

Serotonin ist an diversen essenziellen Körperfunktionen beteiligt und wirkt sowohl im zentralen Nervensystem (ZNS) als auch in der Peripherie über seinen Agonismus an den 5-HT-Rezeptoren. Die Wirkungen des Serotonins auf den menschlichen Körper werden aufgrund ihrer enormen Vielfalt hier nur ausschnittsweise dargestellt.

Auch wenn Serotonin meist mit seiner Funktion im zentralen Nervensystem assoziiert wird, findet sich der Großteil des körpereigenen Serotonins (ca. $95 \%$ ) peripher im Magen-DarmTrakt. Dort wird es hauptsächlich von den enterochromaffinen Zellen im Epithelgewebe des Verdauungstraktes produziert. Doch auch pankreatische B-Zellen, Adipozyten und Osteoklasten können Serotonin produzieren (Berger et al. 2009; El-Merahbi et al. 2015). Das freigesetzte Serotonin kann entweder lokal im Magen-Darm-Trakt wirken oder in Thrombozyten aufgenommen und so dem Blutkreislauf zugeführt werden. Nur ein Bruchteil liegt frei im Blut vor und kann direkt als Hormon agieren (El-Merahbi et al. 2015). Aufgrund der Blut-Hirn-Schranke, welche Serotonin nicht überwinden kann, beeinflusst das peripher produzierte Serotonin die zentralen 5-HT-Rezeptoren nicht (Gershon und Tack 2007).

Im Verdauungstrakt reguliert Serotonin u. a. die Darmmotilität und die Sekretion im Darm. Außerdem dient es als Stimulator für afferente Bahnen, welche Gefühle der Übelkeit und des Unwohlseins aus dem Magen-Darm-Trakt in das ZNS weiterleiten und damit die Nahrungsaufnahme beeinflussen.

Auch am Metabolismus ist Serotonin grundlegend beteiligt. So wurde nachgewiesen, dass Serotonin die Insulinsekretion des Pankreas stimulieren und die Glukoneogenese der Leber bzw. die Glykolyse im Muskel induzieren kann.

Im Herz-Kreislaufsystem wird Serotonin in Thrombozyten aufgenommen und moduliert ihre Funktion, indem es zusammen mit Adenosindiphosphat und Thromboxan A die Thrombozytenaggregation potenziert. Zusätzlich kann es das umliegende Gefäß konstringieren und damit 
die Blutzirkulation verringern (Mohammad-Zadeh et al. 2008). Auch die Blutdruckregulation, die pulmonale Durchblutung und die Atmung werden von Serotonin beeinflusst (Gershon und Tack 2007).

Im ZNS sind die Wirkungen des Serotonins sehr komplex. Die Somata der serotonergen Neurone im ZNS befinden sich hauptsächlich in den Nuclei raphes des Hirnstamms. Das Hauptziel der von hier ausgehenden Bahnen ist der Hippocampus, ein wichtiger Bestandteil des limbischen Systems, welcher vor allem der Verarbeitung von Emotionen und Triebverhalten dient. Auch das Belohnungssystem ist Teil des limbischen Systems, sodass Serotonin beispielsweise auch Einfluss auf hiermit assoziierte Verhaltensweisen wie die Nahrungsaufnahme, das Sexualverhalten und das Suchtverhalten hat. Außerdem werden zentrale Vorgänge wie die Nozizeption oder der Schlaf-Wach-Rhythmus durch Serotonin beeinflusst (Berumen et al. 2012).

Die Wirkung von Serotonin im synaptischen Spalt kann durch die Wiederaufnahme in die Zelle beendet werden. Für die Wiederaufnahme sorgen das selektive und hochaffine Serotonin-Transporter-Protein (5-HTT) und organische Kationentransporter (organic cation transporters, OCTs), welche weniger selektiv und niedrig affin zum Serotonin sind (Schmitt et al. 2003; Goldman et al. 2010).

\subsubsection{Serotoninungleichgewicht und damit assoziierte Erkrankungen}

Ein Ungleichgewicht im serotonergen System kann sich je nach Lokalisation auf verschiedenste Weisen bemerkbar machen. Insbesondere im Zusammenhang mit neurologischen und psychiatrischen Erkrankungen spielen Dysregulationen im serotonergen System eine große Rolle.

Ursächlich für das Serotonin-Ungleichgewicht kann beispielsweise ein Polymorphismus in der Promotor-Region des 5-HTT-Gens sein, welches den Transporter codiert, über den Serotonin aus dem synaptischen Spalt wieder in die Zelle aufgenommen wird. So wird die lange Variante des Rezeptors mit 16 Sequenzwiederholungen (engl. repeats) stärker exprimiert als die kurze Variante mit 14 repeats. Patienten mit der langen Variante des Rezeptors wiesen ein deutlich geringeres Risiko für Depressionen auf als Patienten mit der kurzen Variante (Goldman et al. 2010). Weitere Auswirkungen des Polymorphismus sind Gegenstand aktueller Forschung.

Aufgrund der Wirkung des Serotonins auf das limbische System, welches der Entstehung und Verarbeitung von Emotionen dient, können affektive Störungen wie Depression und Manie oder auch Angststörungen u. a. durch ein Ungleichgewicht an verfügbarem Serotonin im zentralen Nervensystem ausgelöst werden (Lin et al. 2014). Auch eine dysregulierte Verteilung der Serotoninrezeptoren ist Bestandteil der Pathogenese derartiger Erkrankungen. So haben Studien, welche die Wirksamkeit verschiedener Antidepressiva und ihre Rezeptorselektivität 
untersucht haben, gezeigt, dass depressive Menschen häufig eine gestörte Balance der Rezeptoren 5-HT $\mathrm{T}_{1 \mathrm{~A}}, 5-\mathrm{HT}_{2 \mathrm{~A}}$ und 5- $\mathrm{HT}_{2 \mathrm{C}}$ aufweisen (Kleven et al. 1997). Eine gestörte Balance der Rezeptorverteilung kann direkte Auswirkungen auf das Dimerisierungspotential der Rezeptoren haben, sodass eine weitere Untersuchung der Dimerisierung auch hierfür eine interessante Rolle spielt. Auch Zwangsstörungen, Essstörungen oder Schizophrenie werden mit einem Ungleichgewicht verschiedener Serotoninrezeptoren in Verbindung gebracht (Berumen et al. 2012; Lin et al. 2014).

Ein weiteres wichtiges Beispiel aus der Reihe serotoninassoziierter Erkrankungen ist die Migräne. Über die Aktivierung gefäßregulierender 5- $\mathrm{HT}_{2 \mathrm{~B}}$-Rezeptoren wird Stickstoffmonoxid freigesetzt und die Gefäße im Gehirn werden weitgestellt, was zur Migräneentstehung beitragen kann. Daher können 5- $\mathrm{HT}_{2 \mathrm{~B}}$-Antagonisten zur Migräneprophylaxe verwendet werden. Auch 5-

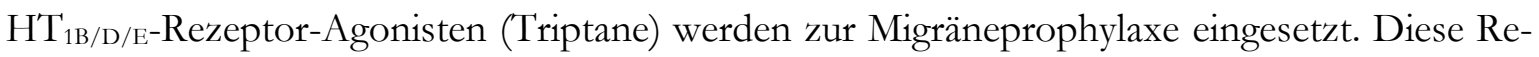
zeptoren sind an ein inhibierendes G-Protein gekoppelt und hemmen bei der Migräne entstehende Schmerzreize (Ebersberger 2002).

Auch bei der Pathogenese des plötzlichen Kindstods (sudden infant death syndrome, SIDS) spielt ein Serotoninungleichgewicht eine tragende Rolle. Bei betroffenen Kindern wurden vergleichsweise wenige Serotonintransporter und 5- $\mathrm{HT}_{1 \mathrm{~A}}$-Rezeptoren in den Zellen der Medulla oblongata gefunden, welche u. a. für die Atmung zuständig ist (Berger et al. 2009).

Ein weiteres auf Serotoninungleichgewicht zurückzuführendes Erkrankungsbild stellt das Reizdarmsyndrom dar, welches daher mit Pharmaka behandelt werden kann, welche am 5-HT und 5-HT4-Rezeptor angreifen (Berger et al. 2009).

\section{$1.3 \quad 5-H T-R e z e p t o r e n$}

Zurzeit sind 14 verschiedene Gene bekannt, die für Serotonin-Rezeptoren kodieren. Die Rezeptoren werden anhand ihrer Liganden-Bindung, struktureller Kriterien und anhand von Unterschieden in der Transduktion in Gruppen eingeteilt. So gibt es die Rezeptorgruppen 5- $\mathrm{HT}_{1}-5-\mathrm{HT}_{7}$, wobei mit Ausnahme des 5- $\mathrm{HT}_{3}$-Rezeptors alle dieser Rezeptoren GPCRs darstellen. 5- $\mathrm{HT}_{3}$ arbeitet als ligandengesteuerter Ionenkanal. Die 5-HT-GPCRs koppeln je nach Rezeptorgruppe hauptsächlich an ein $G_{s^{-}}, G_{i^{-}}, G_{q^{-}}$oder $G_{12}$-Protein (siehe Abbildung 3). 


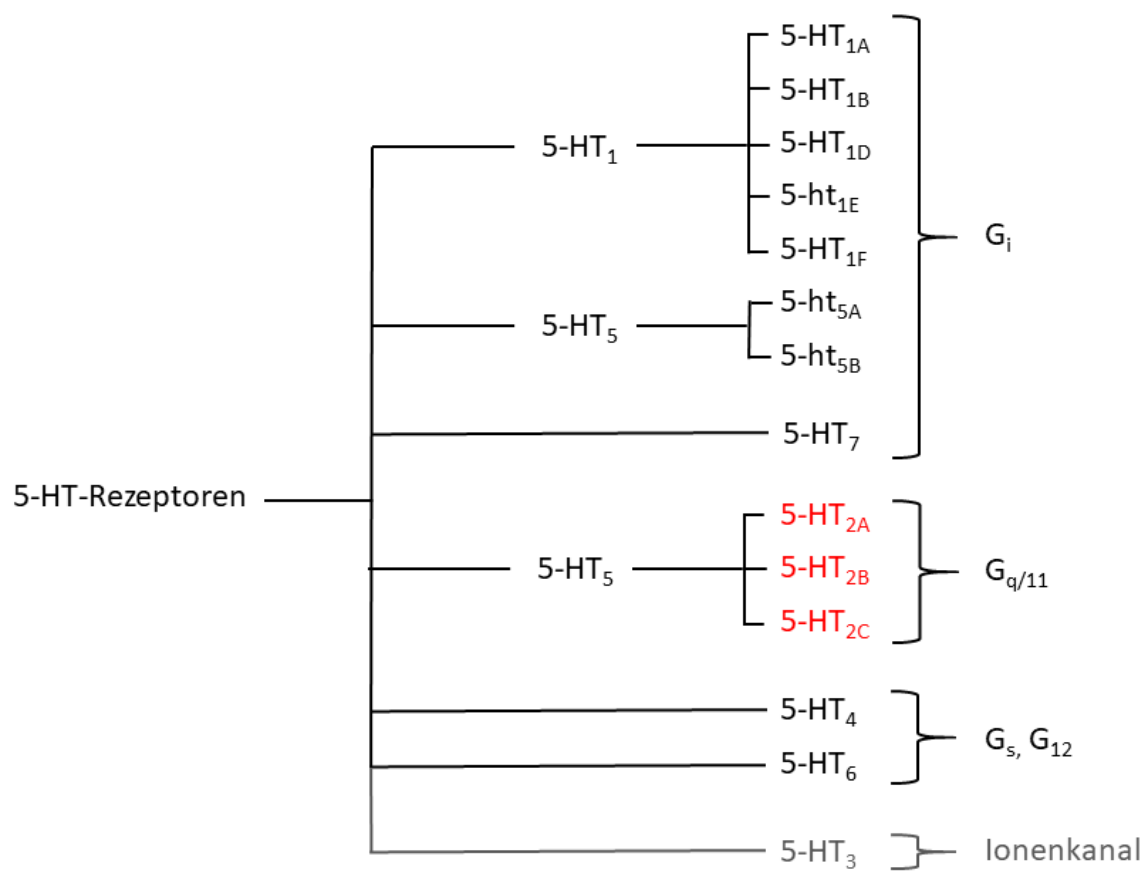

Abbildung 3: Die menschlichen 5-HT-Rezeptoren. Die 5-HT-Rezeptoren sind nach der evolutionären Verwandtschaft und der Signalgebung eingeteilt. Durch die Klammern wird die Art des G-Proteins bzw. der Ionenkanal gekennzeichnet, worüber die Rezeptoren ihr Signal hauptsächlich weiterleiten. Die Klein-

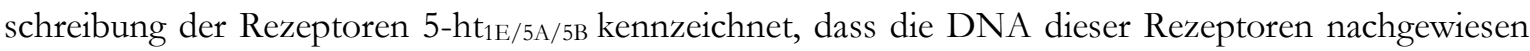
wurde, sie jedoch noch keinen Rezeptorstatus erlangt haben, da für sie keine Signalgebung in nativem Gewebe nachgewiesen wurde (Barnes et al. 2018). Die in der Arbeit behandelten 5-HT2-Rezeptoren sind rot hervorgehoben. Der Rezeptor 5-HT 3 ist ein Ionenkanal, weshalb er in dieser Abbildung grau dargestellt ist. Basierend auf Barnes und Sharp 1999.

In dieser Arbeit wurde die Gruppe der 5- $\mathrm{HT}_{2}$-Rezeptoren betrachtet. Die sieben Transmembrandomänen der Rezeptoren der 5- $\mathrm{HT}_{2}-\mathrm{Gruppe}$ sind sich untereinander sehr ähnlich. In ihrer kodierenden Sequenz befinden sich zwei (5- $\left.\mathrm{HT}_{2 \mathrm{~A}, \mathrm{~B}}\right)$ bzw. drei Introns (5- $\left.\mathrm{HT}_{2 \mathrm{C}}\right)$ und sie alle koppeln i. d. R. an $G_{q / 11}$-Proteine (Barnes und Sharp 1999; Siehler 2009).

Der 5- $\mathrm{HT}_{2 \mathrm{~A}}$-Rezeptor ist sowohl innerhalb als auch außerhalb des ZNS weit verbreitet. Er vermittelt beispielsweise eine Vasokonstriktion, eine Thrombozytenaggregation und eine Erhöhung der Kapillardurchlässigkeit (Hoyer et al. 1994). Zentral liegt er in besonders hoher Dichte im frontalen Kortex und im Claustrum vor (Frazer und Hensler 1999). Auch in Teilen des limbischen Systems wird der Rezeptor exprimiert, hier vor allem im Hippocampus in den Pyramidenzellen des Cornu ammonis (CA1-3) und im Stratum granulosum des Gyrus dentatus. Außerdem konnte er in Astrozyten und olfaktorischen Nuclei nachgewiesen werden (Frazer und Hensler 1999; Berumen et al. 2012).

Der 5-HT $\mathrm{T}_{2 \mathrm{~B}}$-Rezeptor wurde erstmals im Magenfundus der Ratte nachgewiesen, weshalb er initial als 5-HT $\mathrm{T}_{2 \mathrm{~F}}$ bezeichnet wurde. Später wurde der Rezeptor reklassifiziert und in $5-\mathrm{HT}_{2 \mathrm{~B}}$ 
umbenannt. Im Gehirn werden im Vergleich zum 5-HT $\mathrm{T}_{2 \mathrm{~A}}$ und 5- $\mathrm{HT}_{2 \mathrm{C}}$-Rezeptor nur wenige 5- $\mathrm{HT}_{2 \mathrm{~B}}$-Rezeptoren exprimiert. Dort wurde sein Vorkommen beispielsweise in Astrozyten des Hippocampus und in Mikrogliazellen (Berumen et al. 2012), im Cerebellum, dem lateralen Septum, dem dorsalen Hypothalamus und den medialen Amygdala nachgewiesen (Barnes und Sharp 1999).

Der 5-HT $2 \mathrm{C}-$ Rezeptor wird in vielen Regionen des ZNS exprimiert, im Gegensatz zu den anderen Rezeptoren der 5- $\mathrm{HT}_{2}$-Gruppe jedoch kaum außerhalb des ZNS (Berumen et al. 2012). Initial wurde der Rezeptor als 5-HT $1 \mathrm{C}$ bezeichnet, jedoch nach weiterer Forschung aufgrund seiner Eigenschaften als 5-HT 2 C reklassifiziert (Barnes und Sharp 1999). Besonders stark wird der Rezeptor im Plexus choroideus exprimiert, wo er vermutlich Einfluss auf die Menge und die Zusammensetzung der Zerebrospinalflüssigkeit hat (Frazer und Hensler 1999). Außerdem findet er sich in Neuronen der Schicht V des Kortex und in Teilen der Basalganglien, welche die Motorik beeinflussen, hier besonders im Putamen, Nucleus caudatus, Substantia nigra und Globus pallidus. Im Hippocampus liegt der Rezeptor im Feld 3 des Cornu ammonis (CA) (Frazer und Hensler 1999; Pasqualetti et al. 1999).

Im Rahmen dieser Arbeit stellt sich insbesondere die Frage nach Bereichen im menschlichen Körper, in denen verschiedene Rezeptoren der 5- $\mathrm{HT}_{2}$-Gruppe gemeinsam exprimiert werden, um zu prüfen, ob eine mögliche Heterodimerisierung (siehe Kapitel 1.4) auch in vivo eine Rolle spielen kann.

Die 5- $\mathrm{HT}_{2 \mathrm{~A}^{-}}$und 5-HT $\mathrm{HC}_{2 \mathrm{C}}$-Rezeptoren werden in $\gamma$-Aminobuttersäure (Gamma-aminobutyric acid, GABA)-Interneuronen, einer Subpopulation von Pyramidenzellen im präfrontalen Kortex und in dopaminergen Neuronen der Area tegmentalis ventralis ko-exprimiert (Moutkine et al. 2017). Auch in Bereichen des olfaktorischen Systems werden die beiden Rezeptoren gemeinsam exprimiert: Im anterioren Nucleus olfactorius, dem Tuberculum olfactorium und dem Kortex piriformis. Zusätzlich wurden beide Rezeptoren im ventralen Cornu ammonis in der CA3-Zellschicht via in-situ-Hybridisierung nachgewiesen (Pompeiano et al. 1994). Im Gehirn einer Maus wurde außerdem eine Ko-Expression der beiden Rezeptoren im Nucleus arcuatus nachgewiesen (siehe Abbildung 4) (Martin-Gronert et al. 2016). Diese wurde in Vorarbeiten visualisiert und wird hier zur Verdeutlichung dargestellt. 

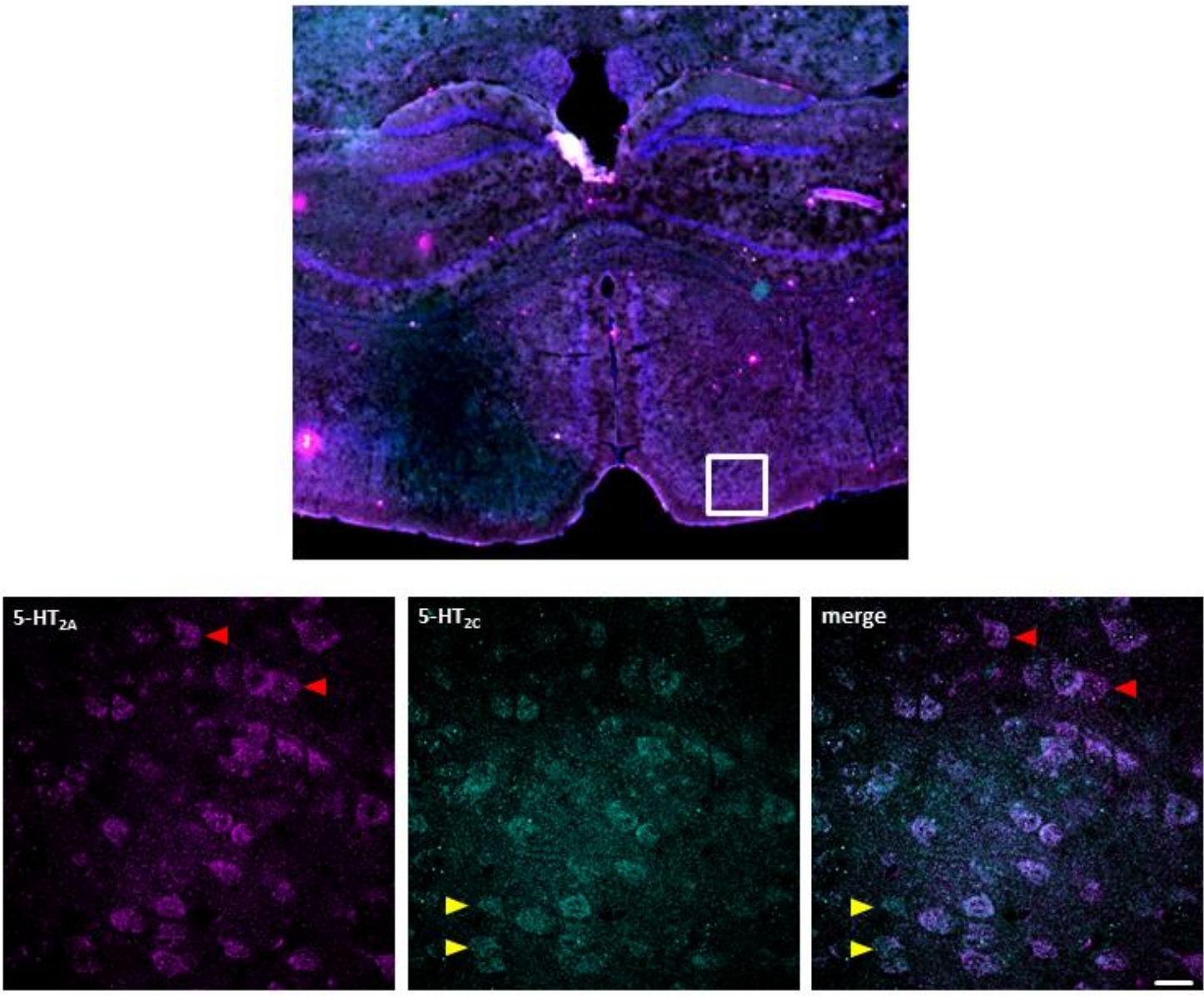

Abbildung 4: Immunhistochemischer Nachweis der Ko-Expression von Serotonin-Rezeptoren 5-HT $\mathrm{T}_{2 \mathrm{~A}}$ und 5-HT $2 \mathrm{C}$ am Nucleus arcuatus des Mäusehirns, durchgeführt im Labor der Neurophysiologie Göttingen. PFA-fixiertes Gewebe (Gehirn Maus) wurde nach Permeabilisierung mit Antikörpern gegen 5- $\mathrm{HT}_{2 \mathrm{~A}}$ (sc-50397, Santa Cruz) und 5-HT2C (sc-15080, Santa Cruz) gefärbt. Die Visualisierung erfolgte mit Sekundär-Antikörpern (A-21447, Molecular Probes; 771-165-152, Jackson immuno Research). Die obere Abbildung zeigt eine Übersicht am Querschnitt des Mäusehirns, in welcher der Ausschnitt des Nucleus arcuatus, welcher in der unteren Reihe dargestellt wird, markiert ist. In der unteren Reihe markieren die roten Pfeile Zellen, die positiv für 5- $\mathrm{HT}_{2 \mathrm{~A}}$ reagieren, während die gelben Pfeile Zellen zeigen, die reaktiv für 5- $\mathrm{HT}_{2 \mathrm{C}}$ sind. In dem dritten Bild der unteren Reihe (merge) wird sowohl die Fluoreszenz des Antikörpers gegen 5- $\mathrm{HT}_{2 \mathrm{~A}}$ als auch des Antikörpers gegen 5-HT $2 \mathrm{C}$ dargestellt. Einige der Zellen weisen beide Effluoreszenzen auf, sie exprimieren die Rezeptoren simultan auf der Oberfläche. Der Maßbalken entspricht $10 \mu \mathrm{m}$.

Die 5-HT 2 2 und 5- $\mathrm{HT}_{2 \mathrm{C}}$-Rezeptoren werden in den Pro-Opiomelanocortin-(POMC-)Neuronen des Nucleus arcuatus ko-exprimiert (Yadav et al. 2009). Der Nucleus arcuatus, der drittgrößte Kern des Hypothalamus, ist afferent und efferent mit diversen Hirnregionen verbunden. Seine prominenteste Funktion ist die Regulation der Nahrungsaufnahme über anorexigene POMCNeuronen und orexigene Neuropeptid-Y-Neuronen. Somit ergibt sich auch ein Einfluss auf den Energiestoffwechsel und den Glukosehaushalt (Sohn et al. 2011). 
Eine Ko-Expression der Rezeptoren 5- $\mathrm{HT}_{2 \mathrm{~A}}$ und 5- $\mathrm{HT}_{2 \mathrm{~B}}$ ist bis dato im menschlichen Gehirn nicht nachgewiesen.

Zusammenfassend wird der Rezeptor 5- $\mathrm{HT}_{2 \mathrm{~B}}$ hauptsächlich peripher, jedoch mit kleinen Anteilen auch zentral exprimiert. Der Rezeptor $5-\mathrm{HT}_{2 \mathrm{~A}}$ lässt sich sowohl peripher als auch zentral nachweisen, während 5- $\mathrm{HT}_{2 \mathrm{C}}$ fast ausschließlich im ZNS exprimiert wird.

Sowohl für 5- $\mathrm{HT}_{2 \mathrm{~A}}$ und $5-\mathrm{HT}_{2 \mathrm{C}}$ als auch für $5-\mathrm{HT}_{2 \mathrm{~B}}$ und $5-\mathrm{HT}_{2 \mathrm{C}}$ wurde in einigen Neuronen im menschlichen Gehirn eine Ko-Expression nachgewiesen.

\section{$1.4 \quad$ Dimerbildung}

Bei den Interaktionen von GPCRs muss zwischen Di- und Oligomerisierung unterschieden werden. Da in dieser Arbeit eine funktionelle Unterscheidung zwischen Di-, Tri-, Tetra- oder höhermolekularen Oligomeren mit vertretbarem Aufwand nicht zu leisten ist, beschränke ich mich sowohl bzgl. der Analyse als auch im Ausdruck nur auf die Unterscheidung von Monound Dimeren. Bezüglich der Dimere unterscheidet man zwischen Homo- und Heterodimeren, wobei ein Heterodimer einen Komplex beschreibt, der von zwei verschiedenartigen Monomeren gebildet wird, während ein Homodimer einen Komplex aus zwei gleichartigen Monomeren benennt.

Für Rezeptoren der Klasse C der GPCRs ist bereits bekannt, dass diese Dimere bilden, welche für die Funktion der Rezeptoren obligat sind (Romano et al. 1996; Zhang et al. 2014). So agieren aus der Klasse $\mathrm{C}$ der GPCRs beispielsweise der $\mathrm{GABA}_{\mathrm{B} 1}$ - und der $\mathrm{GABA}_{\mathrm{B} 2}$-Rezeptor als obligates Heterodimer. Während über den $\mathrm{GABA}_{\mathrm{B} 1}$-Rezeptor der Agonist gebunden wird, aktiviert der $\mathrm{GABA}_{\mathrm{B} 2}$-Rezeptor das G-Protein, sodass eine Signalgebung nur im Dimer erfolgen kann (Xue et al. 2019).

Auch innerhalb der Klasse A der GPCRs, zu welcher die 5-HT-Rezeptoren gehören, wurden bereits einige Dimerbildungen nachgewiesen. Sowohl Heterodimere (z. B. aus Dopamin D1und Adenosin A1-Rezeptoren, Ginés et al. 2000) als auch Homodimere (z. B. Dopamin D2Rezeptor) konnten gezeigt werden. Hierbei wurde zum Teil eine starke Dynamik der Dimerisierung deutlich. So bilden beispielsweise die Dopamin-D2-Rezeptoren schnell Dimere und dissoziieren wieder, was die Erforschung der Dimerisierung verkompliziert.

Bezogen auf die Dopamin-D2-Rezeptoren ist bekannt, dass der Dimeranteil zu einem gemessenen Zeitpunkt in der Regel bei etwa 30\% liegt. Carli et al. haben interessanterweise festgestellt, dass dieser Dimeranteil durch die Bindung gewisser Liganden erhöht werden kann. Die Liganden stabilisieren die Dimerbildung (Carli et al. 2018). Wird von diesem Ansatzpunkt 
ausgegangen, so wird deutlich, welche immensen pharmakologischen Möglichkeiten die Untersuchung der Dimerbildung beispielsweise in Hinblick auf die Entwicklung dimerspezifischer Liganden bietet.

An welcher molekularen Struktur die Rezeptoren aneinander binden und Dimere bilden, wird bereits seit vielen Jahren an Klasse A GPCRs untersucht. Die meisten Studien deuten darauf hin, dass die Rezeptoren über die Transmembrandomänen (TMD) IV und V dimerisieren (González-Maeso et al. 2008; Johnston et al. 2011; Hu et al. 2012). Auch eine Dimerisierung über die TMD I und II sowie die Helix 8 und die TMD V und VI werden diskutiert (HerrickDavis 2013). Die Mechanismen der Dimerisierung sind vielfältig und noch nicht für alle Rezeptorarten untersucht. Auch an den 5- $\mathrm{HT}_{2}$-Rezeptoren ist noch kein eindeutiger Mechanismus zur Dimerisierung belegt.

\subsubsection{Auswirkungen der Dimerisierung}

Die Dimerisierung kann sich auf verschiedenste Stadien im Lebenszyklus des GPCR auswirken und abhängig vom Rezeptor essenziell für die Funktion sein.

Bereits für das Verlassen des endoplasmatischen Retikulums (ER) kann die Dimerisierung vonnöten sein. So wurde für den $\gamma$-Aminobuttersäure(B)-Rezeptor (GbR), welcher aus den Untereinheiten $\mathrm{GbR}_{1}$ und $\mathrm{GbR}_{2}$ besteht, gezeigt, dass $\mathrm{GbR}_{1}$ nur aus dem ER freigesetzt werden kann, wenn er mit $G_{2}$ ko-exprimiert wird. Wahrscheinlich wird durch die Dimerisierung von $\mathrm{GbR}_{1}$ und $\mathrm{GbR}_{2}$ ein Signal unterdrückt, welches den $\mathrm{GbR}_{1}$ bei dessen alleiniger Expression im ER hält (Terrillon und Bouvier 2004).

Hinsichtlich der Signalgebung wurden sowohl potenzierende Effekte (z. B. Somatostatin SSTR5/Dopamin D2-Rezeptor (Rocheville et al. 2000)) als auch eine Abschwächung des Signals (z. B. Angiotensin AT1/Bradykinin B2 (AbdAlla et al. 2000)) beschrieben.

Es zeigte sich außerdem, dass eine Dimerisierung eine Konformationsänderung der einzelnen Monomere bewirken kann (Guo et al. 2003; Vilardaga et al. 2008). In einem solchen Fall kann das zweite Monomer die Effizienz, mit welcher das erste Monomer an G-Proteine bindet, steigern (Kniazeff et al. 2004) oder reduzieren (Han et al. 2009).

Im Beispiel der beschriebenen Rezeptoren $G_{b R}$ und $G_{b R}$ steigert die Dimerisierung nicht nur die Effizienz der Kopplung an ein G-Protein, sondern ist hier tatsächlich notwendig, um überhaupt eine Signalgebung zu ermöglichen (Margeta-Mitrovic et al. 2000). Auch ein Wechsel des gekoppelten G-Proteins $\left(G_{i}, G_{s}, G_{q}\right)$ durch die Dimerisierung wird in einigen Fällen diskutiert (Terrillon und Bouvier 2004). 
Als letzter Teil des Aktivierungszyklus kann auch die Internalisierung der Rezeptoren beeinflusst werden. Wenn ein Rezeptor, welcher in der Regel nach seiner Stimulation internalisiert wird, mit einem Rezeptor gekoppelt ist, welcher physiologischerweise nach der Aktivierung auf der Oberfläche verbleibt, so kann dies die Internalisierung des anderen jeweils verhindern bzw. induzieren (Terrillon und Bouvier 2004).

\subsubsection{Dimere der 5-HT-Rezeptoren}

Innerhalb der 5-HT-Rezeptoren konnte für die Rezeptoren 5- $\mathrm{HT}_{1 \mathrm{~B}}$ und 5-HT $\mathrm{T}_{1 \mathrm{D}}$ nachgewiesen werden, dass diese Homodimere bilden, wenn nur eine Rezeptorart exprimiert wird, und dass bei einer Ko-Expression die Tendenz zur Bildung von Heterodimeren (5- $\left.\mathrm{HT}_{1 \mathrm{~B} / \mathrm{D}}\right)$ anstelle der Homodimere geht (Xie et al. 1999). Außerdem zeigt ein Großteil der Studien, dass die Rezeptoren $5-\mathrm{HT}_{1 \mathrm{~A}}, 5-\mathrm{HT}_{2 \mathrm{~A}}, 5-\mathrm{HT}_{2 \mathrm{C}}, 5-\mathrm{HT}_{4}$, und $5-\mathrm{HT}_{7}$ in der Lage sind Homodimere zu bilden (Herrick-Davis 2013).

Hinsichtlich der in dieser Arbeit betrachteten Rezeptoren 5- $\mathrm{HT}_{2 \mathrm{~A}-\mathrm{C}}$ konnte bisher anhand von BRET (Biolumineszenz-Resonanzenergietransfer)-Experimenten für $5-\mathrm{HT}_{2 \mathrm{~A}}$ und $5-\mathrm{HT}_{2 \mathrm{C}} \mathrm{je}-$ weils eine Homodimer-Bildung gezeigt werden. Außerdem deuten die Daten darauf hin, dass auch Heterodimere zwischen den verschiedenen 5- $\mathrm{HT}_{2}$-Rezeptoren gebildet werden können. Zusätzlich wurde mit verschiedenen anderen GPCRs eine Heterodimerisierung beobachtet, z. B. für 5-HT $\mathrm{T}_{2 \mathrm{~A}}$ mit mGluR2(metabotroper Glutamatrezeptor 2)- und dem D2-Dopamin-Rezeptor, für 5- $\mathrm{HT}_{2 \mathrm{~B}}$ mit dem Angiotensin $\mathrm{AT}_{1}$-Rezeptor und für 5- $\mathrm{HT}_{2 \mathrm{C}}$ mit Ghrelin-Rezeptoren (GHS-R1a) (Moutkine et al. 2017).

Hinsichtlich der Auswirkungen der Dimerisierung auf die Signalgebung liegen für die Kombination 5- $\mathrm{HT}_{1 \mathrm{~A}} / 5-\mathrm{HT}_{7}$ interessante Daten vor. 5- $\mathrm{HT}_{1 \mathrm{~A}}$-Rezeptoren koppeln an $\mathrm{G}_{\mathrm{i}}$-Proteine und 5- $\mathrm{HT}_{7}-$ Rezeptoren u. a. an $\mathrm{G}_{\mathrm{s}}$-Proteine. Bei der Signalgebung aktiviert das Dimer weniger $\mathrm{G}_{\mathrm{i}^{-}}$ Proteine als es bei einem allein exprimierten 5- $\mathrm{HT}_{1 \mathrm{~A}}$-Rezeptor der Fall wäre, während die Aktivierung der $\mathrm{G}_{\mathrm{s}}$-Proteine unbeeinflusst bleibt. Daher wird diskutiert, ob dies dadurch zu begründen ist, dass durch die Dimerisierung eine Konformationsänderung des Rezeptors und somit eine konsekutive Änderung der G-Protein-Bindungsstelle stattfindet. Außerdem zeigt sich für den 5- $\mathrm{HT}_{1 \mathrm{~A}}$-Rezeptor im Dimer mit dem 5-HT $-\mathrm{T}_{7}$-Rezeptor nach deren Aktivierung eine Internalisierung, während dies beim allein exprimierten 5- $\mathrm{HT}_{1 \mathrm{~A}}$-Rezeptor nicht der Fall ist (Renner et al. 2012).

Für das Homodimer des 5-HT $-\mathrm{T}_{4}$-Rezeptors wurde gezeigt, dass sich die Signalstärke des Rezeptorkomplexes bei der Aktivierung beider Rezeptoren des Dimers im Vergleich zu der Aktivierung nur eines Rezeptors verdoppelt. Dabei entsteht die Verdopplung des Signals nicht durch 
die Bindung zweier Agonisten an das Dimer, da experimentell nachgewiesen wurde, dass nur ein G-Protein an das Dimer bindet. Somit müssen der verstärkten Signalweiterleitung andere Mechanismen, welche durch die Dimerbildung bewirkt werden, zugrunde liegen (Pellissier et al. 2011).

\subsection{Zielsetzung und Fragestellung}

Nachdem lange Zeit angenommen wurde, dass G-Protein-gekoppelte Rezeptoren als Monomere arbeiten, eröffneten sich mit der Entdeckung der Dimerisierung bzw. Oligomerisierung der GPCRs ungeahnte Möglichkeiten bzgl. der Vielfalt innerhalb der Rezeptorfamilie. Es taten sich verschiedenste Fragen auf: Welche der GPCRs dimerisieren? Wie dynamisch bzw. stabil ist die Dimerbildung? Hat die Dimerbildung einen Einfluss auf die Signalgebung der Rezeptoren? Und vor allen Dingen: Welche Methoden eignen sich, um diesen Fragen nachzugehen?

In dieser Arbeit wurde insbesondere der Frage nach der Dimerbildung und ihren Auswirkungen auf die Signalgebung der 5- $\mathrm{HT}_{2}$-Rezeptoren nachgegangen. Denn interessanterweise existieren mindestens 14 verschiedene 5-HT-Rezeptoren (siehe Kapitel 1.3), jedoch in Form des Serotonins nur ein physiologischer Ligand. Berücksichtigt man die Verbindung der 5-HT-Rezeptoren zu den verschiedenen G-Proteinen (vgl. Abb. 2), würden vier 5-HT-Rezeptoren (je einer für $\mathrm{G}_{\mathrm{i}}, \mathrm{G}_{\mathrm{s}}, \mathrm{G}_{\mathrm{q}}$ und ein Ionenkanal) ausreichen, um die verschiedenen Signale auszulösen. Jedoch weisen die unterschiedlichen Subtypen variierende Affinitäten, Kinetiken und Expressionsprofile auf. Somit ist es durchaus denkbar, dass durch die Kombination von verschiedenen Rezeptoren in Heterodimeren eine noch größere Vielzahl von fein graduierten Signalantworten realisiert werden können.

Der Interaktionsgrad der 5- $\mathrm{HT}_{2}$-Rezeptoren und damit ihre Dimerisierungsneigung wurden in der vorliegenden Arbeit durch die Methode, fluorescence recovery after photobleaching (FRAP) bestimmt. Die Signalgebung wurde mittels $\mathrm{Ca}^{2+}$-Imaging nach der Stimulation mit Serotonin oder rezeptortyp-spezifischen Agonisten gemessen. Da es uns technisch nicht möglich war, den Interaktionsgrad und das Calciumsignal gleichzeitig zu messen, wurden die Ergebnisse von entsprechenden Versuchen korreliert, um so interpretieren zu können, inwieweit eine Dimerisierung einen Einfluss auf die Signalisierung hat.

Alle Experimente wurden zunächst mit den einzeln exprimierten Rezeptoren 5- $\mathrm{HT}_{2 \mathrm{~A} / 2 \mathrm{~B} / 2 \mathrm{C}}$ durchgeführt. Anschließend wurden alle Experimente mit allen Kombinationen der ko-exprimierten Rezeptoren $(2 \mathrm{~A} / 2 \mathrm{~B}, 2 \mathrm{~A} / 2 \mathrm{C}, 2 \mathrm{~B} / 2 \mathrm{C})$ der verschiedenen Rezeptorarten durchgeführt. Da bei fakultativen Dimeren hinsichtlich der Signalgebung zwischen dem Einfluss der in einem Äquilibrium vorhandenen Mono- und Dimere nicht direkt unterschieden werden kann, 
gestaltet sich die Messung der Auswirkungen der Dimerisierung auf die Signalgebung gerade bei derartigen Rezeptoren als schwierig. Daher war ein Hauptanliegen dieser Arbeit, eine Methode zu entwickeln, mit der sich die Dimerisierung kontrollieren lässt, um das Signal reiner Dimere mit dem natürlichen Signal vergleichen und daraus Rückschlüsse ziehen zu können. Dies wurde mithilfe einer in unserem Labor neuentwickelten Methode zu Erzwingung der Dimerisierung, dem Nanobody-GFP-Konstrukt, ermöglicht.

Eine Übersicht über die Ergebnisse bezüglich der Dimerbildung innerhalb der 5- $\mathrm{HT}_{2}$-Gruppe, welche sich aus der Kombination der verschiedenen Versuchsreihen ergeben haben, ist unter 4.3.3 tabellarisch dargestellt.

Der Vorteil in der Entdeckung neuer Dimerbildungen liegt darin, dass beispielsweise Pharmaka im Sinne von Dimer-spezifischen Liganden entwickelt werden könnten, welche spezifisch an enstprechenden 5-HT $\mathrm{T}_{2}$-Dimeren wirken. Durch die Spezifität der Wirkung würden weniger unerwünschte Arzneimittelwirkungen verursacht werden. Bereits jetzt greifen von den derzeit auf dem Markt verfügbaren Pharmaka etwa 34 \% an GPCRs an (Hauser et al. 2017), sodass Entwicklungen hinsichtlich der Dimerisierungsneigung und deren Auswirkungen weitreichende Möglichkeiten in der Pharmakologie schaffen werden. 


\section{$2 \quad$ Material und Methoden}

\subsection{Material}

Feinchemikalien stammen, wenn nicht anders angegeben, von Sigma-Aldrich Chemie GmbH, Taufkirchen, D. $\mathrm{H}_{2} \mathrm{O}$ steht grundsätzlich für bidestilliertes Wasser.

Tabelle 1: Chemikalien und Substanzen

\begin{tabular}{ll} 
Substanz & Bezugsquelle \\
\hline 5-HT (Serotonin hydrochloride & Sigma-Aldrich Chemie GmbH, Taufkirchen, D \\
H9523-100MG) & \\
\hline 5-HT ${ }_{2 \mathrm{~A}}$ Agonist (WAY629 Hydro- & Tocris Bioscience, Bristol, UK \\
chlorid) &
\end{tabular}

\begin{tabular}{ll}
\hline 5-HT $2 \mathrm{~B}$ Agonist (TCB-2) & Tocris Bioscience, Bristol, UK \\
\hline 5-HT $2 \mathrm{C}$ Agonist (BW723c86 Hy- & Tocris Bioscience, Bristol, UK \\
drochlorid) & \\
\hline
\end{tabular}

\begin{tabular}{ll}
\hline Antarctic Phosphatase & New England Biolabs GmbH, Frankfurt am Main, D \\
\hline Cut Smart Buffer & New England Biolabs GmbH, Frankfurt am Main, D \\
\hline dNTP & New England Biolabs GmbH, Frankfurt am Main, D \\
\hline Gel loading Dye Blue (6x) & New England Biolabs GmbH, Frankfurt am Main, D \\
\hline Ladepuffer Elektrophorese & New England Biolabs GmbH, Frankfurt am Main, D \\
\hline Lipofectamine 2000 Reagent & Thermo Fisher Scientific Inc., Waltham, US \\
\hline Mowiol & Sigma-Aldrich Chemie GmbH, Taufkirchen, D \\
\hline NEBuilder HiFi DNA (DNA-As- & New England Biolabs GmbH, Frankfurt am Main, D \\
sembly-Mix) & \\
\hline Quick-Load 1kb DNA ladder & New England Biolabs GmbH, Frankfurt am Main, D \\
\hline $\begin{array}{l}\text { Taq-Polymerase mit Puffer (One } \\
\text { Taq standard buffer) }\end{array}$ & New England Biolabs GmbH, Frankfurt am Main, D
\end{tabular}


Tabelle 2: Lösungen, Puffer und Medien

Lösung/Puffer/Medium

Agarose-Gel
Protokoll, Bezugsquelle

25 g Agarose (Biozym Scientific GmbH, Hessisch Olendorf, D) in $250 \mathrm{ml}$ TAE-Puffer 1x (Tris Acetate-EDTA Puffer), Auflösen durch Erhitzen, Zugabe von $25 \mu \mathrm{l}$ Ethidiumbromid

\begin{tabular}{ll}
\hline DPBS 1x & Thermo Fisher Scientific Inc., Waltham, US \\
\hline KCM-Lösung 5x & $\begin{array}{l}0,5 \mathrm{M} \mathrm{KCl}, 0,15 \mathrm{M} \mathrm{CaCl}_{2} \text { und } 0,25 \mathrm{M} \mathrm{MgCl}_{2} \text { in } \mathrm{H}_{2} \mathrm{O} \text {, fil- } \\
\text { tern durch einen } 0,22 \mu \mathrm{m} \text { Flaschenfilter }\end{array}$ \\
\hline LB-Agar & $\mathrm{LB}($ lysogeny broth, Nährmedium) - Medium mit $1 \%$ Agar \\
& und $100 \mu \mathrm{g} / \mathrm{ml}$ Ampicillin \\
\hline LB-Medium 5x & $10 \mathrm{~g}$ LB-Pulver in $100 \mathrm{ml} \mathrm{H}_{2} \mathrm{O}$, Autoklavierung \\
\hline Serumfreies Medium (Opti-MEM & Thermo Fisher Scientific Inc., Waltham, US \\
Gibco) & \\
\hline
\end{tabular}

TAE (TRIS-Acetat-EDTA)-Puffer 242,28 g TRIS-Puffer in 750 ml $\mathrm{H}_{2} \mathrm{O}$ lösen, 60,05 g Es-

50x sigsäure und 18,6 g EDTA Na 2 hinzufügen

TSB (Tryptic-Soja-Bouillon) - $\quad$ 5x LB, pH 6.1, 10 \% PEG 3000, 5 \% DMSO,

Lösung

$0,01 \mathrm{M} \mathrm{MgSO}_{4} 7 \mathrm{H}_{2} \mathrm{O}$ und $0,01 \mathrm{M} \mathrm{MgCl}_{2} \times 6 \mathrm{H}_{2} \mathrm{O}$ ver-

mengen, filtern durch einen $0,22 \mu \mathrm{m}$ Flaschenfilter

Wachstumsmedium

$10 \mathrm{~g}$ DMEM-Pulver (Dulbecco's modified eagle's medium) aufgelöst, 1,81 g Hepes, 2,52 g NaHCO 3 und 25 ml MEMNon-Essential Amino Acid Solution 100x vermengen. $\mathrm{pH}-$ Wert mit $\mathrm{NaOH}$ auf 7,4 einstellen.

$\mathrm{H}_{2} \mathrm{O}$ ad $900 \mathrm{ml}$, steril filtrieren

$100 \mathrm{ml}$ Fetales Kälberserum (fetal bovine serum, FBS) hinzufügen 
Tabelle 3: Ansatz SOC(Super Optimal broth with Catabolite repression)-Medium

Ansatz 1

100 g Bacto-Trypton

$1 \mathrm{~g}$ Hefeextrakt

$0,4 \mathrm{ml} 5 \mathrm{M} \mathrm{NaCl}$

$0,167 \mathrm{ml} \mathrm{3M} \mathrm{KCl}$

$200 \mathrm{ml} \mathrm{H}_{2} \mathrm{O}$

Ansatz 2 (Magnesiumlösung) 2,465 $\mathrm{g} \mathrm{MgSO}_{4} * 7 \mathrm{H}_{2} \mathrm{O}$

$2,033 \mathrm{~g} \mathrm{MgCl}_{2} * 6 \mathrm{H}_{2} \mathrm{O}$

$\mathrm{H}_{2} \mathrm{O}$ ad $10 \mathrm{ml}$

Ansatz 3 (Glukoselösung) 3,603 g Glukose

$\mathrm{H}_{2} \mathrm{O}$ ad $10 \mathrm{ml}$

Zur Herstellung des SOB (Super Optimal Broth)-Mediums wurden Ansatz 1 und Ansatz 2 im Verhältnis von $100: 1$ steril vermengt.

Für die Herstellung des SOC-Mediums wurden das SOB-Medium und Ansatz 3 im Verhältnis von $100: 1$ steril vermengt.

Tabelle 4: Kits

Kit

Bezugsquelle

DNA-Ligation Instant Sticky-end New England Biolabs GmbH, Frankfurt am Main, D Ligase Master Mix

Wizard SV Gel and PCR Clean-up Promega, Heidelberg, D

System

Biotin Protein Labeling Kit Sigma-Aldrich Chemie GmbH, Taufkirchen, D

Maxi Prep Plasmid DNA Purifica- Thermo Fisher Scientific Inc., Waltham, US tion Nucleo Bond Xtra Maxi

Wizard Plus SV Minipreps DNA Promega, Heidelberg, D

Purification Systems 


\subsubsection{Biologische Materialien (Zellen, Vektoren, Antikörper, Enzyme, Bakterienstämme)}

\subsubsection{Zelllinie}

Für alle Versuche wurden Zellen der etablierten Zelllinie N1E-115 (ATCC, Manassas, VA, US) genutzt, welche durch eine Klonierung des murinen C-1300 Neuroblastoms gewonnen wurden (Amano et al. 1972). Es wurden ausschließlich Zellen zwischen Passage 20 und 70 verwendet.

\subsubsection{Der Vektor}

Als Klonierungsvektor diente das Plasmid pcDNA 3.1(-) mit einem Ampicillin-Resistenzgen (Takara Bio Inc., CA, US).

Tabelle 5: Desoxyribonukleinsäuren

\begin{tabular}{ll} 
DNA & Gen-Bank-ID/Verweis \\
\hline $5-\mathrm{HT}_{2 \mathrm{~A}}$ & NM_172812 \\
\hline $5-\mathrm{HT}_{2 \mathrm{~B}}$ & NM_008311 \\
\hline $5-\mathrm{HT}_{2 \mathrm{C}}$ & NP_032338 \\
\hline grün fluoreszierendes Protein (GFP) & NC_013179 \\
\hline Einzeldomänenantikörper (Nanobody) & Muyldermans 2001 \\
\hline GCaMP6s & Chen et al. 2013
\end{tabular}

GCaMP6s

Chen et al. 2013

Tabelle 6: Restriktionsendonukleasen

\section{Restriktionsendonuklease Bezugsquelle}

\begin{tabular}{ll}
\hline EcoRV & New England Biolabs GmbH, Frankfurt am Main, D \\
\hline NheI & New England Biolabs GmbH, Frankfurt am Main, D
\end{tabular}


Tabelle 7: Antikörper

\begin{tabular}{lll} 
Antikörper & Spezies & Hersteller \\
\hline HA-Antikörper (Y-11) sc-805 X & Kaninchen & $\begin{array}{l}\text { Santa Cruz Biotechnology, Dal- } \\
\text { las, US }\end{array}$ \\
\hline myc-Antikörper (Santa Cruz) & Maus & $\begin{array}{l}\text { Santa Cruz Biotechnology, Dal- } \\
\text { las, US }\end{array}$ \\
\hline quantum dot 655 goat F & Gans & $\begin{array}{l}\text { Invitrogen AG, Carlsbad, US } \\
\text { (anti-rabbit) }\end{array}$ \\
\hline Streptavidin-bedeckte quantum dots & & $\begin{array}{l}\text { Thermo Fisher Scientific Inc., } \\
\text { Waltham, US }\end{array}$
\end{tabular}

\subsubsection{Verbrauchsmaterialien, Geräte und Software}

Tabelle 8: Verbrauchsmaterialien

Material Hersteller

Deckgläser Thermo Fisher Scientific Inc., Waltham, US

Glasboden-Zellkulturschalen Ibidi GmbH, Planegg, D

$35 \mathrm{~mm}$

Laborflaschen $(50 \mathrm{ml} ; 250 \mathrm{ml}) \quad$ DWK Life Sciences, Wertheim, D

Mikrotiterplatten 4-Loch (12 mm) Thermo Fisher Scientific Inc., Waltham, US

Pasteurpipetten in div. Größen Eppendorf, Hamburg, D

PCR-Reaktionsgefäß 0,2 ml Brand GmbH und Co. KG, Wertheim, D

Pipettenspitzen in div. Größen Starlab GmbH, Hamburg, D

(TipOne)

\begin{tabular}{ll}
\hline Reaktionsgefäß $1,5 \mathrm{ml}$ & Eppendorf, Hamburg, D \\
\hline Zellkulturschalen & Thermo Fisher Scientific Inc., Waltham, US \\
\hline
\end{tabular}

Zentrifugenröhrchen (CentriStar Corning, Corning, US

$15 \mathrm{ml} ; 50 \mathrm{ml})$ 
Tabelle 9: Geräte

\section{Gerät}

Andor iXon Kamera

60×/1.45 NA Plan Apochromat Ob- Olympus, Shinjuku, J

jektiv

$\mathrm{CO}_{2}$-Inkubator (MIDI 40)

Thermo Fisher Scientific Inc., Waltham, US

Durchflusszytometer (BD LSR II)

Eppendorf-BioPhotometer 6131

Gelelektrophorese (Agagel Mini

Biometra)

\begin{tabular}{ll}
\hline Inkubationsschüttler (Minitron) & INFORS HT, Bottmingen, CH \\
\hline IX71 Mikroskop & Olympus, Shinjuku, J \\
\hline Laborwaage (L2200P) & Sartorius, Göttingen, D \\
\hline Laborwaage (Sartorius handy H51) & Sartorius, Göttingen, D \\
\hline Laseremittierende Diode & TOPTICA Photonics, Gräfelfing, D \\
\hline LSM-Mikroskop (Zeiss LSM & Carl Zeiss AG, Oberkochen, D \\
\hline 510 Meta) & \begin{tabular}{l} 
Werkstatt UMG, Universitätsmedizin Göttingen, D \\
\hline Mikroskophalterung (nach Maß)
\end{tabular} \\
\hline PCR-Block (C1000 Thermal Cycler) & BioRad, Hercules, US \\
\hline PCR-Block (Primus25 advanced) & peqlab, Erlangen, D \\
\hline Sicherheitswerkbank (SAFE 2020) & Thermo Fisher Scientific Inc., Waltham, US \\
\hline TIRF-Kondensator & Olympus, Shinjuku, J \\
\hline Thermomixer comfort & Eppendorf, Hamburg, D \\
\hline Wasserbad (Lauda A100) & $\begin{array}{l}\text { Lauda Dr. R. Wobser GmbH \& Co. KG, Lauda-Kö- } \\
\text { nigshofen, D }\end{array}$ \\
\hline Werkbank (Captair Flow) & Erlab, Val de Reuil, F \\
\hline Heraeus, Hanau, D \\
\hline Lenge (Biofuge pico)
\end{tabular}

Becton, Dickinson and Company, Franklin Lakes, US

Eppendorf, Hamburg, D

Biometra biomed. Analytik GmbH, Göttingen, D

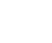


Tabelle 10: Software

Programm

Bezugsquelle

Andor iQ Software

Oxford instruments plc, Abingdon, UK

Flowjo Software v10.0.7

FlowJo, Ashland, US

GraphPad Prism v5.01

Graphpad Software, Inc, San Diego, US

Microsoft Excel 2013

Microsoft Corporation, Redmond, US

Programm LSM-Mikroskop (ZEN

Carl Zeiss AG, Oberkochen, D

2009) 


\subsection{Methoden}

\subsubsection{Forcierte Dimerisierung}

Im Rahmen dieser Arbeit wurden die 5- $\mathrm{HT}_{2}$-Rezeptoren in Dimere forciert, um u. a. die Signalgebung reiner Dimere mit der Signalgebung einfach exprimierter Rezeptoren vergleichen zu können und so Rückschlüsse auf das Dimerisierungsverhalten der Rezeptoren und dessen Auswirkungen auf die Signalgebung ziehen zu können. Auch konnten so die Diffusionskoeffizienten für reine Dimere gemessen und mit den Diffusionskoeffizienten der einfach exprimierten Rezeptoren verglichen werden. Für die Forcierung in ein Dimer wurden GFP und ein AntiGFP-Nanobody genutzt.

Die verschiedenen 5- $\mathrm{HT}_{2}$-Rezeptoren wurden mit einem Anti-GFP-Nanobody gekoppelt und gemeinsam mit einem anderen 5- $\mathrm{HT}_{2}$-Rezeptor exprimiert, welcher an GFP gekoppelt war. Aufgrund hydrophober Wechselwirkungen ist die Bindung des Nanobodys an das GFP hochaffin. Gleichzeitig ist die Bindung durch hydrophile Seitenketten und Salzbrücken hochspezifisch (Kubala et al. 2010). Durch die Bindung des Nanobodys an das GFP werden die Rezeptoren in eine enge räumliche Nähe gebracht und mögliche Interaktionen gefördert (siehe Abbildung 5).

Auf die Klonierung der Fluorophor- bzw. Nanobody-gekoppelten 5-HT-Rezeptoren wird in Kapitel 2.2.2 weiter eingegangen.

1)

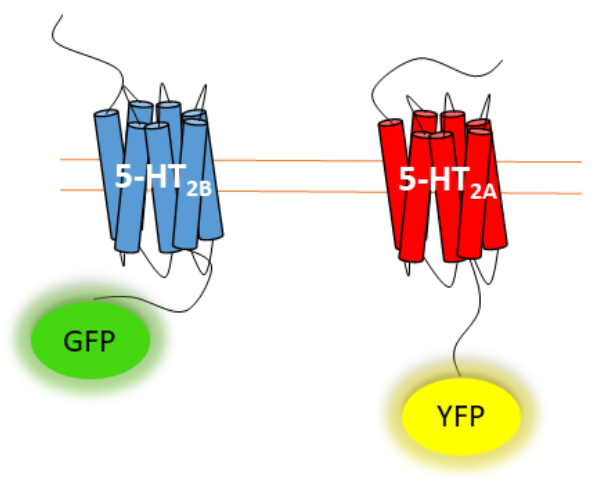

2)

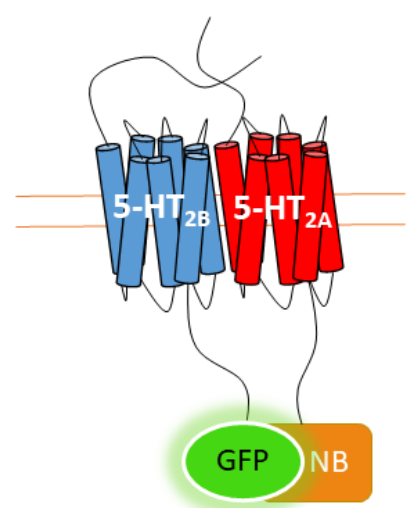

Abbildung 5: Schematische Darstellung der forcierten Dimerisierung für die Rezeptoren 5- $\mathrm{HT}_{2 \mathrm{~A}}$ und 5- $\mathrm{HT}_{2 \mathrm{~B}}$. 5- $\mathrm{HT}_{2 \mathrm{~A}}$ ist rot und 5-HT $\mathrm{T}_{2 \mathrm{~B}}$ blau dargestellt. 1) Beide Rezeptoren sind an fluoreszente Proteine (GFP und YFP) gebunden, eine Dimerisierung kann in dieser Konstellation ggf. dynamisch stattfinden. 2) $5-\mathrm{HT}_{2 \mathrm{~A}}$ ist an einen Nanobody (NB) und $5-\mathrm{HT}_{2 \mathrm{~B}}$ an GFP gebunden. Durch die GFP-NB-Bindung bildet sich ein stabiles Dimer aus 5- $\mathrm{HT}_{2 \mathrm{~A}}$ und 5- $\mathrm{HT}_{2 \mathrm{~B}}$. 


\subsubsection{Grün fluoreszierendes Protein (GFP)}

Das GFP, welches u. a. als Antigen für den Nanobody Verwendung fand, wurde 1962 erstmals in der Quallenart Aequorea victoria entdeckt (Shimomura et al. 1962). Es leuchtet bei Anregung mit kurzwelligem Licht grün (Exzitationsmaximum ca. $395 \mathrm{~nm}$, Emissionsmaximum ca. $505 \mathrm{~nm}$ ) (Tsien 1998). Die DNA des Proteins kann an die DNA anderer Zellproteine gekoppelt werden, wodurch sich die Möglichkeit ergibt, deren Interaktionen, Bewegung und Funktion zu untersuchen (Chalfie et al. 1994). Für die vorliegenden Experimente wurde die GFP-DNA an die Rezeptor-DNA der 5- $\mathrm{HT}_{2}$-Rezeptoren gekoppelt.

\subsubsection{Nanobodys}

Nanobodys sind extrem kleine Antikörper. Im Serum von Kamelen fand man erstmals Antikörper, welche im Gegensatz zu den bis dato bekannten Antikörpern nicht aus zwei identischen schweren Ketten und zwei identischen leichten Ketten, sondern ausschließlich aus zwei schweren Ketten bestanden, die IgG Schwerkettenantikörper (Hamers-Casterman et al. 1993). Die Antigenerkennungsstelle $\mathrm{V}_{\mathrm{H}}$, welche normalerweise von der schweren und der leichten Kette zusammen gebildet wird, besteht bei diesen Antikörpern alleine aus der variablen Domäne der schweren Kette und wird als $\mathrm{V}_{\mathrm{H}} \mathrm{H}$ bezeichnet (Muyldermans et al. 1994). Diese $\mathrm{V}_{\mathrm{H}} \mathrm{H}$ kann isoliert als sogenannter Nanobody eingesetzt werden und hat mit $\sim 15 \mathrm{kDa}$ eine sehr viel geringere Molekülmasse als herkömmliche Antikörper (IgG $\sim 150$ kDa, siehe Abbildung 6). Da die Nanobodys nur aus einer Domäne bestehen, sind sie besonders stabil und gut löslich (Muyldermans 2001).

1)

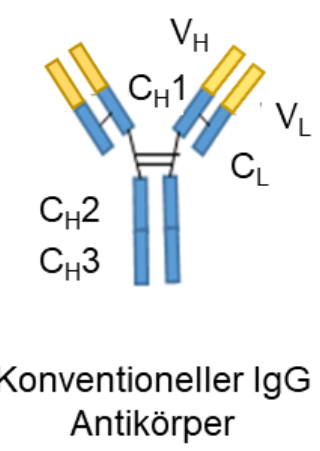

$150 \mathrm{kDa}$
2)

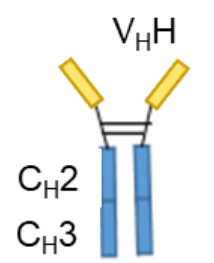

IgG Schwerketten-

antikörper

$75 \mathrm{kDa}$
3)

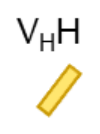

Nanobody $\mathrm{V}_{\mathrm{H}} \mathrm{H}$

$15 \mathrm{kDa}$

Abbildung 6: IgG-Antikörper und Nanobody mit Molekülgrößen. $C=$ konstante Domäne, $V=$ variable Domäne, $\mathrm{H}$ = heavy (schwer), $\mathrm{L}=$ light (leicht). 1) In den konventionellen IgG-Antikörpern wird die variable Region aus einer schweren und einer leichten Kette gebildet $\left(V_{H}\right.$ und $\left.V_{L}\right)$. 2) In den SchwerkettenAntikörpern der Kamele wird die variable Region einzig aus einer schweren Kette $\left(\mathrm{V}_{\mathrm{H}} \mathrm{H}\right)$ gebildet. 3) Als Nanobody wird die alleinige $\mathrm{V}_{\mathrm{H}} \mathrm{H}$-Region der Schwerketten-Antikörper bezeichnet. Nach Muyldermans 2001. 


\subsubsection{Klonierung}

Um die Experimente der forcierten Dimerisierung durchführen zu können, wurden sowohl Nanobody- als auch GFP-gekoppelte 5- $\mathrm{HT}_{2}$-Rezeptoren benötigt, sodass diese vorab kloniert werden mussten.

Die Klonierung des 5-HT2C-NB/-GFP-Rezeptors erfolgte durch eine Fusions-PCR. Dieser konnte als Basis für die Herstellung der weiteren NB/GFP-gekoppelten Rezeptoren 5-HT2A und 5- $\mathrm{HT}_{2 \mathrm{~B}}$ genutzt werden, welche mit Hilfe einer Gibson-Assembly kloniert wurden.

\subsubsection{PCR}

Die 5- $\mathrm{HT}_{2 \mathrm{C}}$-Rezeptor-DNA und die Nanobody- bzw. GFP-DNA wurden durch eine PCR amplifiziert. Dieser Schritt war zum einen nötig, um einen passenden Überhang zu schaffen, an dem die 5-HT $\mathrm{HC}_{2 \mathrm{C}}$ Rezeptor-DNA und die Nanobody-/GFP-DNA revers komplementär zueinander waren und ligiert werden konnten. Zum anderen wurden die Enden des Inserts (Rezeptor + NB/GFP) so verlängert, dass sie Schnittstellen für Restriktionsendonukleasen bildeten, um das Insert später in die Vektor-DNA einzufügen.

So wurde beispielsweise für die Amplifikation eines 5- $\mathrm{HT}_{2 \mathrm{C}} / \mathrm{NB}$-Inserts die 5- $\mathrm{HT}_{2 \mathrm{C}}-\mathrm{DNA}$ mit dem Vorwärtsprimer passend zu der NheI-Schnittstelle und dem Rückwärtsprimer passend zu dem NB amplifiziert. Die NB-DNA wurde mit einem Vorwärtsprimer passend zu 5- $\mathrm{HT}_{2 \mathrm{C}}$ und einem Rückwärtsprimer passend zu der EcoRV-Schnittstelle amplifiziert (siehe Abbildung 7 und Primer in Tabelle 11).

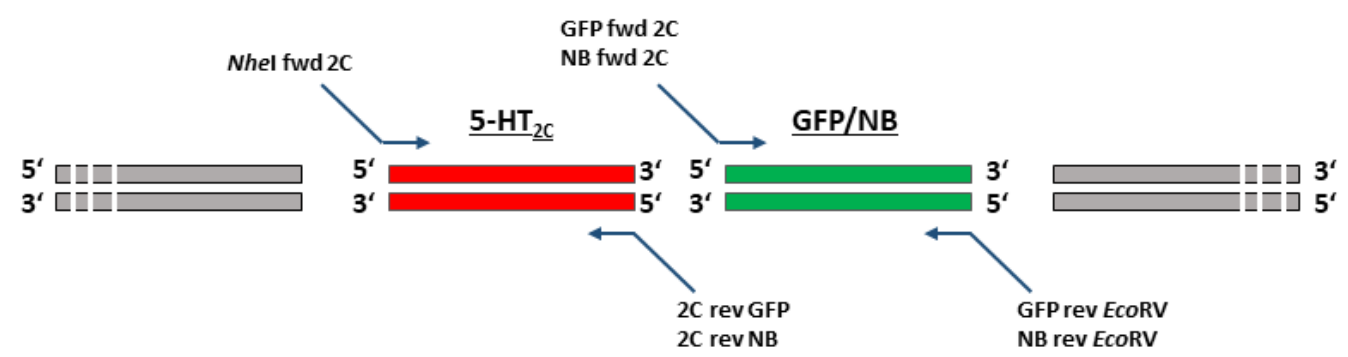

Abbildung 7: Die DNA-Fragmente 5- $\mathrm{HT}_{2 \mathrm{C}}$ und GFP bzw. NB mit den jeweiligen Primern, mit denen sie für die Fusions-PCR verlängert wurden. 
Tabelle 11: Primer für die PCR der 5-HT 2 -Rezeptor-DNA bzw. GFP oder NB-DNA.

\begin{tabular}{ll} 
Primer & Sequenz 5' $\rightarrow$ 3' \\
\hline 2C_fwd NheI & gccGCTAGCaccATGGTGAACCTGGGCACT \\
\hline fusion2C+GFP_fwd & GGATTAGTAGTGTGATGGTGAGCAAGGGC \\
\hline fusion2C+GFP_rev & GCCCTTGCTCACCATCACACTACTAATCC \\
\hline fusion2C+NB_fwd & GGATTAGTAGTGTGATGGCCCAGGTGC \\
\hline fusion2C+NB_rev & GCACCTGGGCCATCACACTACTAATCC \\
\hline GFP_rev EcoRV & gccGATATCttaCTTGTACAGCTCGTCC \\
\hline NB_rev EcoRV & gccGATATCtcaGCTGGACACGGTC
\end{tabular}

In der Bezeichnung sind die komplementären Enden bzw. Enden für die Schnittstellen der Enzyme NheI und EcoRV angegeben. Sämtliche Primer stammen von Metabion, Planegg/Steinkirchen, D.

Für die PCR wurden 1 ng der zu amplifizierenden DNA (DNA-Template), $2 \mu$ l je Oligonukleotid-Primer (Verdünnung $1: 10$ ), $2 \mu \mathrm{l}$ dNTP, $10 \mu \mathrm{l}$ PCR-Puffer, 0,5 $\mu \mathrm{l}$ Taq-Polymerase und 32,5 $\mu \mathrm{l} \mathrm{H}_{2} \mathrm{O}$ im PCR-Reaktionsgefäß angesetzt.

Dieser Ansatz wurde im Thermocycler mit folgendem Programm amplifiziert: 5 min bei $95{ }^{\circ} \mathrm{C}$, $35 \mathrm{x}\left(30\right.$ s bei $95^{\circ} \mathrm{C}, 30 \mathrm{~s}$ bei $58^{\circ} \mathrm{C}, 150$ s bei $\left.72{ }^{\circ} \mathrm{C}\right), 10 \mathrm{~min}$ bei $72{ }^{\circ} \mathrm{C}$.

\subsubsection{Gelelektrophorese}

Nach der PCR erfolgte die Auftrennung der DNA-Fragmente in der Gelelektrophorese. Zum späteren Ablesen der DNA-Größen wurde eine DNA-Leiter in eine der Elektrophoresetaschen pipettiert. Die amplifizierte DNA wurde mit 6x Ladepuffer $5+1$ versetzt und in das $1 \%$ Agarose-Gel geladen. Die Elektrophorese wurde für 30 min bei $100 \mathrm{~V}$ durchgeführt, die entstehenden Banden unter UV-Licht sichtbar gemacht, ausgeschnitten und nach Herstellerangaben mit dem Gel-Aufreinigungskit gereinigt.

\subsubsection{Fusions-PCR}

In der Fusions-PCR wurden die elongierten DNA-Fragmente des 5- $\mathrm{HT}_{2 \mathrm{C}}$-Rezeptors mit denen des Nanobodys bzw. des GFPs verbunden.

Für die PCR wurden 0,1-1 ng je DNA-Template, $2 \mu \mathrm{l}$ je Oligonukleotid Primer, (Verdünnung 1 : 10), $2 \mu \mathrm{l}$ dNTP, $10 \mu \mathrm{l}$ PCR-Puffer und 0,5 $\mu \mathrm{l}$ Taq-Polymerase in $50 \mu \mathrm{l} \mathrm{H}_{2} \mathrm{O}$ angesetzt.

Die PCR wurde im Thermocycler durchgeführt $\left(5 \mathrm{~min}\right.$ bei $95^{\circ} \mathrm{C}, 10 \mathrm{x}\left(10 \mathrm{~s}\right.$ bei $95^{\circ} \mathrm{C}, 30 \mathrm{~s}$ bei $60{ }^{\circ} \mathrm{C}, 120$ s bei $\left.72{ }^{\circ} \mathrm{C}\right), 20 \mathrm{x}\left(15 \mathrm{~s}\right.$ bei $95^{\circ} \mathrm{C}, 35$ s bei $62^{\circ} \mathrm{C}, 120$ s bei $\left.72{ }^{\circ} \mathrm{C}\right), 10 \mathrm{~min}$ bei $\left.72{ }^{\circ} \mathrm{C}\right)$. 
Erneut wurde eine Gelelektrophorese durchgeführt (siehe Kapitel 2.2.2.2.).

\subsubsection{Verdau}

Der Klonierungsvektor (pcDNA 3.1(-)) und das Insert (5-HT-Rezeptor + Nanobody/GFP aus Fusions-PCR) wurden mit den Restriktionsendonukleasen NheI und EcoRV nach dem Protokoll des Cut-smart-buffers verdaut. Nach dem Verdau wurde der Ansatz für 20 min bei $80{ }^{\circ} \mathrm{C}$ inkubiert, um die Restriktionsendonukleasen zu denaturieren.

Um eine Re-Ligation der geöffneten Vektor-DNA zu verhindern, wurden die Enden der verdauten pcDNA3.1(-)//NheI//EcoRV (//steht dafür, dass die DNA an der genannten Stelle geschnitten wurde) im nächsten Schritt dephosphoryliert. Dafür wurden $20 \mu \mathrm{l}$ aus dem DNAVerdau mit $2 \mu$ l Antarktischer Phosphatase, $3 \mu$ One Taq Standard Buffer und $5 \mu \mathrm{l}_{2} \mathrm{O}$ für $40 \mathrm{~min}$ bei $37^{\circ} \mathrm{C}$ und $600 \mathrm{rpm}$ im Thermoschüttler inkubiert. Darauf folgten $20 \mathrm{~min}$ bei $80^{\circ} \mathrm{C}$ zur Denaturierung der Phosphatase.

Erneut wurde eine Gelelektrophorese durchgeführt. Für das reine Plasmid wurde eine Größe von etwa 5.500 bp erwartet, für die Rezeptor-DNA ligiert mit GFP eine Größe von ca. 2.100 bp und für die Rezeptor-DNA ligiert mit der Nanobody-DNA ca. 1.750 bp.

\subsubsection{Ligation}

Die verdaute DNA des Vektors und des Inserts wurde mit dem Quick Ligation Master Mix ligiert. Es wurden $2 \mu \mathrm{l}$ pcDNA3.1(-)//EcoRV//NheI, $8 \mu \mathrm{l}$ Insert-DNA//EcoRV //NheI und $10 \mu \mathrm{l}$ Ligase Master Mix für 5 min bei Raumtemperatur inkubiert.

\subsubsection{Gibson-Assembly}

In der HiFi- oder Gibson-Assembly können mehrere DNA Fragmente in einer isothermalen Reaktion in eine Vektor-DNA eingebaut werden. Diese Methode ist schneller durchführbar als die Methode der Fusions-PCR, welche in den Kapiteln 2.2.2.1-2.2.2.5 dargestellt ist. Für unsere Versuche wurde mit Hilfe der Fusions-PCR der Rezeptor 5-HT $2 \mathrm{C}$ an GFP gekoppelt. Dieses Konstrukt konnte als Basis für die weiteren Rezeptor-/GFP/NB-Konstrukte dienen (5- $\left.\mathrm{HT}_{2 \mathrm{~A} / 2 \mathrm{~B}}+\mathrm{GFP} / \mathrm{NB}\right)$, welche mit Hilfe der Gibson-Assembly hergestellt wurden.

Vorab ist für die Gibson-Assembly genau wie bei der Fusions-PCR eine Verlängerung der DNA-Fragmente nötig, um Überhänge von 15-25 bp zu erzeugen, welche revers komplementär zu der zu assemblierenden DNA sind. Auch der Vektor wird durch eine PCR amplifiziert. Ein Verdau mittels Restriktionsendonukleasen ist im Gegensatz zu der Methode 
der Fusions-PCR vorab nicht notwendig. Die PCR zur Elongation der Fragmente erfolgte ana$\log$ zu der PCR in Kapitel 2.2.2.1. Die Primer sind in Tabelle 12 aufgeführt.

Tabelle 12: Primersequenzen für die PCR der DNA-Fragmente für die Gibson-Assembly.

Primer

\begin{tabular}{ll}
\hline pcDNA3.1(-)_fwd & GCTGGATATCTGCAGAATTC \\
\hline pcDNA3.1(-)_rev & TTTAAACGCTAGCCAGCTTG \\
\hline 2A_fwd pcDNA3.1 (-) & caagctggctagcgtttaaaATGGAAATTCTCTGTGAAG \\
\hline 2A_rev eGFP & tgctcaccatCACACAGCTAACCTTTTC \\
\hline 2A_rev NB & cctgggccatCACACAGCTAACCTTTTC \\
\hline eGFP_fwd 2A & tagctgtgtgATGGTGAGCAAGGGCGAG \\
\hline eGFP_rev pcDNA3.1(-) & gaattctgcagatatccagcTTACTTGTACAGCTCGTCCATG \\
\hline NB_fwd 2A & tagctgtgtgATGGCCCAGGTGCAGCTG \\
\hline NB_rev pcDNA3.1 (-) & gaattctgcagatatccagCTCAGCTGGACACGGTCAC \\
\hline 2B_fwd pcDNA3.1 (-) & caagctggctagcgtttaaaATGGCTTCATCTTATAAAATGTC \\
\hline 2B_rev eGFP & tgctcaccatTATGTAGCTGACCTGCTC \\
\hline 2B_rev NB & cctgggccatTATGTAGCTGACCTGCTC \\
\hline eGFP_fwd 2B & cagctacataATGGTGAGCAAGGGCGAG \\
\hline NB_fwd 2B & cagctacataATGGCCCAGGTGCAGCTG
\end{tabular}

Die DNA-Fragmente und der Vektor wurden nach dem Protokoll der NEBuilder HiFi DNA im Verhältnis 2:1 mit dem HiFi-Assembly Mix für 15 min bei $50{ }^{\circ} \mathrm{C}$ im Thermoschüttler inkubiert und danach für bis zu 60 min auf Eis gelagert. Es wurden sämtliche Kombinationen aus der Rezeptor-DNA 5-HT $2 \mathrm{~A} / \mathrm{B}$ mit GFP- bzw. Nanobody-DNA in den Vektor pcDNA 3.1(-) eingefügt. Während der Inkubation schneidet die im Master-Mix enthaltene Exonuklease die 5`Enden zurück, sodass 3`-Überhänge entstehen. Die Überhänge hybridisieren mit der komplementären DNA, wobei die Effektivität durch einen Hybridisierungs-Verstärker gesteigert wird. Eine Polymerase füllt die verbliebenen Lücken zwischen den Strängen auf und durch eine Ligase werden die Stränge verbunden. Alle benötigten Enzyme sind im HiFi Master-Mix enthalten (siehe Abbildung 8). 


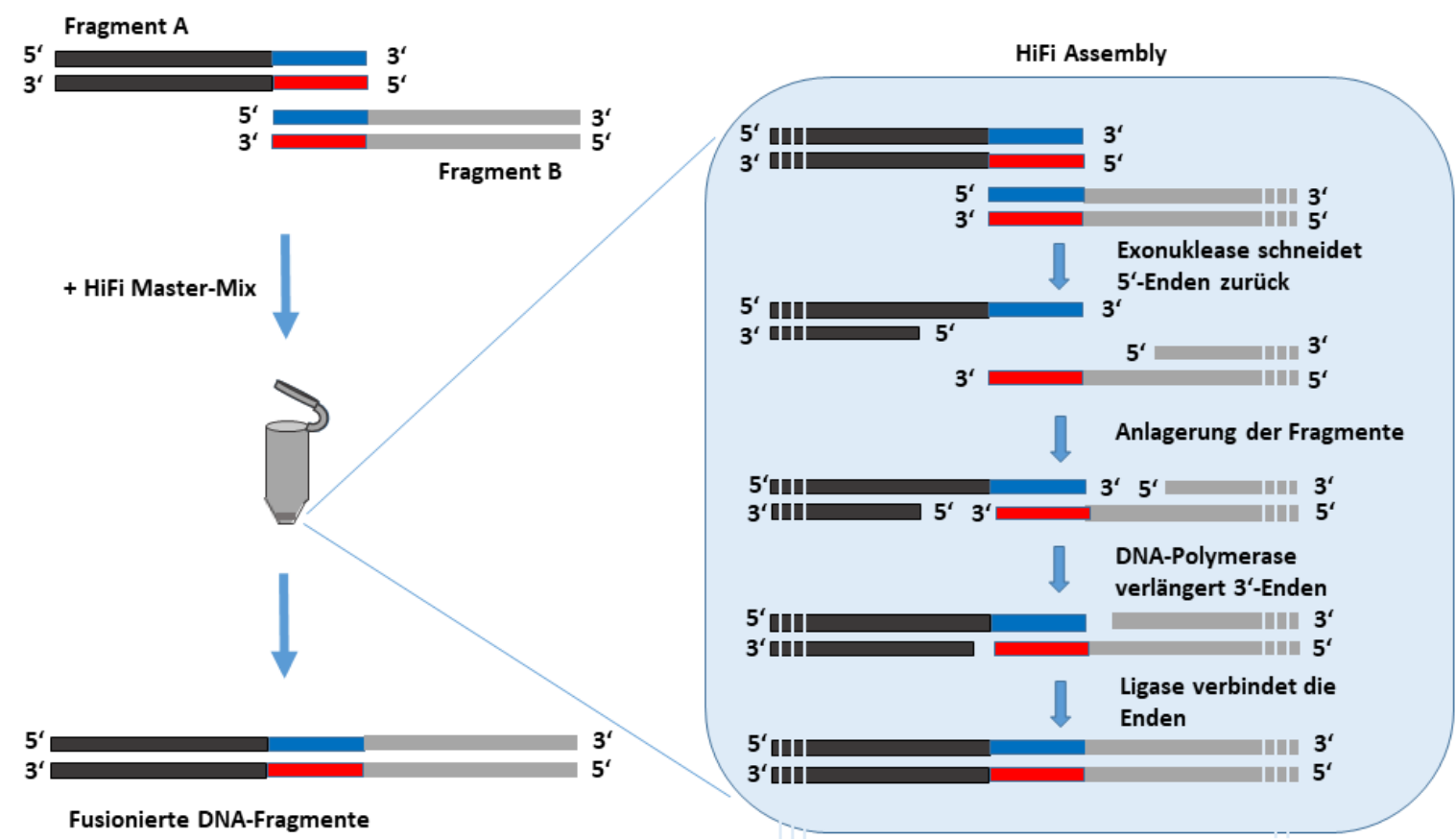

Abbildung 8: Darstellung der HiFi-Assembly. Die elongierten DNA-Fragmente A und B werden mit dem HiFi Master-Mix inkubiert. Durch die enthaltene Exonuklease werden die 5'-Enden zurückgeschnitten, sodass 3‘-Überhänge entstehen. Die Überhänge hybridisieren mit der komplementären DNA und eine Polymerase füllt die verbliebenen Lücken zwischen den Strängen auf. Durch eine Ligase werden die Stränge verbunden. Nach Gibson et al. 2009.

\subsubsection{Transformation und Aufreinigung der DNA}

Als Transformation wird die Einbringung von DNA in eine entsprechend vorbehandelte Bakterienzelle bezeichnet.

Für die Herstellung kompetenter Zellen wurden $5 \mathrm{ml}$ einer Vorkultur über Nacht bei $37^{\circ} \mathrm{C}$ geschüttelt. Anschließend wurden $500 \mathrm{ml} \mathrm{LB-Medium} \mathrm{mit} \mathrm{der} \mathrm{Vorkultur} \mathrm{angeimpft} \mathrm{und} \mathrm{bei}$ $37^{\circ} \mathrm{C}$ bis zu einer optischen Dichte (OD) von $\mathrm{OD}_{600} 0.3$ bis 0.6 inkubiert. Die Bakterien wurden für 5 min bei $4{ }^{\circ} \mathrm{C}$ und $1000 \mathrm{~g}$ abzentrifugiert und das sich daraus ergebende Pellet anschließend in $5 \mathrm{ml}$ eiskaltem TSB-Puffer re-suspendiert. Die Suspension wurde für 10-15 min auf Eis inkubiert, in Aliquots à $500 \mu \mathrm{l}$ abgefüllt, in flüssigem Stickstoff schockgefroren und bei $-80{ }^{\circ} \mathrm{C}$ gelagert.

Für die Transformation wurden $100 \mu \mathrm{l}$ kompetente Zellen auf Eis aufgetaut. In einem 1,5 mlReaktionsgefäß wurden $20 \mu \mathrm{l}$ KCM-Lösung mit 1,5 $\mu \mathrm{g}$ der zu transformierenden DNA gemischt und mit $70 \mu \mathrm{l} \mathrm{H}_{2} \mathrm{O}$ aufgefüllt. Hinzu wurden die $100 \mu \mathrm{l}$ kompetente Zellen gegeben und der Ansatz für 20 min auf Eis inkubiert. Darauf folgte der Hitzeschock für 5 min bei $37^{\circ} \mathrm{C}$ im Thermoinkubator, bei dem die DNA in die Zellen aufgenommen wurde. Schließlich wurden $300 \mu \mathrm{l} \mathrm{SOC-Medium} \mathrm{(vorgewärmt} \mathrm{auf} 37^{\circ} \mathrm{C}$ ) hinzugefügt und der Ansatz für $60 \mathrm{~min}$ bei $37^{\circ} \mathrm{C}$ 
inkubiert. Die Zellen wurden abzentrifugiert, das Pellet in einem kleinen Volumen re-suspendiert, auf LB-Agar-Platten mit Ampicillin ausplattiert und über Nacht bei $37^{\circ} \mathrm{C}$ inkubiert.

Durch das in der pcDNA3.1(-) enthaltene Ampicillin-Resistenzgen konnten auf den LB-Platten, deren Nährboden das $\beta$-Lactam-Antibiotikum Ampicillin enthielt, nur solche E. coli-Bakterien überleben und wachsen, in die die DNA aufgenommen worden war.

Nach der erfolgreichen Transformation wurden Kolonien von der LB-Agarplatte gepickt und aus der Bakterien-DNA eine Kolonie-PCR angefertigt, um das Insert nachzuweisen.

Für die Kolonie-PCR wurden $5 \mu \mathrm{l}$ der Bakterien (suspendiert in $10 \mu \mathrm{l} \mathrm{H}_{2} \mathrm{O}$ ), 0,2 $\mu \mathrm{l}$ Taq-Polymerase, $4 \mu$ l Polymerase-Puffer, $1 \mu \mathrm{l}$ je Primer, $1 \mu \mathrm{l}$ dNTP und 8,8 $\mu \mathrm{l} \mathrm{H}_{2} \mathrm{O}$ angesetzt.

Als Primer wurden die zum jeweiligen Rezeptor und Marker passenden eingesetzt. Beispielsweise wurden für das Insert 5- $\mathrm{HT}_{2 \mathrm{~A}}+\mathrm{NB}$ der Rückwärtsprimer für den Nanobody passend zu der EcoRV-Schnittstelle und der Vorwärtsprimer für 5-HT $\mathrm{H}_{2 \mathrm{~A}}$ passend zu der NheI-Schnittstelle eingesetzt. Es wurde eine 2kbp-PCR (vgl. 2.2.2.1) durchgeführt und die DNA in der Gelelektrophorese aufgetrennt und sichtbar gemacht.

Wenn sich in der Kolonie-PCR die erwarteten Banden gezeigt haben, wurden weitere Kolonien von der Agarplatte gepickt, um die DNA zu vervielfältigen und zu isolieren. Die Kolonien wurden in Zentrifugenröhrchen gegeben, welche je $5 \mathrm{ml} 37^{\circ} \mathrm{C}$ warmes LB-Medium versetzt mit Ampicillin im Verhältnis $1000: 1$ enthielten. Die Röhrchen wurden bei $37^{\circ} \mathrm{C}$ und $140 \mathrm{UpM}$ über Nacht im Inkubationsschüttler inkubiert.

Die DNA aus Bakterien der Schüttelkultur wurde mittels einer Maxi-Plasmidpräparation nach dem Protokoll der Maxi Prep Plasmid DNA Purification isoliert.

Die aufgereinigte DNA wurde im Verhältnis 1 : 1000 mit $\mathrm{H}_{2} \mathrm{O}$ verdünnt und die Konzentration der Lösung im Photometer anhand der Extinktion bei einer Wellenlänge von $260 \mathrm{~nm}$ bestimmt. Als Referenz diente $\mathrm{H}_{2} \mathrm{O}$. Zusätzlich wurde der Quotient der Extinktion bei $260 \mathrm{~nm} / 280 \mathrm{~nm}$ bestimmt, welcher eine Aussage über die Reinheit der DNA zulässt. Nur DNA mit einem Quotienten von 1,7-1,9 wurde für die weiteren Versuche genutzt.

Die aufgereinigte DNA wurde von der Firma Microsynth Seqlab (Göttingen, D) sequenziert.

\subsubsection{Zellkultur}

Für die Versuche wurden N1E-115-Zellen genutzt, deren Kultivierung in DMEM versetzt mit Glutamin und fetalem Kälberserum im Brutschrank bei einer Temperatur von $37{ }^{\circ} \mathrm{C}, 95 \%$ Luftfeuchtigkeit und $5 \% \mathrm{CO}_{2}$ erfolgte. Sämtliche Arbeiten an der Zellkultur wurden unter 
sterilen Bedingungen durchgeführt und alle Medien vor dem Einsatz in der Zellkultur im Wasserbad auf $37^{\circ} \mathrm{C}$ erwärmt. Nach dem Erreichen von 80-90 \% Konfluenz wurden die Zellen passagiert bzw. auf 4-Loch-Mikrotiterplatten, die autoklavierte Deckgläser enthielten, oder $35 \mathrm{~mm}$-Glasboden-Zellkulturschalen ausgesät.

\subsubsection{Liposomale Transfektion}

Zum Einbringen der Rezeptor-DNA in höhere Zellen (Transfektion) wurde Lipofectamin, ein kationisches Lipid, eingesetzt. Dieses lagert sich um die negative geladene DNA, sodass ein Liposomen-Nukleinsäure-Komplex entsteht, welcher mit der Zellmembran fusionieren kann. So war es möglich, die gewünschten Rezeptoren bzw. Rezeptorkombinationen auf der Zellmembran zu exprimieren.

In zwei getrennten Ansätzen wurden $2 \mu \mathrm{l}$ Lipofectamin bzw. $2 \mu \mathrm{g}$ DNA (1 $\mu \mathrm{g}$ Rezeptor-DNA 5- $\mathrm{HT}_{2 \mathrm{~A} / 2 \mathrm{~B} / 2 \mathrm{C}}$ und $1 \mu \mathrm{g}$ GCaMP6s-DNA) mit jeweils $25 \mu \mathrm{l}$ OptiMEM vermengt. Beide Ansätze wurden zusammengefügt und $30 \mathrm{~min}$ bei Raumtemperatur inkubiert. Von 4-Loch-Mikrotiterplatten, auf denen am Vortag Zellen ausgesät worden waren, wurde das DMEM abgesaugt, durch $450 \mu \mathrm{l}$ OptiMEM je Loch ersetzt und der inkubierte Ansatz mit der DNA und dem Lipofectamin (50 $\mu \mathrm{l}$ je Loch) dazugegeben. Darauf folgte eine Inkubation für mindestens $16 \mathrm{~h}$ im Brutschrank.

Für die Expression zweier verschiedener Rezeptoren wurde dasselbe Protokoll befolgt, wobei anstelle von $1 \mu \mathrm{g}$ DNA eines Rezeptors 0,5 $\mu \mathrm{g}$ DNA je Rezeptor verwendet wurden.

\subsubsection{Durchflusszytometrie}

Die Durchflusszytometrie (fluorescence-activated cell scanning, FACS) wurde genutzt, um die Menge der auf der Zelloberfläche exprimierten Rezeptoren darzustellen. Hierfür wurden zwei Versuchsreihen durchgeführt.

In der ersten Versuchsreihe wurde der Rezeptor 5- $\mathrm{HT}_{2 \mathrm{~A}}$ gekoppelt mit HA in steigenden Konzentrationen von 10 bis 2000 ng in N1E-Zellen transfiziert. Anschließend wurde die Menge an Rezeptor auf der Zelloberfläche gemessen, um darzustellen, wie sich diese zu der Menge an transfizierter DNA verhält.

In der zweiten Versuchsreihe wurden in einer Zellreihe $1 \mu \mathrm{g}$ 5- $\mathrm{HT}_{2 \mathrm{~A}}$-DNA transfiziert und in einer weiteren $0,5 \mu \mathrm{g}$ 5- $\mathrm{HT}_{2 \mathrm{~A}}$-DNA zusammen mit 0,5 $\mu \mathrm{g}$ 5- $\mathrm{HT}_{2 \mathrm{~B}}-\mathrm{DNA}$. Die Menge der an der Oberfläche der Zellen exprimierten Rezeptoren wurde gemessen und verglichen, um eine eventuelle Beeinflussung des Expressiongsgrades durch die Transfektion zweier verschiedener 
Rezeptoren darzustellen. Gleichzeitig konnten Rückschlüsse auf die Transfektionseffizienz des Rezeptors 5- $\mathrm{HT}_{2 \mathrm{~B}}$ gezogen werden.

Die mit den entsprechenden Rezeptoren transfizierten Zellen wurden für 15 min in $2 \%$ Paraformaldehyd/PBS fixiert und mit einem Überschuss an primärem Antikörper gegen die extrazelluläre HA-Domäne markiert. Es folgte die Markierung mit quantum dots. Während der Versuchsreihe wurde eine Permeabilisierung der Zellen vermieden, um keine intrazellulären Proteine zu markieren.

Die Proben wurden im Durchflusszytometer gemessen, wobei übliche Anregungs- und Emissions-Filter genutzt wurde. Die Daten wurden mit der FlowJo Software ausgewertet.

\subsubsection{Fluorescence Recovery after Photobleaching}

Mit Hilfe der fluorescence recovery after photobleaching (FRAP) können Diffusionskoeffizienten von Molekülen in der Zellmembran berechnet werden. Da der Diffusionskoeffizient D negativ mit der Molekülgröße korreliert, ermöglicht die FRAP so Rückschlüsse auf die Größe der betrachteten 5-HT-Rezeptor-Moleküle und damit auf deren Vorliegen als Monomer, Dimer oder Oligomer. Die FRAP ist seit der Kommerzialisierung von Laserrastermikroskopen in den 1990er Jahren zu einer populären Methode geworden, um das Diffusionsverhalten und molekulare Interaktionen der Rezeptoren zu messen (Lorén et al. 2015).

Bei der FRAP wird eine kleine Region der Zellmembran $\left(\sim 10 \mu \mathrm{m}^{2}\right)$, welche mobile fluoreszente Moleküle enthält, als sogennante region of interest (ROI, Region von Interesse) markiert. Mit einer kurzen, aber intensiven Laserbestrahlung werden die Fluorophore der Moleküle in der ROI irreversibel gebleicht. Aufgrund der lateralen Diffusion in der Doppellipidmembran diffundieren Moleküle aus ungebleichten Regionen der Zellmembran in das gebleichte Areal und andersherum bis die Fluoreszenz der ROI nahezu wieder dem Ausgangswert entspricht.

Der Diffusionskoeffizient (D) wird anhand der Erholungskinetik der Fluoreszenz berechnet, wobei $\mathrm{t}_{1 / 2}$ genutzt wird (Axelrod et al. 1976). $\mathrm{t}_{1 / 2}$ entspricht der Zeit nach dem Bleichvorgang, nach der die Helligkeit der Fluoreszenz die Hälfte des Endwertes wieder erreicht hat. Je schneller die gebleichte Region sich regeneriert, desto kleiner ist $t_{1 / 2}$ und desto größer ist $\mathrm{D}$, da die Moleküle schneller in die gebleichte Region bzw. aus der gebleichten Region in andere Areale diffundieren.

Anhand des ermittelten Diffusionskoeffizienten können Rückschlüsse auf den hydrodynamischen Durchmesser der Moleküle gezogen werden. Die Einstein-Stokes-Gleichung zeigt eine umgekehrte Proportionalität des Diffusionskoeffizienten zum Molekülradius. 


$$
D=\frac{k T}{6 \pi \eta r}
$$

Formel 1: Einstein-Stokes-Gleichung. $\mathrm{D}=$ Diffusionskoeffizient, $\mathrm{k}=$ Boltzmannkonstante, $\mathrm{T}=$ absolute Temperatur, $\eta=$ Viskosität der Flüssigkeit, $r=$ Partikelradius.

Da die Einstein-Stokes-Gleichung jedoch nur in Flüssigkeiten anwendbar ist, in welchen die Moleküle frei diffundieren können, ist sie nicht direkt auf die Diffusion in der Zellmembran anwendbar (Edward 1970). Es wird also keine direkte Proportionalität erwartet, wobei dennoch ein größerer Diffusionskoeffizient auf einen geringeren hydrodynamischen Durchmesser hinweisen wird.

Trotz eingehender Recherche konnten nicht für alle Rezeptoren der 5- $\mathrm{HT}_{2}$-Gruppe entschlüsselte Molekülstrukturen und damit hydrodynamische Durchmesser gefunden werden, jedoch sind die Molekülgrößen der verschiedenen 5- $\mathrm{HT}_{2}$-Rezeptoren sehr ähnlich (siehe Tabelle 13). Außerdem sind die molekularen Strukturen der Ergotamin-gebundenen Rezeptoren 5-HT $\mathrm{H}_{1 \mathrm{~B}}$ und 5- $\mathrm{HT}_{2 \mathrm{~B}}$ bekannt, welche sich kaum voneinander unterscheiden (Herrick-Davis 2013).

Tabelle 13: Molekülgrößen der 5- $\mathrm{HT}_{2}$-Rezeptoren.

\begin{tabular}{ll} 
Rezeptor & Molekülgröße \\
\hline $\mathbf{5}-\mathbf{H T}_{2 \mathrm{~A}}$ & $\sim 52,6 \mathrm{kDa}$ \\
\hline $\mathbf{5}-\mathbf{H T}_{2 \mathrm{~B}}$ & $\sim 54,3 \mathrm{kDa}$ \\
\hline $\mathbf{5}-\mathbf{H T}_{2 \mathrm{C}}$ & $\sim 51,8 \mathrm{kDa}$
\end{tabular}

Hinsichtlich der GPCRs, deren Molekülstruktur bereits entschlüsselt sind, existieren durch die allen gemeinsamen sieben Transmembrandomänen viele strukturelle Ähnlichkeiten. Die Hauptunterschiede in der Struktur sind bei unterschiedlichen Molekülgrößen im N- und C-Terminus zu finden (Zhang et al. 2015). Aufgrund der sehr ähnlichen Molekülgrößen der hier betrachteten GPCRs gehen wir daher davon aus, dass Unterschiede in der Molekülstruktur und somit deren Auswirkungen auf den hydrodynamischen Durchmesser vernachlässigbar gering sind und die Radien der verschiedenen Rezeptoren vergleichbar groß sind. Damit können die Ergebnisse der Diffusionskoeffizienten zwischen den verschiedenen Rezeptoren und Versuchsreihen verglichen werden. Aufgrund konstanter Umgebungsfaktoren und der ähnlichen Radien der Rezeptoren können signifikante Unterschiede der Diffusionskoeffizienten somit auf das Vorliegen der Rezeptoren als Monomer, Dimer oder Oligomer zurückgeführt werden. 
In unseren Versuchsreihen mit zwei verschiedenen ko-exprimierten Rezeptoren wurde im Vergleich zu den Versuchen mit einzeln exprimierten Rezeptoren nur die halbe Menge DNA je Rezeptor transfiziert. So wurde insgesamt die gleiche Dichte an exprimierten Rezeptoren erreicht und damit auch eine vergleichbare Dimerisierungsrate (siehe Abbildung 13).

Für die FRAP-Experimente wurden die N1E-115 Zellen auf 35 mm Glasboden Zellkulturschalen ausgesät und CFP (cyan fluorescent protein)- oder YFP (yellow fluorescent protein)-gekoppelte 5$\mathrm{HT}_{2}$-Rezeptor-DNA transfiziert. Die Transfektion verlief analog zu Kapitel 2.2.3, wobei $6 \mu \mathrm{l}$ Lipofectamin und $2 \mu \mathrm{g}$ DNA in jeweils $100 \mu \mathrm{l}$ OptiMEM gelöst wurden.

Die FRAP wurde sowohl an Zellen mit ausschließlich einer Rezeptorart als auch an verschieden kombinierten Rezeptoren durchgeführt. Außerdem wurde zum Messen des Diffusionskoeffizienten der forcierten Dimere 5- $\mathrm{HT}_{2}$-Rezeptor-DNA gekoppelt mit einem Nanobody gemeinsam mit 5- $\mathrm{HT}_{2}$-DNA gekoppelt mit GFP transfiziert.

Die FRAP-Experimente wurden unter dem LSM-Mikroskop mit dem C-Apochromat 63x/1.2 W corr Objektiv (Zoom 5,3x, Pixelverweildauer 2,51 $\mu$ s, Bildgröße 27,1 $\mu \mathrm{m}^{2}$, Anregungswellenlänge 458 nm, Emissionsfilter 475 nm, Intervall zwischen den Aufnahmen $2 \mathrm{~s}$, 50 \% Laser Output) durchgeführt. Auf einer mikroskopierten Zelle wurden zwei runde ROIs mit einem Radius von durchschnittlich 7,5 $\mu \mathrm{m}$ festgelegt, von denen einer als Kontrolle diente und der andere gebleicht wurde. Nach zehn Scans erfolgte das Bleichen bei $\lambda_{\text {exc }}=458 \mathrm{~nm}$, $\lambda_{\mathrm{em}}=475 \mathrm{~nm}$ mit 25 Scans und $100 \%$ Laserstärke. Darauf folgten 200 weitere Scans, um die Erholung zu messen. Die Messung ging nur dann mit in die Auswertung ein, wenn die KontrollROI in der Auswertung eine konstante Helligkeit zeigte.

Die Intensität der Helligkeit, die in der ROI gemessen wurde, wurde in Microsoft Excel auf den Mittelwert der Helligkeit der ersten zehn Bilder normiert. Somit ging in die Auswertung nicht die absolut gemessene Helligkeit, sondern ihre Veränderung im Vergleich zu der Ausgangshelligkeit ein. Die normierte Intensität wurde in arbiträren Einheiten (a. E.) angegeben. 

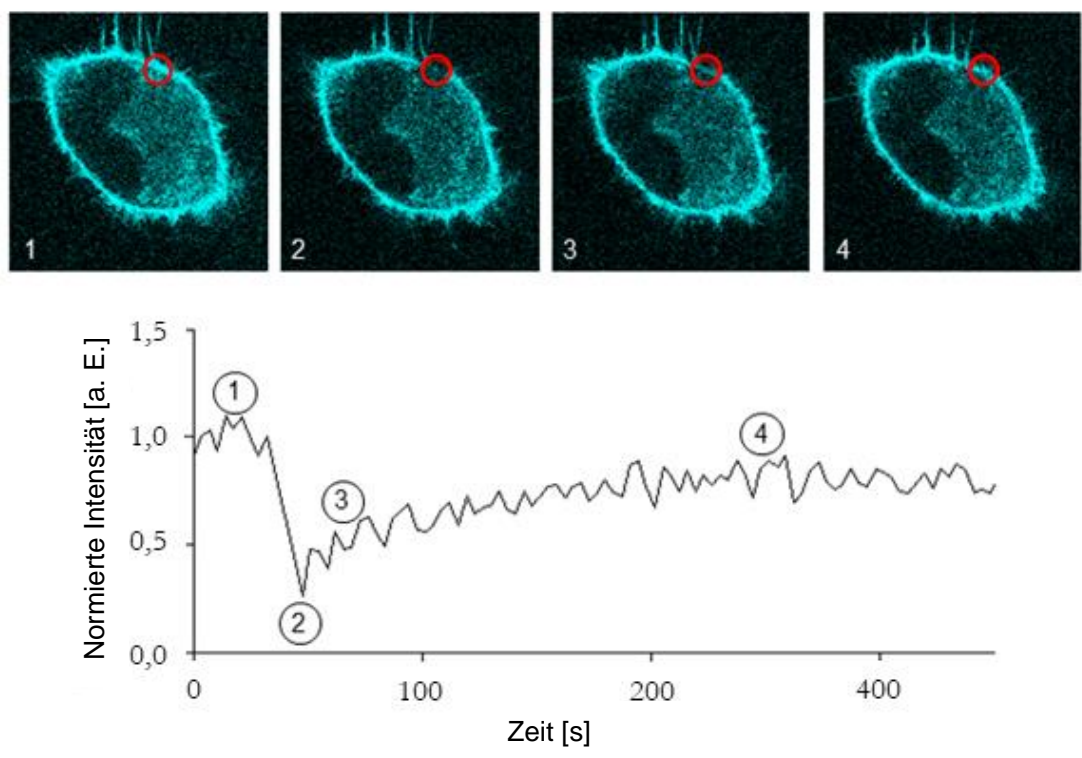

Abbildung 9: FRAP an einer Zelle mit 5- $\mathrm{HT}_{2 \mathrm{~A}}$-Rezeptoren gekoppelt mit GFP. Oben Aufnahmen aus dem LSM-Mikroskop bei 63x ursprünglicher Vergrößerung, unten die normierte Intensität der Helligkeit der betrachteten ROI. Durch Ziffern sind die verschiedenen Phasen der FRAP gekennzeichnet. 1.) Zustand vor dem Bleichvorgang; 2.) Das Bleichareal (gekennzeichnet durch einen roten Kreis) wurde auf $26 \%$ der ursprünglichen Intensität gebleicht; 3.) $20 \mathrm{~s}$ nach dem Bleichen, Erholungsphase, $55 \%$ der ursprünglichen Intensität wurden erreicht; 4.) 200 s nach dem Bleichen, Plateauphase, ca. $85 \%$ der ursprünglichen Intensität wurden erreicht. Zur deutlicheren Darstellung wurden bei den Zellaufnahmen die Helligkeit um $40 \%$ und der Kontrast um $20 \%$ erhöht.

In GraphPad Prism wurde das Ende des Bleichvorgangs mit $\mathrm{X}=0$ gleichgesetzt, sodass die Kurve eine Exponentialfunktion darstellte, welche mit der Funktion ,One Phase Decay' analysiert wurde. Für jeden Rezeptor wurde so die Halbwertszeit $\mathrm{t}_{1 / 2}$ ermittelt, bei welcher die halbe Intensität der Endfluoreszenz erreicht war. Anhand derer wurde der Diffusionskoeffizient des Rezeptors bzw. der Rezeptorkombination errechnet, wobei aufgrund konstanter Rahmenbedingungen ( $\mathrm{T}$ (Temperatur), $\eta$ (die dynamische Viskosität des Lösungsmittels) und r (Radius der ROI)) für die Berechnung des Diffusionskoeffizienten eine vereinfachte Formel nach Soumpasis eingesetzt werden konnte (Soumpasis 1983):

$$
D=0,224 * \frac{r^{2}}{t_{\frac{1}{2}}}
$$

Formel 2: Berechnung des Diffusionskoeffizienten D nach Soumpasis (Soumpasis 1983). $\mathrm{r}=$ Radius der ROI; $\mathrm{t}_{1 / 2}=$ Zeit nach dem Bleichen, $\mathrm{zu}$ der die halbe Endhelligkeit der Fluoreszenz erreicht ist; 0,224 = empirisch ermittelte Konstante. Bei konstantem $\mathbf{r}$ hängt der Diffusionskoeffizient also ausschließlich von $\mathrm{t}_{1 / 2} \mathrm{ab}$. 
Die ermittelten Diffusionskoeffizienten wurden in Graph Pad Prism durch einen ungepaarten t-Test mit einem Konfidenzintervall von $95 \%$ miteinander verglichen. Im Schnitt wurden $\mathrm{n}=16$ Messungen pro Rezeptor bzw. Rezeptorkombination ausgewertet. Im Vergleich wurden ein $\mathrm{p}$-Wert von $\leq 0,05$ als niedrige Signifikanz $\left(^{*}\right)$, ein $\mathrm{p}$-Wert von $\mathrm{p} \leq 0,01$ als mittelstarke $(* *)$ und ein $\mathrm{p}$-Wert von $\mathrm{p} \leq 0,001$ als starke Signifikanz $(* * *)$ gewertet.

In einem Kontrollexperiment wurde das Bleichen an einer fixierten Zelle durchgeführt. Dies war nötig, um die Irreversibilität des Bleichens der Fluorophore sicherzustellen, welche für die erfolgte Auswertung grundlegend ist. Die Fixierung erfolgte durch $100 \mu \mathrm{l}$ DPBS $+100 \mu \mathrm{l}$ PFA $4 \%$, daraufhin eine Waschung mit DPBS und eine Inkubation für 10 min mit $4 \% \mathrm{PFA}$ in DBPS. Danach wurde reines DPBS auf die Zellen gegeben. In diesen Versuchen zeigte sich nach dem Bleichvorgang kein Anstieg der Fluoreszenz in der ROI, sodass von einer Irreversibilität des Bleichens ausgegangen werden konnte.

\subsubsection{Single Particle Tracking}

Zusätzlich zu der FRAP wurde die Einzelteilchenverfolgung (single particle tracking, SPT) zur Analyse der Diffusionskoeffizienten genutzt, da hier im Gegensatz zu der FRAP nicht der Durchschnittswert der Diffusionskoeffizienten ermittelt wird, sondern den einzelnen Rezeptoren jeweils ein Koeffizient zugeordnet werden kann. Aus Zeitgründen wurde das SPT nur für den Rezeptor 5- $\mathrm{HT}_{2 \mathrm{~B}}$ und von dem Betreuenden der Doktorarbeit durchgeführt. Dennoch soll es in diese Arbeit aufgenommen werden, da die Methode weitere Details zur Dimerisierung des Rezeptors $5-\mathrm{HT}_{2 \mathrm{~B}}$ liefert.

Für das SPT werden an Moleküle Nanopartikel geheftet (z. B. Gold-Nanopartikel, quantum dots oder fluoreszente Moleküle) und mit einem Fluoreszenzmikroskop in kurzen Abständen Bilder aufgenommen. Grundlegend ist hierbei, dass die Teilchen in so geringer Menge vorliegen, dass einzelne Teilchen differenziert betrachtet werden können. Bei der Verknüpfung der aufgenommenen Bilder werden die verschiedenen Teilchenpositionen einem Teilchen zugeordnet. Dadurch entstehen Bewegungsbahnen (Trajektorien), welche die Bewegung der Moleküle darstellen. Anhand der Trajektorien kann die Diffusionsgeschwindigkeit der Partikel berechnet werden (Manzo und Garcia-Parajo 2015).

Alle Experimente des SPT wurden bei $37^{\circ} \mathrm{C}$ und konstanter Perfusion mit gepufferten Medien durchgeführt. Die Zellen wurden auf $35 \mathrm{~mm}$ Glasboden-Zellkulturschalen ausgesät und mit der Rezeptor-DNA transfiziert (siehe 2.2.3).

Da keine Rezeptor-Antikörper verfügbar waren, die direkt extrazelluläre Domänen der 5-HTRezeptoren erkennen, wurden monoklonale Antikörper gegen HA- und myc-Tags genutzt, um 
quantum dots (QDs) an die Zelloberfläche zu koppeln. Die Anti-HA/myc-Fragmente wurden durch einen Pepsinverdau monoklonaler Antikörper erzeugt. Das durch den Verdau entstandene $\mathrm{F}(\mathrm{ab}) 2-$ Fragment wurde durch ein kommerzielles Kit an Biotin konjugiert. Um eine $1: 1$ Bindung von Rezeptor und QD sicherzustellen, wurden kommerziell erhältliche Streptavidinbedeckte QDs (2 nM) mit einer niedrigen Konzentration von Fab-Fragmenten $(0,5 \mathrm{nM})$ inkubiert.

Das SPT der QDs wurde an der dorsalen Membran mittels total internal reflection (TIRF) Mikroskopie durchgeführt. Hierfür wurden ein IX71 Mikroskop mit einem 60×/1.45 NA Plan Apochromat Objektiv sowie einem TIRF Kondensator und eine laseremittierende Diode bei $405 \mathrm{~nm}$ genutzt. Die Bilder wurden mit einer Andor iXon Kamera erfasst, welche durch die Andor iQ Software gesteuert wurde. Die Bilder wurden mit einer Geschwindigkeit von 12$14 \mathrm{~Hz}$ aufgenommen und 20-30 ms dem Laser exponiert. Die Pixelgröße betrug $120 \mathrm{~nm}$ und die Eindringtiefe $63 \mathrm{~nm}$.

Die Genauigkeit der Messung wurde durch Aufnahmen von QDs geschätzt, welche auf polyL-Lysin-bedeckten Deckgläsern fixiert waren. Die Standardabweichung der gemessenen Positionen betrug $90 \mathrm{~nm}$, sodass diese auch für die weiteren SPT Experimente angenommen wurde.

\subsection{8 $\mathrm{Ca}^{2+}$-Imaging}

Das $\mathrm{Ca}^{2+}$-Imaging wurde genutzt, um die Signalgebung der Rezeptoren nach deren Stimulation mit Serotonin oder einem entsprechenden Agonisten zu messen.

Nach der Stimulation $\mathrm{G}_{\mathrm{q}^{-}}$-Protein gekoppelter Rezeptoren, zu denen alle drei Rezeptoren der 5- $\mathrm{HT}_{2}$-Gruppe gehören, wird intrazellulär $\mathrm{Ca}^{2+}$ aus dem endoplasmatischen Retikulum freigesetzt, welches als sekundärer Botenstoff (,second messenger') dient. Die Menge des freigesetzten $\mathrm{Ca}^{2+}$ ist ligandenabhängig (Zhang und Xie 2012).

Für die Messung des $\mathrm{Ca}^{2+}$ wurde die DNA des $\mathrm{Ca}^{2+}$-Sensors GCaMP6s in die Zellen transfiziert. Genetisch codierte Calciumsensoren bestehen aus dem M13-Fragment der Myosin-LeichteKette, einem zirkulären eGFP und Calmodulin, einem $\mathrm{Ca}^{2+}$ bindenden regulatorischen Protein. Der $\mathrm{Ca}^{2+}$-Sensor GcaMP6s hat im Vergleich zu anderen $\mathrm{Ca}^{2+}$-Sensoren eine helle Fluoreszenz und ist sehr sensitiv (Chen et al. 2013). Wenn das GCaMP6s in der Zelle exprimiert wird, bindet freigesetztes $\mathrm{Ca}^{2+}$ über das Calmodulin. Dies bewirkt eine Konformationsänderung des GCaMP6s-Komplexes und infolgedessen eine Helligkeitsveränderung, welche mit Hilfe der Fluoreszenzmikroskopie gemessen werden kann. 
Im Rahmen der Arbeit wurden die verschiedenen Signalgebungen der einzelnen 5- $\mathrm{HT}_{2}$-Rezeptoren bzw. der ko-exprimierten oder forciert dimerisierten 5-HT $\mathrm{T}_{2}$-Rezeptor-Kombinationen gemessen.

Für alle Versuche wurden Rezeptoren genutzt, an welche fluoreszente Proteine (CFP, GFP, YPF) gekoppelt waren, da die fluoreszente Markierung für die anderen Experimente vonnöten war. Für die Kombination aus 5- $\mathrm{HT}_{2 \mathrm{C}}$ und YFP wurde bereits nachgewiesen, dass die fluoreszenten Anhänge die Ligandenbindung nicht beeinflussen (Herrick-Davis et al. 2004), sodass dies auch für die anderen Rezeptor- und Fluorophorkombinationen angenommen werden kann und die gekoppelten Rezeptoren für die Experimente der Signalgebung verwendet werden konnten.

Auf 4-Loch-Mikrotiterplatten mit Deckgläsern wurden Zellen (N1E-115) ausgesät und die Rezeptoren transfiziert. Die Deckgläser wurden in eine Mikroskophalterung eingespannt und mit OptiMEM bedeckt. Am laser scanning microscope (LSM) wurden je nach Zelldichte pro Messung 10-15 Zellen als ROI festgelegt, sodass bei diesen während der Messung die Helligkeit und die Veränderung der Fluoreszenz des GCaMP6s gemessen wurden. Um einen Bias durch die manuelle Selektion zu minimieren, wurden alle zu messenden Zellen vor der Stimulation als ROI festgelegt.

Die Aufnahme erfolgte mit dem Fluar 20x/0,75 UV-Objektiv bei einer Pixelverweildauer von 2,51 $\mu$ s, einer Bildgröße von $635 \mu \mathrm{m}^{2}$, einem Anregungslaser von $488 \mathrm{~nm}$, einer Laserpower von $30 \mathrm{~mW}$, einem Laser-Output von $25 \%$ und einem Emissionsfilter von $505 \mathrm{~nm}$ mit einem Bildabstand von $1 \mathrm{~s}$.

Zusätzlich wurden mit einer ROI der Hintergrund und mit einer weiteren ROI die Gesamthelligkeit der Zellen gemessen, um ein eventuelles Hintergrundrauschen, Ausbleichen oder einen Verlust des Fokus zu detektieren und dies bei der Auswertung zu berücksichtigen. Es wurden nur Versuche ausgewertet, in denen diese beiden ROIs konstante Werte aufwiesen.

Nach dem Start der Messung wurden 30 Bilder als Referenzwert ohne Stimulation aufgenommen und bei Bild 30 die gewünschte Menge 5-HT zu den Zellen pipettiert (siehe Abbildung 10). 

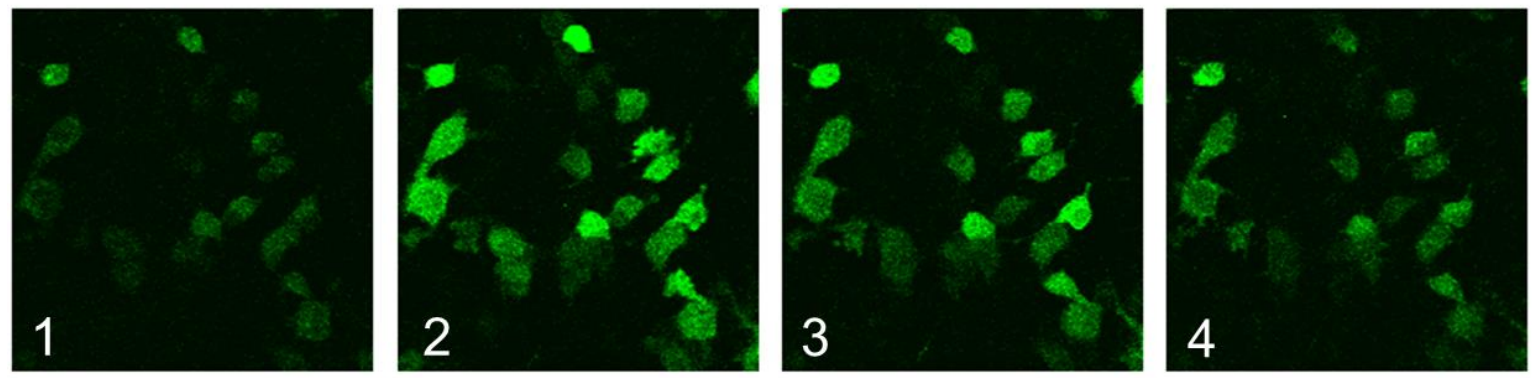

Abbildung 10: $\mathrm{Ca}^{2+}$-Signal der mit 5-HT2A- und GCaMP6s-DNA transfizierten Zellen nach Stimulation mit 0,05 mM 5-HT. Bilder aus dem LSM-Mikroskop bei 20facher Vergrößerung. 1.) vor Stimulation. 2.) 30 s nach Stimulation, das $\mathrm{Ca}^{2+}$-Signal wird stärker. 3.) 200 s nach Stimulation, das Signal wird schwächer. 4.) $500 \mathrm{~s}$ nach Stimulation, weitere Abschwächung des Signals.

In einem ersten Schritt wurde die mittlere effektive Konzentration $\left(\mathrm{EC}_{50}\right)$ der Rezeptoren 5- $\mathrm{HT}_{2 \mathrm{~A} / 2 \mathrm{~B} / 2 \mathrm{C}}$ ermittelt. Die $\mathrm{EC}_{50}$ entspricht der Menge an Stimulans, welche zur halbmaximalen Anregung der Rezeptoren nötig ist.

Die Konzentration wurde schrittweise von $0,0001 \mathrm{mM}$ bis $0,1 \mathrm{mM}$ um den Faktor 10 gesteigert. In dem Bereich zwischen unter- und überschwelliger Konzentration wurde außerdem mit 0,002 mM, 0,02 mM und 0,05 mM stimuliert, um eine genauere Kurvenanpassung und somit EC50Bestimmung zu ermöglichen. Die Auswertung erfolgte mit im Schnitt $\mathrm{n}=12$ Messwerten pro Konzentration.

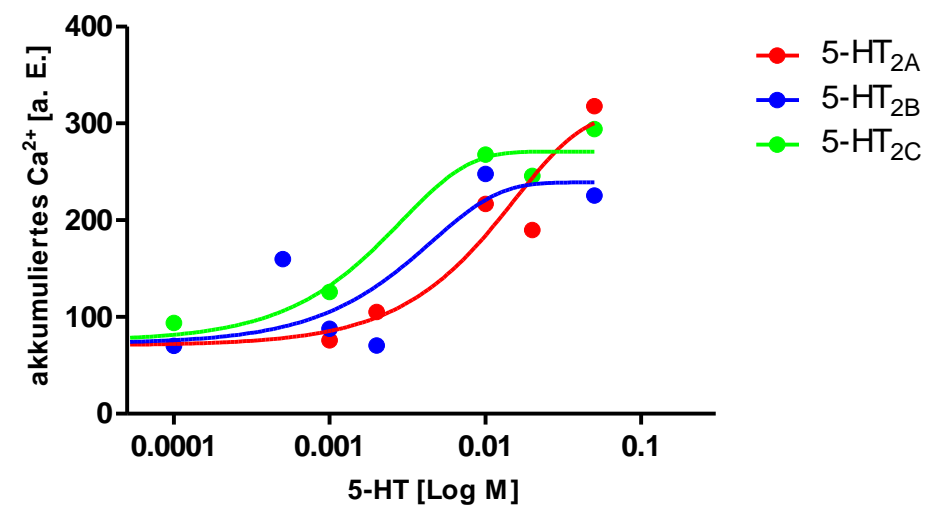

Abbildung 11: $\mathrm{Ca}^{2+}-$ Reaktionskurven für die 5-HT-Stimulation der Rezeptoren 5-HT $2 \mathrm{~A}, 5-\mathrm{HT}_{2 \mathrm{~B}}$ und 5-HT2C. Die Fluoreszenz des akkumulierten intrazellulären $\mathrm{Ca}^{2+}$ wird gegen die Konzentration des stimulierenden 5-HT, welche logarithmisch dargestellt wird, aufgetragen. Die Punkte kennzeichnen den Mittelwert der $\mathrm{Ca}^{2+}$-Menge bei der jeweiligen Konzentration. Im Schnitt erfolgten $\mathrm{n}=12$ Messungen je 5-HT-Konzentration. Die Anpassung der Kurven an die einzelnen Werte und ihre Auswertung erfolgte mit der Funktion, One Phase Decay in GraphPad Prism. Die Kurve des 5-HT $2 \mathrm{~A}$ ist rot dargestellt, die des $5-\mathrm{HT}_{2 \mathrm{~B}}$ blau und die des $5-\mathrm{HT}_{2 \mathrm{C}}$ grün.

Die $\mathrm{EC}_{50}$-Werte lagen bei 0,011 $\mathrm{mM}\left(5-\mathrm{HT}_{2 \mathrm{~A}}\right), 0,003 \mathrm{mM}\left(5-\mathrm{HT}_{2 \mathrm{~B}}\right)$ und 0,002 $\mathrm{mM}\left(5-\mathrm{HT}_{2 \mathrm{C}}\right)$. 
In sämtlichen Folgeexperimenten wurde mit einer Konzentration von 0,01 mM 5-HT stimuliert. So war sichergestellt, dass die Rezeptoren aktiviert werden und die Stimulation nicht unterschwellig ist, gleichzeitig aber auch keine starke Überstimulation der Rezeptoren stattfindet. Um zu ermöglichen, dass die Rezeptoren selektiv stimuliert werden, wurde eine zweite Versuchsreihe durchgeführt, in welcher anstelle von 5-HT mit selektiven Agonisten für die jeweiligen Rezeptoren stimuliert wurde. Die Agonisten sind mit ihren dazugehörigen Strukturformeln und Ki-Werten (Gleichgewichtsdissoziationskonstanten, soweit bekannt) in

dargestellt. Der Versuchsablauf der Agonistenstimulation entsprach dem des $\mathrm{Ca}^{2+}$-Imagings, wobei aus Zeitgründen auf die Erstellung einer Stimulations-Signal-Kurve verzichtet werden musste. Die Agonisten wurden nach Herstelleranweisung in $\mathrm{H}_{2} \mathrm{O}$ gelöst und die Zellen mit einer Konzentration von $0,02 \mathrm{mM}$ Agonist stimuliert.

Tabelle 14: 5-HT $\mathrm{H}_{2}$-Rezeptor-Agonisten mit ihren Strukturformeln und Ki-Werten.

\begin{tabular}{|c|c|c|c|}
\hline Agonist & $\begin{array}{c}\text { Höchste } \\
\text { Rezeptoraffinität }\end{array}$ & Strukturformel & Ki-Wert \\
\hline TCB-2 & $5-\mathrm{HT}_{2 \mathrm{~A}}$ & (nach Fox et al. 201 & $\begin{array}{l}\text { 5-HT } 2 \mathrm{~A} 0,73 \mathrm{nM} \\
\text { (Fox et al. 2010) }\end{array}$ \\
\hline $\begin{array}{c}\text { BW723c86 } \\
\text { Hydrochlorid }\end{array}$ & $5-\mathrm{HT}_{2 \mathrm{~B}}$ & (nach Kennett et al. & Ki-Werte unbekannt. \\
\hline $\begin{array}{c}\text { WAY629 } \\
\text { Hydrochlorid }\end{array}$ & $5-\mathrm{HT}_{2 \mathrm{C}}$ & (nach Sabb et al. 20 & $\begin{array}{c}5-\mathrm{HT}_{2 \mathrm{~A}} 2530 \mathrm{nM} \\
5-\mathrm{HT}_{2 \mathrm{C}} 56 \mathrm{nM} \\
\text { (Sabb et al. 2004) }\end{array}$ \\
\hline
\end{tabular}


Die Daten aus dem $\mathrm{Ca}^{2+}$-Imaging wurden in Microsoft Excel ausgewertet. Um die Vergleichbarkeit zwischen den verschiedenen Versuchen zu gewährleisten, wurde die Helligkeit der betrachteten Zelle auf den Mittelwert ihrer Helligkeit der ersten 20 Bilder normiert und in arbiträren Einheiten angegeben. Zeigte sich hierbei an den Kontroll-ROIs eine Veränderung der Gesamthelligkeit oder des Hintergrundrauschens, so wurden die Daten des Versuchs nicht in die Auswertung mit einbezogen.

In GraphPad Prism wurden aus den normierten Werten Graphen erstellt. Um die Stärke des Signals zu messen, wurde die area under the curve (AUC, Fläche unter der Kurve) analysiert. Diese entspricht der freigesetzten $\mathrm{Ca}^{2+}$-Menge. In der Analyse ,Area under the Curve ${ }^{\varsigma}$ in GraphPad Prism wurde 1 a. E. als baseline (Grundlinie) der Intensität gesetzt, der Beginn der Kurve bei 35,8 s und das Ende bei 350,48 s (siehe Abbildung 12).

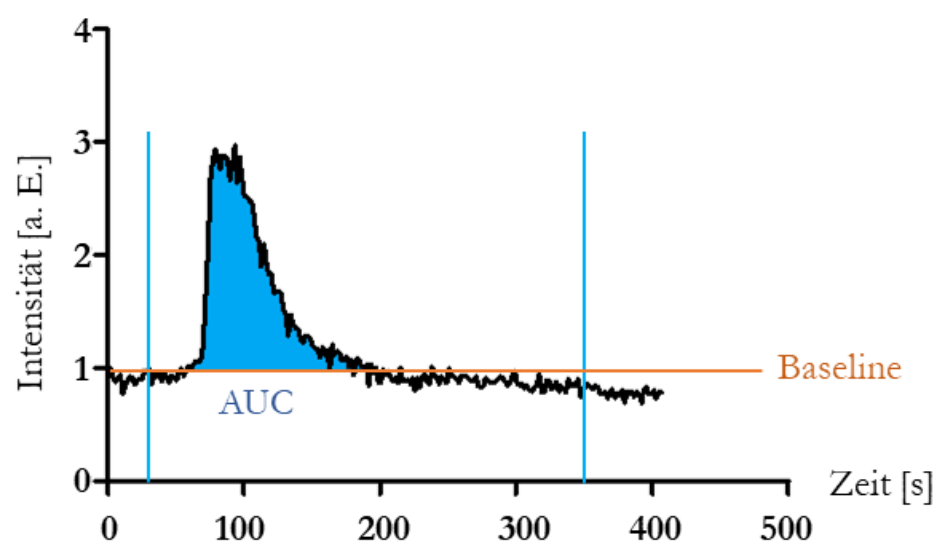

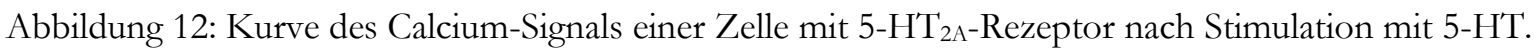
Auf der Abszisse ist die Zeit [s] und auf der Ordinate die Intensität der Helligkeit der Zellen [a. E.] aufgetragen. Bei 55 s wurde mit 0,05 mM 5-HT stimuliert. Die area under the curve (AUC) ist blau gekennzeichnet. Der Bereich der Messung, dessen AUC ausgewertet wurde, ist durch die senkrechten Striche bei 35,8 s und 350,5 s gekennzeichnet. Die Baseline ist bei einer Intensität von 1 a. E. eingezeichnet.

Aus durchschnittlich $\mathrm{n}=15$ Messungen wurde ein Mittelwert mit Standardabweichung ermittelt. Die Werte der verschiedenen Rezeptoren beziehungsweise Rezeptor-Kombinationen wurden durch einen ungepaarten t-Test mit einem Konfidenzintervall von 95 \% in GraphPad Prism verglichen.

In einem Kontrollexperiment wurde außerdem die Zellhelligkeit über 600 s ohne Stimulation gemessen. Die Helligkeit der Zelle blieb erhalten und die Fluoreszenz wurde durch den Anregungslaser nicht geblichen. 


\section{Ergebnisse}

Gegenstand der vorliegenden Arbeit war die Frage, ob die Rezeptoren der 5- $\mathrm{HT}_{2}$-Gruppe obligate oder fakultative Dimere bilden und welche Auswirkungen eine solche Dimerisierung auf ihre Signalgebung hat.

Bei der Auflistung der Ergebnisse werden anstelle der vollständigen Rezeptorbezeichnung die

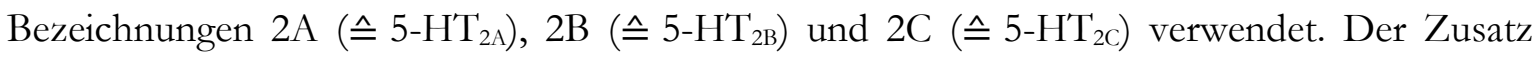
,forc.' steht für ein forciertes Dimer.

Er wird der Mittelwert plus/minus die Standardabweichung angegeben.

\subsection{Rezeptorexpression}

Um die Dimerbildung zu untersuchen, war es notwendig, die verschiedenen 5- $\mathrm{HT}_{2}$-Rezeptoren zu ko-exprimieren, also innerhalb einer Zellmembran verschiedene Rezeptoren zu exprimieren. Diesbezüglich wurden vorab verschiedene Überlegungen angestellt. Es stellte sich vor allen Dingen die Frage nach der Menge der zu transfizierenden Rezeptor-DNA in den Experimenten der Ko-Expression. Hier musste zwischen zwei Möglichkeiten entschieden werden, welche in Abbildung 13 graphisch dargestellt sind:

In der ersten Möglichkeit wird von den beiden Rezeptoren, die ko-exprimiert werden, jeweils nur die halbe DNA-Menge verwendet im Vergleich zu der einfachen Expression der Rezeptoren. Dadurch bleibt die Anzahl der Rezeptoren auf der Zelloberfläche gleich, sodass die Dimerbildung weniger beeinflusst wird, jedoch reduzieren sich die Signale der beiden Rezeptoren (siehe Abbildung 13 (2)).

In der zweiten Möglichkeit wird von den beiden Rezeptoren, die ko-exprimiert werden, die gleiche Menge DNA verwendet wie auch bei der einfachen Expression der Rezeptoren. Dadurch bleiben die Signale der Rezeptoren konstant, jedoch ergibt sich insgesamt die doppelte Anzahl an Rezeptoren auf der Zelloberfläche, was die Dimerisierung der Rezeptoren beeinflussen kann (siehe Abbildung 13 (3)). 


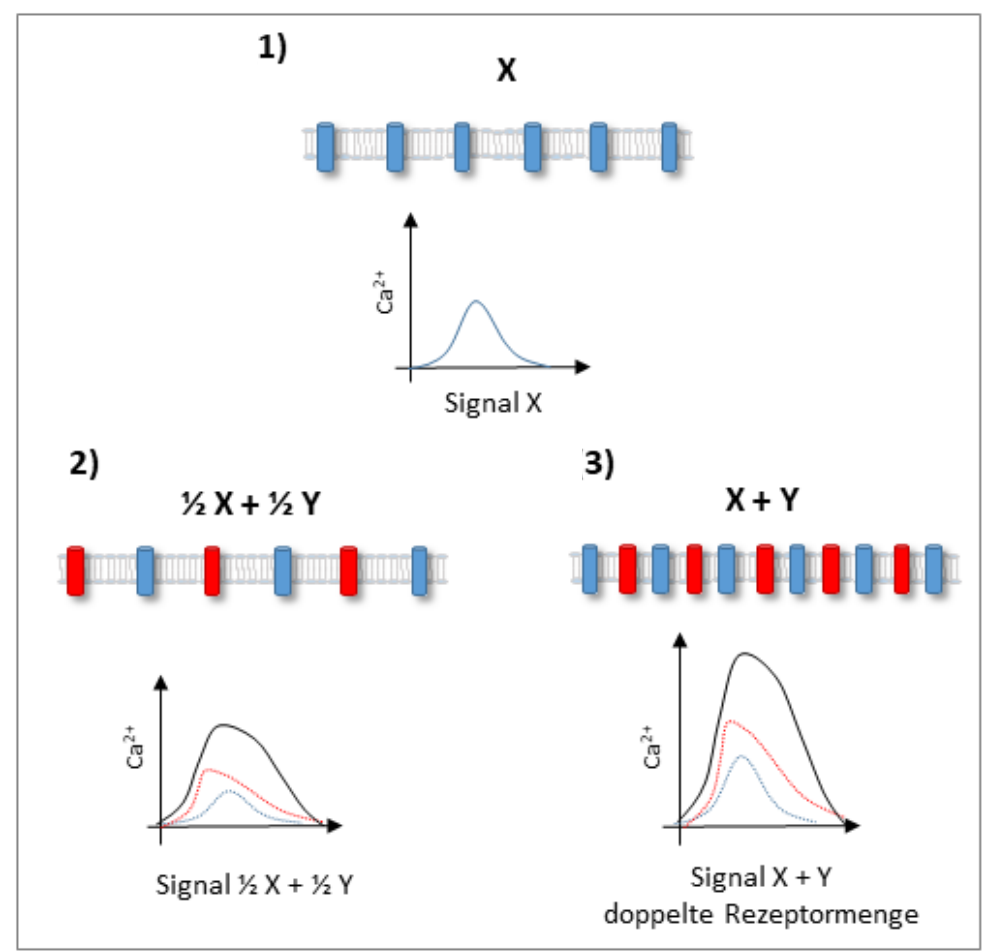

Abbildung 13: Expressionsrate der transfizierten Rezeptoren und die dazugehörige Signalgebung. Rezeptor X bzw. dessen Signal sind blau und Rezeptor Y rot gekennzeichnet. Das Signal der co-exprimierten Rezeptoren $\mathrm{X}+\mathrm{Y}$ ist schwarz. Wird bei der Ko-Expression je Rezeptor im Vergleich zu der einfachen Expression eines Rezeptors (1.) die halbe DNA-Menge ( $1 / 2 \mathrm{X}+1 / 2 \mathrm{Y})$ transfiziert (2.), so wird die halbe Anzahl je Rezeptor exprimiert und die jeweiligen Signale werden geringer. Wird die gleiche DNA-Menge $(\mathrm{X}+\mathrm{Y})$ je Rezeptor transfiziert (3.), so wird eine größere Anzahl an Rezeptoren exprimiert und das Signal der Rezeptoren entspricht der Addition der Signale der einfach exprimierten Rezeptoren.

Nach Abwägung der Vor- und Nachteile der beiden Möglichkeiten wurde für die Experimente Mögichkeit 1, also die Reduktion der transfizierten Rezeptor-DNA auf die Hälfte bei einer KoExpression mit einem weiteren Rezeptor, gewählt. Der große Vorteil liegt hierbei darin, dass die auf der Zelloberfläche exprimierte Rezeptormenge konstant bleibt. Somit bleiben auch Dimerbildungen genauso wahrscheinlich wie bei der einfachen Expression der Rezeptoren und die Experimente sind gut vergleichbar. Bei Möglichkeit 2 wäre die Anzahl der Rezeptoren auf der Zelloberfläche deutlich höher, sodass die Dimerisierung aufgrund der engeren räumlichen Nähe wahrscheinlicher wird und die Daten nicht direkt mit denen aus der einfachen Expression vergleichbar sind. Der Nachteil der gewählten Methode liegt darin, dass die Signale der jeweiligen Rezeptoren bei einer geringeren Expression reduziert werden, was die Vergleichbarkeit wiederum etwas erschwert.

Damit die Vergleichbarkeit der durchgeführten Experimente gewährleistet werden konnte, musste vorab gemessen werden, ob die Rezeptoren gleichmäßig exprimiert werden. Hierfür 
wurde die Durchflusszytometrie genutzt. Durch eine fluoreszente Markierung wurde die Menge der an der Zellmembran exprimierten Rezeptoren gemessen (siehe Kapitel 2.2.5).

Diese Daten wurden nicht im Rahmen der Doktorarbeit erhoben, da Ergebnisse des Betreuenden der Doktorarbeit aus Vorarbeiten genutzt werden konnten. Die Ergebnisse sind jedoch essenziell für die Auswertbarkeit der weiteren Daten, weshalb sie an dieser Stelle aufgeführt werden.

Im ersten Versuchsteil wurde die cDNA (complementary deoxyribonucleic acid, komplementäre Desoxyribonukleinsäure) des 5-HT ${ }_{2 \mathrm{~A}}$-Rezeptors in steigender Konzentration transfiziert, die an der Oberfläche der Zellen exprimierten Rezeptoren wurden fluoreszent markiert und die Intensität der Fluoreszenz im Durchflusszytometer gemessen (siehe Kapitel 2.2.5).

1)

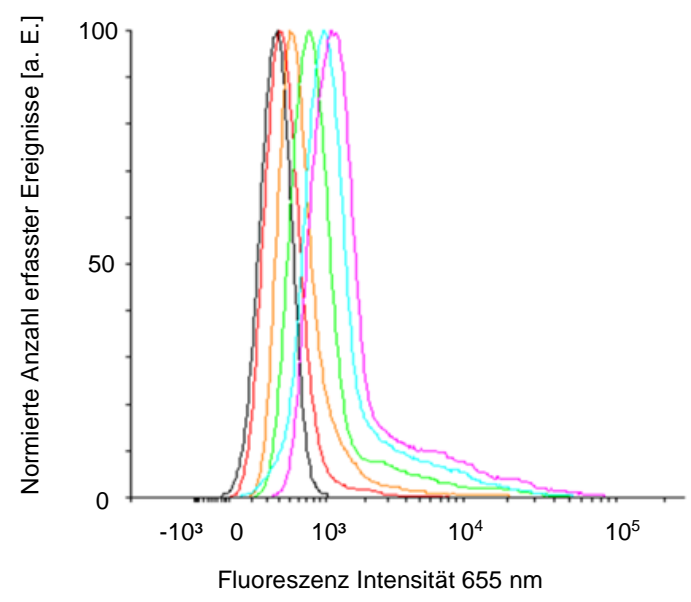

2)

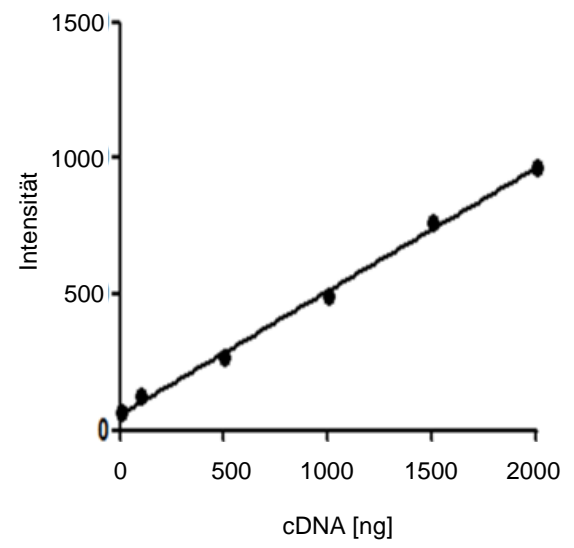

Abbildung 14: Histogramm der FACS-Analyse an Zellen mit transfiziertem Rezeptor 2A mit steigender Menge der transfizierten cDNA und die entsprechende graphische Auftragung. In 1.) ist ein Histogramm der FACS-Analyse an Zellen mit dem transfizierten Rezeptor 2A dargestellt. Auf der Abszisse wurde die Intensität der Fluoreszenz bei einer Emissionswellenlänge von $655 \mathrm{~nm}$ und auf der Ordinate die normierte Anzahl erfasster Ereignisse aufgetragen. Die Intensität entspricht der Menge an die exprimierten Rezeptoren gebundener quantum dots. Die transfizierte cDNA-Menge wurde stets gesteigert, was durch die verschiedenen Farben der Kurven dargestellt wird. Es zeigte sich eine mit steigender cDNA höhere Intensität in der FACS, was in 2.) zur Verdeutlichung graphisch dargestellt ist. Die Intensität ist gegen die cDNA-Menge [ng] aufgetragen. Es ergibt sich eine proportionale Zuordnung der cDNA zu der Intensität.

In der Auswertung der Daten ergab sich eine Proportionalität der transfizierten cDNA-Menge des Rezeptors 2A zu der gemessenen Intensität. Da die gemessene Intensität die Menge exprimierter Rezeptoren darstellt, folgt daraus die Proportionalität der transfizierten cDNA-Menge zu der exprimierten Rezeptormenge. 
Im zweiten Versuchsteil wurden 2A und 2B gemeinsam exprimiert, wobei je Rezeptor-DNA nur $0,5 \mu \mathrm{g}$ transfiziert wurden. Die sich in der FACS ergebende Kurve erfasster Ereignisse aufgetragen gegen die Intensität wurde mit der Kurve verglichen, die sich bei der Transfektion von $1 \mu \mathrm{g} 2 \mathrm{~A}$ ergab (siehe Abbildung 15).

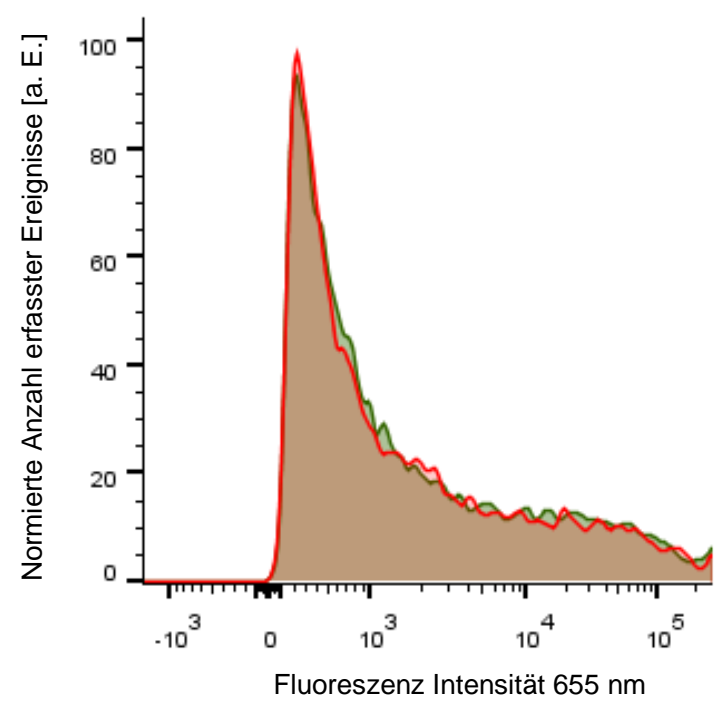

Abbildung 15: Histogramm der FACS-Analyse nach Transfektion von Rezeptor 2A bzw. den ko-exprimierten Rezeptoren 2A und 2B. Es wurden Zellen gemessen, in die $1 \mu \mathrm{g}$ der DNA von Rezeptor 2A (rot) bzw. 0,5 $\mu \mathrm{g} 2 \mathrm{~A}$ und 0,5 $\mu \mathrm{g} 2 \mathrm{~B}$ (grün) transfiziert wurden. Beide Spuren sind beinahe identisch. Auf der Abszisse wurde die Intensität der Fluoreszenz bei einer Emissionswellenlänge von $655 \mathrm{~nm}$ und auf der Ordinate die normierte Anzahl erfasster Ereignisse aufgetragen. Die Intensität entspricht der Menge der an die exprimierten Rezeptoren gebundenen quantum dots.

Der zweite Versuchsteil zeigt beinahe identische Intensitätskurven für die Transfektion von $1 \mu \mathrm{g}$ Rezeptor 2A bzw. 0,5 $\mu \mathrm{g}$ 2A + 0,5 $\mu \mathrm{g}$ 2B. Dies spricht dafür, dass die Menge an exprimiertem Rezeptor auf der Zelloberfläche bei einer Ko-Expression mit einem weiteren Rezeptor der Rezeptormenge bei einer einfachen Expression eines Rezeptors entspricht, vorausgesetzt die Gesamtmenge der transfizierten DNA bleibt gleich.

Dieses Ergebnis ist grundlegend für die weiteren Experimente. Da der Schwerpunkt der vorliegenden Arbeit auf der Analyse der Dimerisierung liegt, war es wichtig immer die gleiche Rezeptormenge zu exprimieren. Denn bei einer erhöhten Rezeptordichte wäre eine erhöhte Dimerisierungsrate wahrscheinlich, da die Rezeptoren in engerer räumlicher Nähe zueinander liegen. Das Gegenteil ergibt sich für eine niedrigere Rezeptordichte. Somit war das Ziel immer die gleiche Menge an Rezeptoren zu exprimieren, auch bei der Ko-Expression verschiedener 
Rezeptoren, sodass hierfür jeweils 0,5 $\mu \mathrm{g}$ DNA je Rezeptorart, also $1 \mu \mathrm{g}$ Gesamt-DNA, transfiziert wurden. Für die Expression eines einfachen Rezeptors wurden $1 \mu \mathrm{g}$ DNA gewählt.

\subsection{Single Particle Tracking}

Vor Durchführung der FRAP- und $\mathrm{Ca}^{2+}$-Imaging-Versuche wurde das single particle tracking (SPT) am Beispiel des Rezeptors 2B durchgeführt, um stichprobenartig den Nachweis einer dynamischen Dimerisierung in der 5- $\mathrm{HT}_{2}$-Familie zu erbringen.

Im SPT können durch die Bestimmung der Trajektorien einzelner markierter Rezeptoren deren Diffusionskoeffizienten bestimmt werden (siehe Kapitel 2.2.7). Dabei wird der Diffusionskoeffizient für jedes Molekül einzeln bestimmt. Es ergibt sich kein Mittelwert, sondern es werden verschiedene Fraktionen der Diffusionskoeffizienten gebildet. So zeigt sich beispielsweise ein Anteil der Rezeptoren, welcher schneller diffundiert (Monomer) und ein Anteil, welcher langsamer diffundiert (Dimer). Außerdem kann die Dimerbildung direkt visualisiert werden, wie in Abbildung 16 gezeigt.

1)
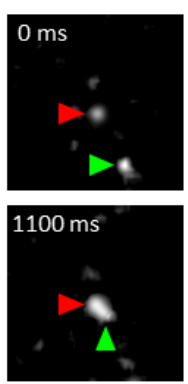

$1900 \mathrm{~ms}$

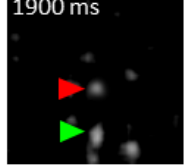

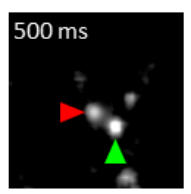

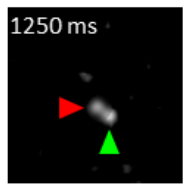

$2000 \mathrm{~ms}$

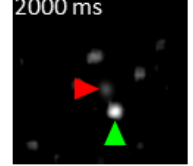

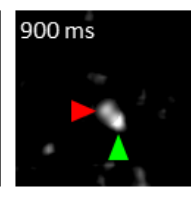

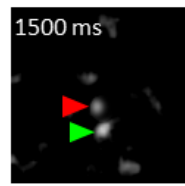

$2100 \mathrm{~ms}^{2}$

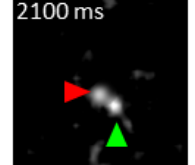

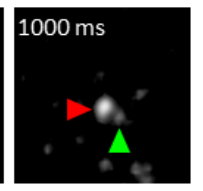

$1750 \mathrm{~ms}$

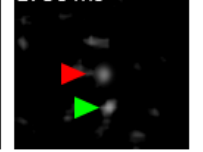

$2200 \mathrm{~ms}$

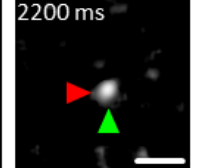

2)

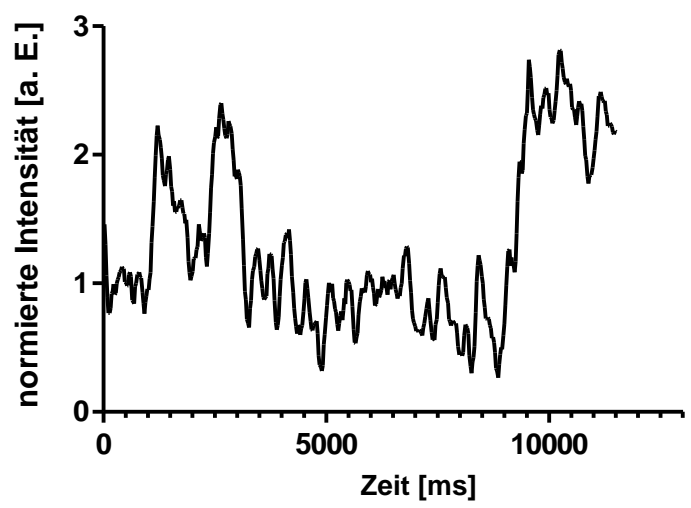

Abbildung 16: Das SPT des Rezeptors 5- $\mathrm{HT}_{2 \mathrm{~B}}$, fluoreszent markiert mit quantum dots. Vergrößerung 60x. 1.) zeigt die Bildaufnahmen im Mikroskop im zeitlichen Verlauf. Die Rezeptoren sind durch farbige Pfeile gekennzeichnet, um zu verdeutlichen, an welcher Position sie sich jeweils zu verschiedenen Zeiten befinden. Es zeigt sich, dass die Rezeptoren sich aneinanderlagern (1100 ms), wieder auseinander diffundieren und sich schließlich wieder zusammenlagern $(2200 \mathrm{~ms})$. Verdeutlicht wird dies durch das Diagramm 2.). Hier werden auf der Abszisse die Zeit [ms] und auf der Ordinate die normierte Intensität [a. E.] der Helligkeit des betrachteten Moleküls dargestellt. Die Intensität ist dahingehend normiert, dass an einem einzelnen Rezeptor eine Fluoreszenz mit einer Intensität von 1 a. E. gemessen wird. Anhand des Kurvenverlaufs wird deutlich, dass diese Intensität zu einigen Zeitpunkten etwa verdoppelt ist. Die Verdopplung der Intensität korreliert zeitlich mit der Zusammenlagerung der Rezeptoren in der mikroskopischen Aufnahme. 
Das SPT zeigt deutlich, dass der Rezeptor 2B zwar größtenteils als Monomer vorliegt, jedoch fakultativ Dimere bilden kann. Diese sind nur von kurzer Dauer, jedoch ist die Dimerisierung deutlich messbar, da die QDs, durch welche der Rezeptor fluoreszent markiert ist, in diesen Zeiträumen in Resonanz zusammentreten und sich so deren Intensität verdoppelt. Eine Dimerisierung innerhalb der Gruppe der 5-HT $\mathrm{T}_{2}$-Rezeptoren ist also durchaus existent, auch wenn die Dimere bei einigen Rezeptoren kurzzeitiger exisitieren als bei anderen. Aufgrund der Dynamik der Dimerisierung, welche zwar bei einigen Rezeptoren ausgeprägter ist als bei anderen, aber dennoch bei allen Rezeptoren eine Rolle spielt, ist eine Kontrolle der Dimerbildung für die weitere Analyse der Auswirkungen auf die Signalgebung essenziell. Im Folgenden wird die Dimerbildung anhand der forcierten Dimerisierung, der FRAP- und $\mathrm{Ca}^{2+}{ }_{-}$Versuche analysiert.

\subsection{Kontrolle der Dimerisierung}

Die 5- $\mathrm{HT}_{2}$-Rezeptoren wurden durch Rezeptor-gekoppelte Anti-GFP-Nanobodys bzw. gekoppeltes GFP in konsitutive Dimere forciert. Diese forcierte Dimerisierung wurde sowohl für die FRAP als auch für die Experimente des $\mathrm{Ca}^{2+}$-Imagings genutzt, um Vergleichswerte der reinen Dimere zu erhalten (siehe Kapitel 2.2.1).

Um nachzuweisen, dass die Kopplung eines Nanobodys an einen Rezeptor funktioniert und dass die Nanobody-GFP-Bindung effizient ist, wurden freies GFP und weitere fluorophore Proteine ohne bzw. zusammen mit einem Nanobody-gekoppelten Rezeptor exprimiert und unter dem LSM-Mikroskop betrachtet (siehe Abbildung 17). 


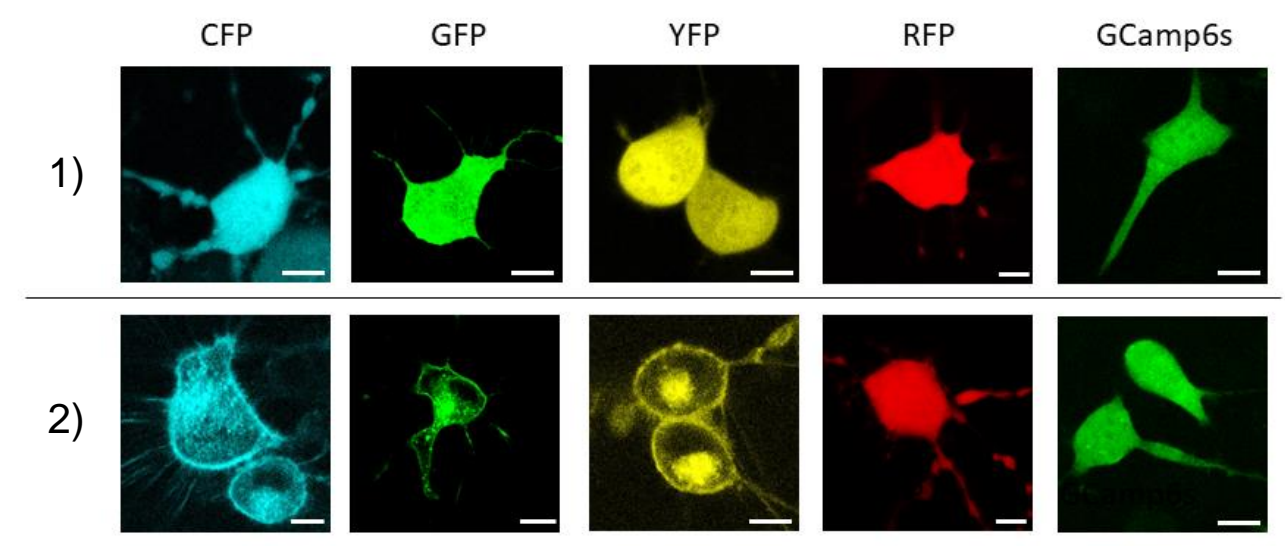

Abbildung 17: Neuroblastomzellen mit fluoreszenten Proteinen mit bzw. ohne Nanobody-gekoppelten Rezeptor. Der weiße Balken stellt als Vergleich $10 \mu \mathrm{m}$ in der entsprechenden Vergrößerung dar. Die Aufnahmen erfolgten unter dem Laser-Scanning-Mikroskop bei 63x Vergrößerung. In der oberen Bilderreihe 1.) sind Aufnahmen von Zellen abgebildet, in die verschiedene fluoreszente Proteine transfiziert wurden. Die Überschrift über der Spalte zeigt, welches Protein jeweils transfiziert wurde (CFP = cyan fluorescent protein; $\mathrm{GFP}=$ green fluorescent protein; $\mathrm{YFP}=$ yellow fluorescent protein; $\mathrm{RFP}=$ red fluorescent protein; GCaMP6s = Calcium-Sensor). Der gesamte Zellkörper zeigt sich fluoreszent. In der unteren Reihe 2.) wurde zusätzlich ein Nanobody-gekoppelter Rezeptor transfiziert. Für CFP, GFP und YFP zeigt sich ein deutlicher Unterschied in der Verteilung der Fluoreszenz: Die Fluoreszenz ist in der zweiten Bilderreihe eher membranständig. Zusätzlich zeigt sich eine Anreicherung der Fluoreszenz in einem intrazellulären Bereich, welcher als endoplasmatisches Retikulum, in dem die Entwicklung der Rezeptoren stattfindet, gedeutet werden kann. In den Aufnahmen mit RFP und GCaMP6s zeigt sich hingegen keine veränderte Verteilung der Fluoreszenz, wenn ein Nanobody-gekoppelter Rezeptor ko-transfiziert wird.

In Abbildung 17 zeigt sich der Unterschied von frei exprimiertem Fluorophor (1) und der gemeinsamen Expression mit einem Nanobody-gekoppelten Rezeptor (2). Während in Abbildung 17 (1) die Fluoreszenz in der gesamten Zelle verteilt ist, ist sie in Abbildung 17 (2) in der CFP, GFP und YFP-Transfektion hauptsächlich membranständig bzw. im endoplasmatischen Retikulum erkennbar, also dort, wo der transfizierte Nanobody-gekoppelte Rezeptor vorliegt. Dies lässt darauf schließen, dass der Nanobody erfolgreich an den Rezeptor gekoppelt wurde und dieser effizient CFP, GFP und YFP bindet. Für RFP und GCaMP6s zeigt sich diese Akkumulation am Nanobody-gekoppelten Rezeptor nicht. Sie binden nicht effizient an den Nanobody. Besonders bezüglich des GCaMP6s ist dies für die Experimente der Arbeit von Interesse, da der Calcium-Sensor im Calcium-Imaging genutzt wurde. Eine Bindung des GCaMP6s an den Nanobody könnte die Fluoreszenzmessung beeinflussen.

\subsection{FRAP und $\mathrm{Ca}^{2+}$-Imaging}

Um die Dimerisierung der Rezeptoren und deren Auswirkungen auf die Signalgebung zu messen, wurden hauptsächlich die FRAP und das $\mathrm{Ca}^{2+}$-Imaging genutzt. 


\subsubsection{FRAP}

In Vorversuchen wurde die FRAP bereits an den Oberflächenproteinen CD28 und CD86 durchgeführt, da bekannt ist, dass diese als obligates Dimer bzw. Monomer vorliegen. CD28 liegt aufgrund von intermolekularen Disulfidbrücken als obligates Dimer vor (Linsley et al. 1995), während CD86 ein obligates Monomer darstellt (James et al. 2006). Beide Oberflächenproteine sind sich mit jeweils nur einer Transmembrandomäne struktuell ähnlich. Mit $28 \mathrm{kDa}$ liegt das Molekulargewicht von CD28 unter dem von CD86 mit 35 kDa (Dorsch et al. 2009; Woods und Flies 2019).

1)

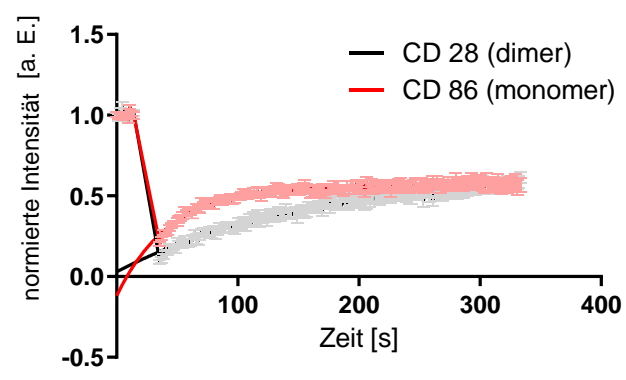

2)

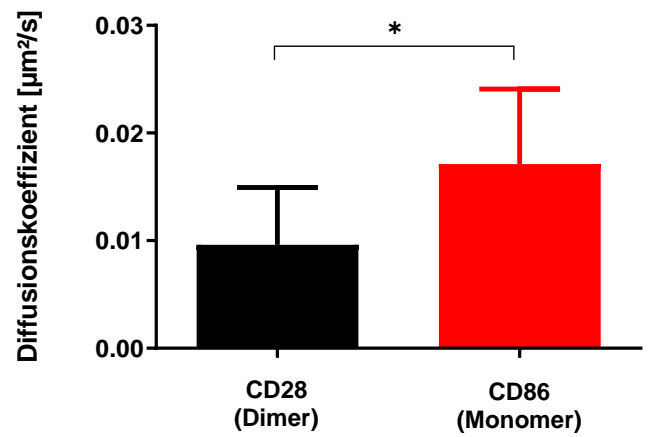

Abbildung 18: Ergebnisse der FRAP für die Oberflächenproteine CD28 und CD86. 1) zeigt den Kurvenverlauf der FRAP für die jeweiligen Proteine, wobei CD28 schwarz und CD86 rot dargestellt sind. Auf der Abszisse ist die Zeit [s] und auf der Ordinate die normierte Intensität der Helligkeit des gebleichten Abschnittes dargestellt. Bei $10 \mathrm{~s}$ beginnt der Bleichvorgang, welcher bei $30 \mathrm{~s}$ beendet ist. Darauf folgt die Erholungsphase, in der sich die Fluoreszenz durch Diffusion regeneriert. Hier zeigt sich ein deutlich steilerer Anstieg der Kurve von CD86, das Endplateau der Helligkeit wird von diesem schneller wieder erreicht als von CD28. 2) zeigt in einem Balkendiagramm die Höhe der Diffusionskoeffizienten $\left[\mathrm{\mu m}^{2} / \mathrm{s}\right.$ ] von CD28 bzw. CD86 mit Standardabweichung, die sich aus dem FRAP-Experiment ergeben. Hier zeigt sich ein für CD86 signifikant größerer, fast doppelt so großer Diffusionskoeffizient wie für CD28. Die Signifikanz der Abweichung ist durch einen Stern gekennzeichnet.

In den Vorversuchen zu der FRAP zeigten sich deutliche Unterschiede bezüglich der Kurvenverläufe und somit der Diffusionskoeffizienten der Oberflächenproteine CD28 und CD86 (siehe Abbildung 18). Der Anstieg der Kurve von CD86 ist im Vergleich zu der Kurve von CD28 deutlich steiler. Wird der Diffusionskoeffizient berechnet, so liegt $\mathrm{D}_{\mathrm{CD} 28}$ (Dimer) bei etwa

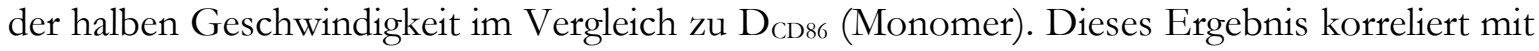
der Annahme, dass die Diffusionskoeffizienten im Vergleich eine Aussage über das Dimerisierungsverhalten der Rezeptoren zulassen, vorausgesetzt die Rezeptoren besitzen einen ähnlichen hydrodynamischen Durchmesser. Im Rahmen der Arbeit wurden die aus der FRAP berechneten 
Diffusionskoeffizienten genutzt, um Aussagen bezüglich des Dimerisierungsverhaltens der 5- $\mathrm{HT}_{2}$-Rezeptoren zu treffen. Diese werden in Balkendiagrammen dargestellt.

\subsection{2 $\mathrm{Ca}^{2+}$-Imaging}

Da bei der Stimulation der 5- $\mathrm{HT}_{2}$-Rezeptoren eine mit der Stimulationsstärke korrelierende Menge $\mathrm{Ca}^{2+}$ freigesetzt wird, kann das $\mathrm{Ca}^{2+}$-Imaging zur Analyse der Signalstärke eingesetzt werden.

Die Konzentration des stimulierenden 5-HT war in allen Experimenten konstant bei 0,01 mM. Diese wurde vorab anhand von Reaktionskurven der einzelnen Rezeptoren ermittelt, sodass bei der Stimulation alle Rezeptoren reagieren, jedoch keine starke Überstimulation stattfindet (siehe Kapitel 2.2.8). Im Schnitt wurden $n=15$ Messungen ausgewertet, deren Ergebnisse im Folgenden durch Balkendiagramme mit der zugehörigen Standardabweichung dargestellt sind. Die Auswertung erfolgte anhand der AUC, also der freigesetzten $\mathrm{Ca}^{2+}$-Menge (siehe Kapitel 2.2.8). Signifikante Abweichungen sind in den Graphen durch Sterne gekennzeichnet. Ein p-Wert von $\leq 0,05$ wird als niedrige Signifikanz $\left(^{*}\right)$, ein $\mathrm{p}$-Wert von $\mathrm{p} \leq 0,01$ als mittelstarke $\left(^{* *}\right)$ und ein $\mathrm{p}$ Wert von $\mathrm{p} \leq 0,001$ als starke Signifikanz $\left.{ }^{(* *}\right)$ gewertet. Aus Übersichtsgründen wurden in den Graphen nicht alle signifikanten Abweichungen gekennzeichnet, sondern nur solche, die zur Klärung der Fragestellung beitrugen.

Als ko-exprimierte Rezeptoren werden im Folgenden solche Rezeptoren bezeichnet, die gemeinsam exprimiert, aber nicht per GFP-nanobody-Interaktion in ein Dimer gezwungen (forciert) werden. 


\subsection{Homodimerisierung und Signalgebung}

1)

Diffusionskoeffizient

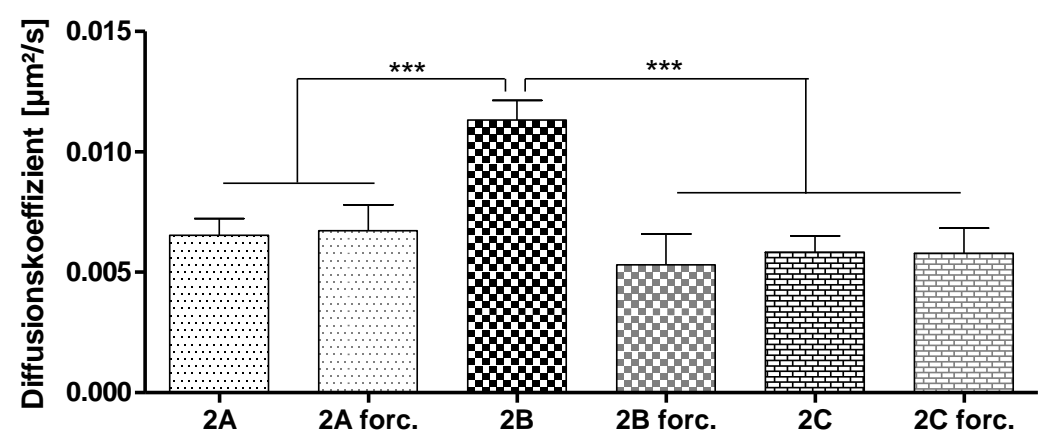

\section{2)}

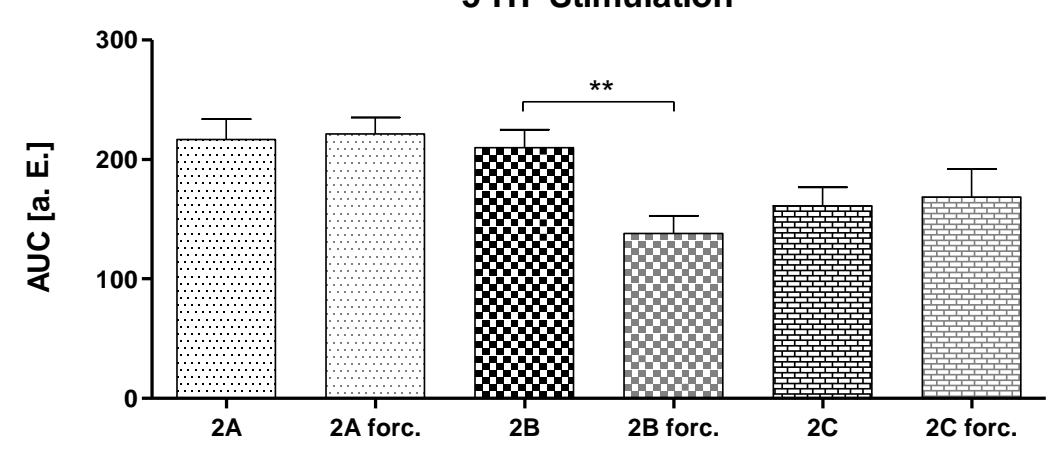

Abbildung 19: Diffusionskoeffizienten der nicht forcierten und forciert dimerisierten Homodimere 2A, 2B und 2C und deren Signalgebungen. 1) Die Diffusionskoeffizienten der einzeln exprimierten und for-

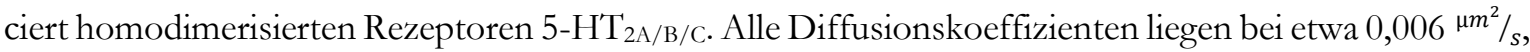
bis auf $\mathrm{D}_{2 \mathrm{~B}}$ (nicht forciert), welcher fast doppelt so hoch ist. Diese Abweichung ist stark signifikant. 2) Das $\mathrm{Ca}^{2+}$-Signal der einfach exprimierten und forciert homodimerisierten Rezeptoren an5hand der AUC nach Stimulation mit 5-HT. Das Signal des Rezeptors 2A zeigt keinen signifikanten Unterschied zwischen dem forcierten Homodimer und dem einfach exprimierten Rezeptor. Das Signal des Rezeptors 2B ist im forcierten Dimer signifikant kleiner ist als bei der einfachen Rezeptorexpression. Am 2C-Rezeptor lässt sich in der Signalgebung kein Unterschied vom einfach exprimierten zum forciert homodimerisierten Rezeptor feststellen.

\subsubsection{Homodimerisierung}

Die Diffusionskoeffizienten der Rezeptoren 2A, 2B und 2C wurden jeweils sowohl für die einfach exprimierten Rezeptoren als auch für die forciert homodimerisierten Rezeptoren bestimmt. Hinsichtlich der einfach exprimierten und damit nicht forciert dimerisierten Rezeptoren zeigte sich, dass sich die Diffusionskoeffizienten der Rezeptoren 2A und 2C 
$\left(\mathrm{D}_{2 \mathrm{~A}}=0,0065 \pm 0,0029^{\mu m^{2}} / \mathrm{s}, \mathrm{n}=17 ; \mathrm{D}_{2 \mathrm{C}}=0,0055 \pm 0,0027 \mu \mathrm{m}^{2} / \mathrm{s}, \mathrm{n}=16\right)$ nicht signifikant voneinander unterscheiden.

Für 2B ergab sich ein stark signifikant größerer Diffusionskoeffizient als es für Rezeptor 2A und 2C der Fall war $\left(\mathrm{D}_{2 \mathrm{~B}}=0,0110 \pm 0,0030 \mathrm{\mu m}^{2} / \mathrm{s}, \mathrm{n}=13\right)$ (siehe Abbildung $19 \mathrm{~A}$ ).

In der forcierten Homodimerisierung durch das Nanobody-GFP-Konstrukt ergaben sich für alle drei Rezeptorarten ähnliche, nicht signifikant unterschiedliche Diffusionskoeffizienten $\left(\mathrm{D}_{2 \mathrm{~A} \text { forc. }}=0,0067 \pm 0,003 \mathrm{\mu m}^{2} / \mathrm{s}, \mathrm{n}=11 ; \mathrm{D}_{2 \mathrm{~B} \text { forc. }}=0,0050 \pm 0,003 \mathrm{\mu m}^{2} / \mathrm{s}, \mathrm{n}=8 ; \mathrm{D}_{2 \mathrm{C} \text { forc. }}=0,0058\right.$ $\left.\pm 0,0026^{\mu \mathrm{m}} / \mathrm{s}, \mathrm{n}=6\right)($ siehe Abbildung $19 \mathrm{~B})$.

Damit war der Diffusionskoeffizient des Rezeptors 2B im forcierten Homodimer nur etwa halb so groß wie der des nicht forciert dimerisierten Rezeptors 2B. Die Diffusionskoeffizienten der Rezeptoren 2A und 2C zeigten in der forcierten Homodimerisierung keine signifikanten Veränderungen im Vergleich zu der einfachen Expression der Rezeptoren.

\subsubsection{Signalgebung der Homodimere}

Es wurden jeweils sowohl die Signale der einfach exprimierten als auch der forciert homodimerisierten Rezeptoren 2A, 2B und 2C gemessen und anhand der freigesetzten $\mathrm{Ca}^{2+}$-Menge (AUC) ausgewertet.

Dort zeigte sich, dass in der Serotonin-Stimulation an dem Rezeptor 2A das stärkste $\mathrm{Ca}^{2+}$-Signal ausgelöst wurde $\left(\mathrm{AUC}_{2 \mathrm{~A}}=216 \pm 64\right.$ a. E., $\mathrm{n}=14 ; \mathrm{AUC}_{2 \mathrm{~A} \text { forced }}=221 \pm 58$ a.E., $\left.\mathrm{n}=18\right)$. Der Rezeptor 2B zeigte als Monomer eine starke Signalgebung, während das Signal im forcierten Dimer deutlich abnahm $\left(\mathrm{AUC}_{2 \mathrm{~B}}=204 \pm 51\right.$ a. E., $\mathrm{n}=14 ; \mathrm{AUC}_{2 \mathrm{~B} \text { forced }}=100 \pm 40$ a. E., $\left.\mathrm{n}=15\right)$. Das Signal des Rezeptors 2C lag bei $\mathrm{AUC}_{2 \mathrm{C}}=161 \pm 57$ a. E., $\mathrm{n}=14$ und $\mathrm{AUC}_{2 \mathrm{C} \text { forced }}=$ $168 \pm 66$ a. E., $n=8$.

Die Signale der einfach exprimierten Rezeptoren unterschieden sich hinsichtlich der Rezeptoren 2A und 2C nicht signifikant von den Signalen der forciert homodimerisierten Rezeptoren. Im Falle des Rezeptors 2B zeigte sich ein signifikant kleineres Signal für den forciert homodimerisierten Rezeptor ( $\mathrm{p} \leq 0,01$, siehe Abbildung 19 C). Die entsprechenden Signalkurven sind in Abbildung 20 dargestellt. 
5-HT-Stimulation

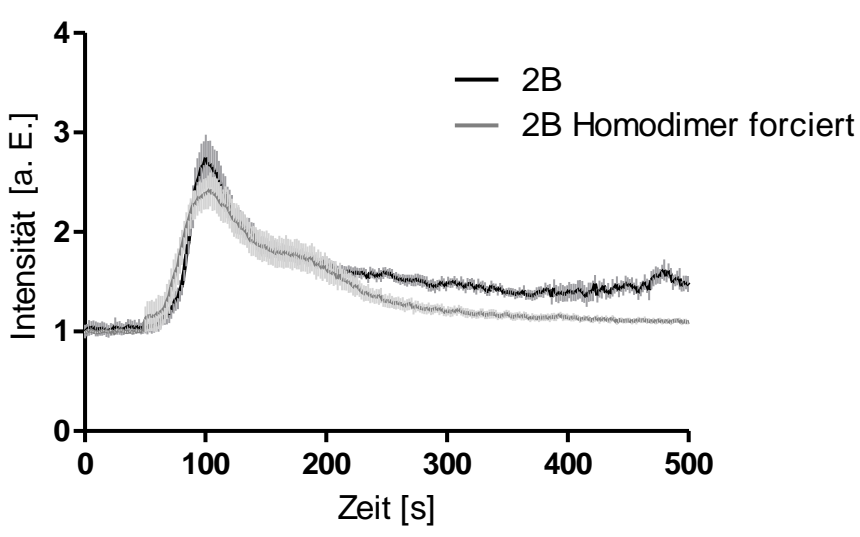

Abbildung 20: $\mathrm{Ca}^{2+}$-Signal des Rezeptors $2 \mathrm{~B}$ im nicht forcierten und forciert dimerisierten Zustand nach Stimulation mit 5-HT. Das Signal des nicht forciert dimerisierten Rezeptors $(n=14)$ ist schwarz dargestellt, das des forciert-dimerisierten $(n=15)$ grau, jeweils mit dazugehöriger Standardabweichung als senkrechte Balken. Es zeigen sich ähnliche Kurvenverläufe, wobei die Kurve des nicht forciert dimerisierten Rezeptors nur einen minimal höheren Peak aufweist. Auffällig ist, dass die Kurve einen langsameren Abfall der Intensität zeigt. Die AUC wurde zwischen 35 s und 350 s verglichen.

Betrachtet man die Signalkurve des nicht forciert und forciert dimerisierten Rezeptors 2B, so zeigen sich sehr ähnliche Kurvenverläufe, also ähnliche Signalgebungen. Auffällig ist, dass das Signal des nicht forciert dimerisierten Rezeptors nicht wieder auf die Ausgangsintensität zurückgeht (siehe Abbildung 20).

Aufgrund der sehr ähnlichen Kurvenverläufe haben wir zusätzlich die Amplitude als Vergleichsparameter hinzugezogen. Hier ergaben sich für den einfach exprimierten Rezeptor $2 \mathrm{~B}$ eine Amplitude von 2,748 $\pm 0,821$ a. E. und für den forciert dimerisierten Rezeptor $2 \mathrm{~B}$ eine Amplitude von 2,428 \pm 0,832 a. E. Die Reaktionskurven der beiden Rezeptoren weichen bezüglich der Amplitude nicht signifikant voneinander ab.

\subsubsection{Zusammenfassung Homodimere}

Zusammengefasst weisen die Rezeptoren 2A und 2C weder bezüglich ihrer Diffusionskoeffizienten noch hinsichtlich ihrer Signalgebung Unterschiede zwischen den einfach exprimierten und den forciert homodimerisierten Rezeptoren auf.

Der Rezeptor 2B zeigt bei der einfachen Expression einen sehr hohen Diffusionskoeffizienten im Vergleich zu den anderen Rezeptoren, was ich als monomere Konfiguration interpretiere (siehe Kapitel 2.2.6). Der Diffusionskoeffizient im forcierten Homodimer ist nur fast halb so groß, was ich als erfolgreiche Dimerisierung über die NB-GFP-Interaktion interpretiere. Im SPT (siehe 3.2) wurde deutlich, dass der Rezeptor natürlicherweise Dimere bildet, diese jedoch 
nur für eine kurze Dauer bestehen. In der Signalgebung war das Signal des forciert homodimerisierten Rezeptors 2B gemessen an der freigesetzten $\mathrm{Ca}^{2+}$-Menge signifikant kleiner als das des einfach exprimierten Rezeptors, wobei sich jedoch sehr ähnliche Kurvenverläufe darstellten und sich die Amplituden nicht signifikant voneinander unterschieden. Das Signal des nicht forciert dimerisierten Rezeptors geht in der gemessenen Zeitspanne nicht auf die Ausgangsintensität zurück, sodass dadurch die höhere insgesamt freigesetzte $\mathrm{Ca}^{2+}$-Menge zu erklären ist. 


\subsection{Heterodimerisierung und Signalgebung}

Zur Messung der Auswirkungen einer Heterodimerbildung wurden die nicht forcierten und forcierten Heterodimere nicht nur mit 5-HT stimuliert, sondern zusätzlich mit Rezeptoragonisten für 5-HT $\mathrm{T}_{2 \mathrm{~A} / 2 \mathrm{~B} / 2 \mathrm{C}}$ (siehe Kapitel 2.2.8). Das Ziel war hierbei zu messen, ob sich das Signal des stimulierten Rezeptors ändert, wenn ein weiterer 5-HT-Rezeptor exprimiert wird. In den Abbildungen ist die Selektivität der Agonisten durch Pfeile auf den jeweilig stimulierten Rezeptor des Heterodimers dargestellt.

Die Selektivität der Agonisten wurde vorab getestet (siehe Abbildung 21).

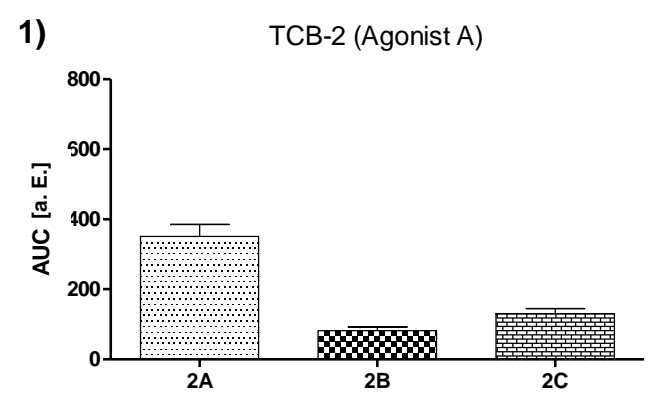

2)

BW723c86 Hydrochlorid (Agonist B)
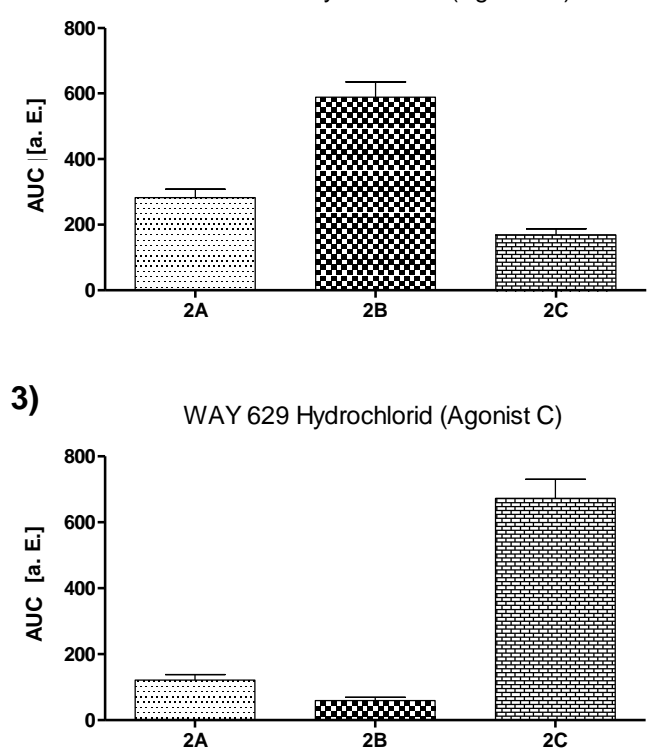

Abbildung 21: Die 5- $\mathrm{HT}_{2}$-Rezeptor-Agonisten und ihre Wirkung auf die verschiedenen 5-HT toren. Alle Rezeptoren wurden einzeln exprimiert und mit einer Konzentration von 0,02 mM des Agonisten stimuliert. 1) Der Agonist TCB-2 (Agonist 2A) löst an 2A ein deutliches Signal aus. 2B und 2C werden nur relativ schwach stimuliert, wobei an $2 \mathrm{C}$ ein etwas stärkeres Signal ausgelöst wird als an $2 \mathrm{~B}$. 2) Der Agonist BW723c86 Hydrochlorid (Agonist 2B) löst an 2B das stärkste Signal aus, wobei auch 2A ein relativ deutliches Signal zeigt. Am Rezeptor 2C wird ein geringeres Signal ausgelöst. 3) Der Agonist WAY629 Hydrochlorid (Agonist 2C) löst an 2C ein sehr starkes Signal aus, während 2A und 2B kaum stimuliert werden. 
Die Messungen der Stimulation mit den Rezeptoragonisten TCB-2, BW723c86 Hydrochlorid und WAY629 Hydrochlorid (Abbildung 21) zeigen, dass die Agonisten zwar selektiv jeweils

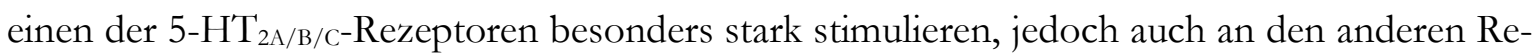
zeptoren der 5- $\mathrm{HT}_{2}-\mathrm{Gruppe}$ ein Signal auslösen.

In der Stimulation mit dem Agonisten für den Rezeptor 2A, TCB-2, zeigte sich eine Selektivität für den Rezeptor 2A. Es wurde eine freigesetzte $\mathrm{Ca}^{2+}$-Menge (AUC) von 351 a. E. ( $\left.\mathrm{n}=11\right)$ für den Rezeptor 2A gemessen. Das Signal der weiteren Rezeptoren lag bei 82 a. E. (Rezeptor 2B $(\mathrm{n}=14)$ und 130 a. E. (Rezeptor $2 \mathrm{C}(\mathrm{n}=8)$ ).

Für die Stimulation mit BW723c86 Hydrochlorid, dem Agonisten am Rezeptor 2B, zeigte sich auch an den Rezeptoren 2A und 2C ein relativ starkes Signal. Die gemessene freigesetzte $\mathrm{Ca}^{2+}$ Menge fiel zwar mit 589 a. E. $(\mathrm{n}=13)$ am Rezeptor $2 \mathrm{~B}$ am größten aus, jedoch wurden mit 283 a. E. (Rezeptor $2 \mathrm{~A}(\mathrm{n}=19))$ und 169 a. E. (Rezeptor $2 \mathrm{C}(\mathrm{n}=18))$ auch an den anderen beiden Rezeptoren verhältnismäßig starke Signale ausgelöst.

Die vergleichsweise selektivste Wirkung der Agonisten zeigte WAY629 Hydrochlorid, der Agonist für den Rezeptor 2C. Während an dem Rezeptor 2C ein Signal von 671 a. E. (n=15) ausgelöst wurde, lagen die Signale der Rezeptoren 2A und 2B nach der Stimulation mit WAY629 Hydrochlorid nur bei 121 a. E. (Rezeptor 2A $(\mathrm{n}=18)$ ) und 59 a. E. (Rezeptor 2B (n=21)). 


\subsubsection{5-H $\mathrm{T}_{2 \mathrm{~A}}$ und $5-\mathrm{HT}_{2 \mathrm{~B}}$}

1)

Diffusionskoeffizient

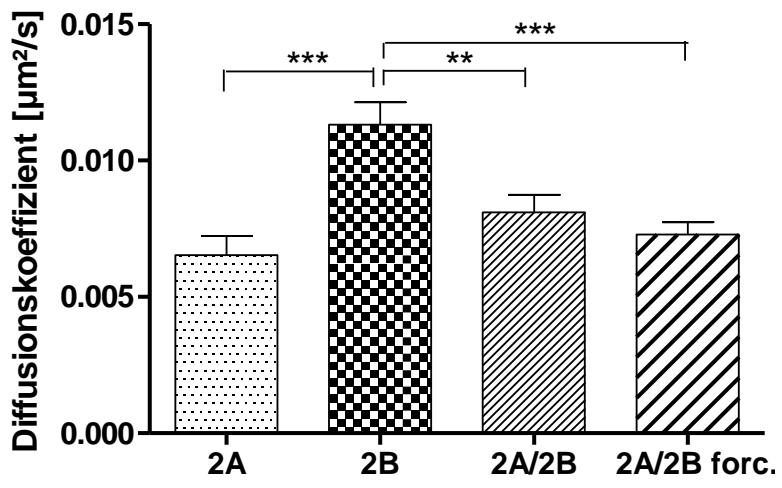

2)

Signalgebung

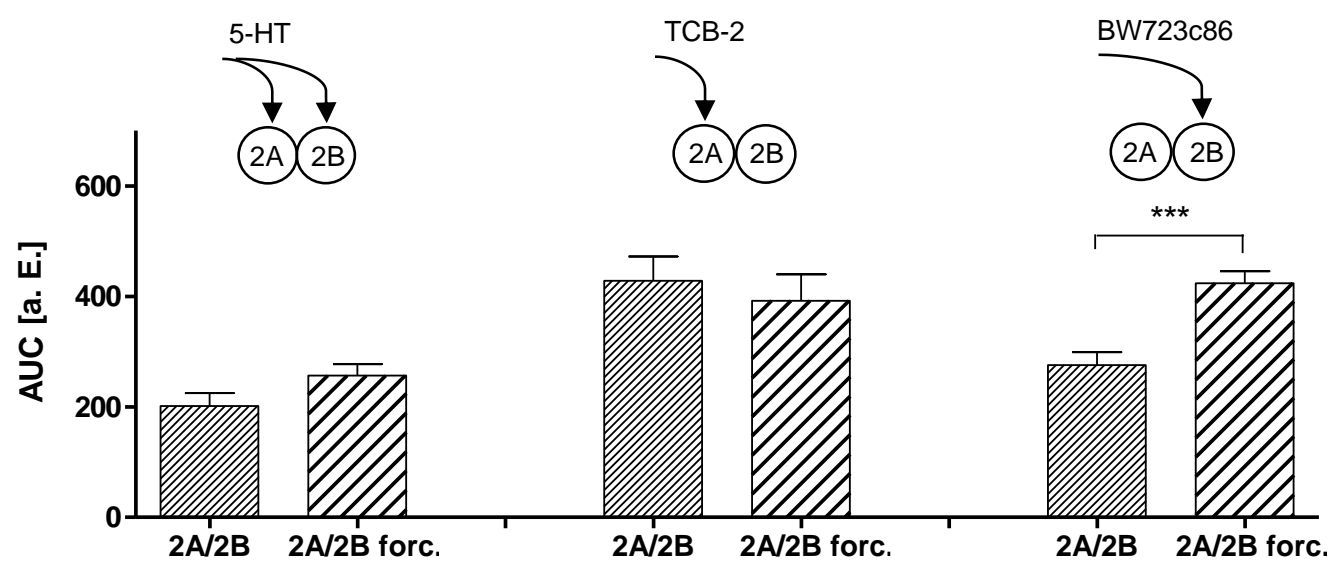

Abbildung 22: Die Diffusionskoeffizienten und Signalkurven der Rezeptoren 2A/2B. 1) Diffusionskoeffizienten der allein exprimierten Rezeptoren 2A, 2B, der ko-exprimierten und der forciert dimerisierten 2A/2B. Es zeigen sich keine signifikanten Unterschiede hinsichtlich der Diffusionskoeffizient von 2A, der ko-exprimierten oder forciert dimerisierten Rezeptoren 2A/2B. Der Diffusionskoeffizient des Rezeptors 2B ist signifikant größer. 2) AUC des Signals der entsprechenden Rezeptoren nach Stimulation mit 5-HT, TCB-2 (Agonist 2A) bzw. BW723c86 Hydrochlorid (Agonist 2B). Während sich nach 5-HT- und TCB-2-Stimulation kein signifikanter Unterschied in der Signalgebung der einfach koexprimierten bzw. forciert dimerisierten Rezeptoren zeigt, liegt das Signal der forciert dimerisierten Rezeptoren nach BW723c86-Hydrochlorid-Stimulation signifikant höher als das der ko-exprimierten Rezeptoren.

\subsubsection{Dimerisierung 2A und 2B}

Bei der Betrachtung der Diffusionskoeffizienten der Rezeptoren 2A, 2B, der ko-exprimierten und forciert dimerisierten Rezeptoren 2A/2B zeigt sich, dass weder der Diffusionskoeffizient der ko-exprimierten Rezeptoren 2A/2B $\left(\mathrm{D}_{2 \mathrm{~A} / 2 \mathrm{~B}}=0,0081 \pm 0,0030 \mu \mathrm{m}^{2} / \mathrm{s}, \mathrm{n}=22\right)$ noch der Dif-

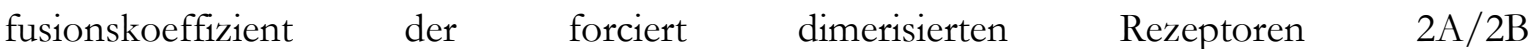


$\left(\mathrm{D}_{2 \mathrm{~A} / 2 \mathrm{~B} \text { forc. }}=0,0073 \pm 0,0020 \mathrm{\mu m}^{2} / \mathrm{s}, \mathrm{n}=21\right)$ signifikant von dem Diffusionskoeffizienten des Rezeptors $2 \mathrm{~A}\left(\mathrm{D}_{2 \mathrm{~A}}=0,0065 \pm 0,0029 \mathrm{\mu m}^{2} / \mathrm{s}, \mathrm{n}=17\right)$ abweichen. Auch im Vergleich der ko-exprimierten Rezeptoren mit den forciert dimerisierten Rezeptoren zeigte sich kein signifikanter Unterschied. Es fällt jedoch auf, dass der Diffusionskoeffizient des Rezeptors 2B $\left(\mathrm{D}_{2 \mathrm{~B}}=0,0110 \pm 0,0030 \mathrm{\mu m}^{2} / \mathrm{s}, \mathrm{n}=13\right)$ signifikant größer ausfällt als der Diffusionskoeffizient von 2A und der Diffusionskoeffizient der ko-exprimierten bzw. forciert dimerisierten Rezeptoren (siehe Abbildung $22 \mathrm{~A}$ ).

\subsubsection{Signalgebung $2 \mathrm{~A}$ und $2 \mathrm{~B}$}

Nach Stimulation mit 5-HT und TCB-2 (Agonist 2A) zeigen sich zwischen den ko-exprimierten und den forciert dimerisierten Rezeptoren 2A/2B keine signifikanten Unterschiede.

Die Stimulation mit BW723c86 Hydrochlorid (Agonist 2B) hingegen löst an den koexprimierten Rezeptoren ein deutlich geringeres Signal aus als an den forciert dimerisierten Rezeptoren $\left(\mathrm{AUC}_{2 \mathrm{~A} / 2 \mathrm{~B}}=275 \pm 97\right.$ a. E., $\mathrm{n}=17, \quad \mathrm{AUC}_{2 \mathrm{~A} / 2 \mathrm{~B} \text { forc. }}=424 \pm 108$ a. E., $\left.\mathrm{n}=23\right)$ (Abbildung 22 C). Die Signalkurven sind in Abbildung 23 dargestellt.

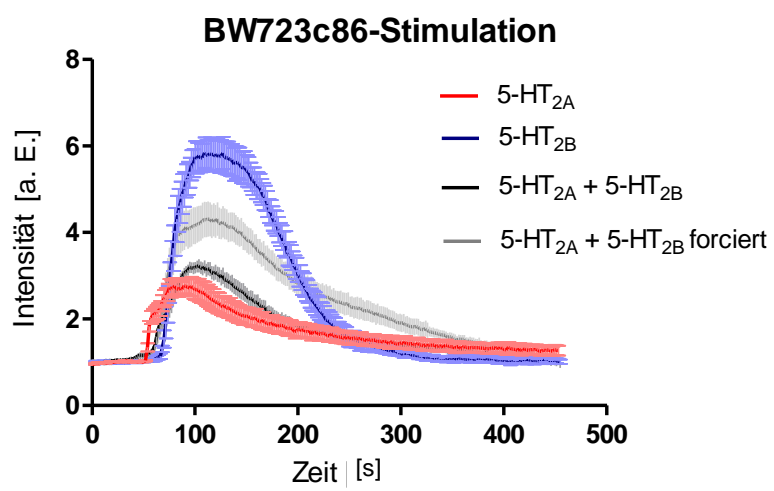

Abbildung 23: $\mathrm{Ca}^{2+}$-Signal der Rezeptoren 2A/2B im nicht forcierten und forciert dimerisierten Zustand nach Stimulation mit BW723c86 Hydrochlorid. Das Signal der nicht forciert dimerisierten Rezeptoren ( $\mathrm{n}=17$ ) ist schwarz dargestellt, das der forciert-dimerisierten $(\mathrm{n}=23)$ grau, das des Rezeptors $2 \mathrm{~A}$ $(\mathrm{n}=22)$ rot und das des Rezeptors $2 \mathrm{~B}(\mathrm{n}=18)$ blau. Die Standardabweichung ist als hellerer senkrechter Balken dargestellt. Es zeigen sich ähnliche Kurvenverläufe, wobei die Kurve der forciert dimerisierten Rezeptoren konstant über der Kurve der ko-exprimierten Rezeptoren liegt. Die AUC zwischen 35 s und $350 \mathrm{~s}$ wurde verglichen.

In der Betrachtung der Signalkurven zeigen sich für die ko-exprimierten und forciert dimerisierten Rezeptoren 2A/2B nach Stimulation mit BW723c86 Hydrochlorid ähnliche Kurvenverläufe, wobei die Kurve des forcierten Dimers eine höhere Amplitude, also eine höhere Geschwindigkeit der $\mathrm{Ca}^{2+}$-Freisetzung erreicht (Amplitude 2A/2B: 3,23 a. E.; Amplitude 2A/2B $\mathrm{B}_{\text {forc }}$ : 4,31 a. E.) und damit auch eine größere Gesamtmenge an $\mathrm{Ca}^{2+}$ freisetzt. 
3.6.1.3 Zusammenfassung Heterodimer 5- $\mathrm{HT}_{2 \mathrm{~A} / 2 \mathrm{~B}}$

Die Diffusionskoeffizienten sowohl der ko-exprimierten Rezeptoren als auch der forciert dimerisierten Rezeptoren liegen signifikant niedriger als der Diffusionskoeffizient von 2B, während sie von dem Diffusionskoeffizienten von 2A nicht signifikant abweichen.

In der Stimulation mit dem 2B-Agonisten BW723c86 Hydrochlorid fällt das $\mathrm{Ca}^{2+}$-Signal der forciert dimerisierten Rezeptoren stärker aus als das der ko-exprimierten Rezeptoren.

Zusammengefasst sprechen die Daten für eine Heterodimerbildung der Rezeptoren 2A/2B, was in Kapitel 4.3.2.1 diskutiert wird. 


\subsubsection{5-HT $\mathrm{T}_{2 \mathrm{~A}}$ und $5-\mathrm{HT}_{2 \mathrm{C}}$}

\section{1) Diffusionskoeffizient}

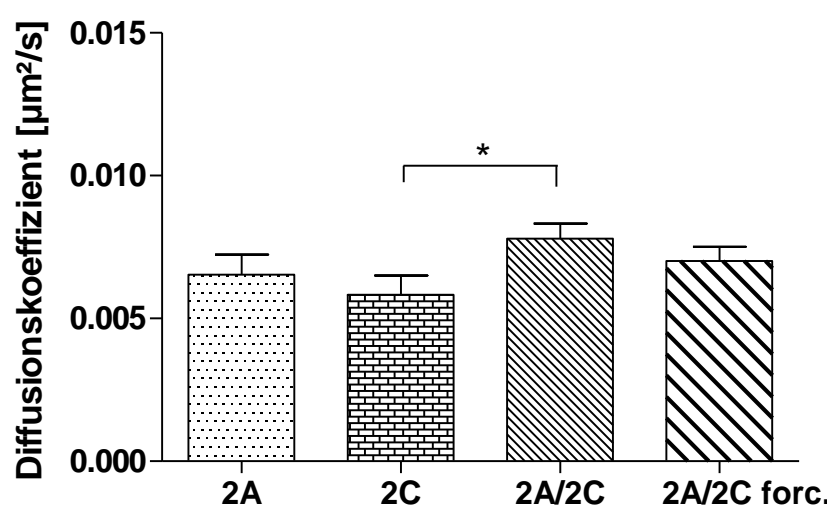

2)

Signalgebung

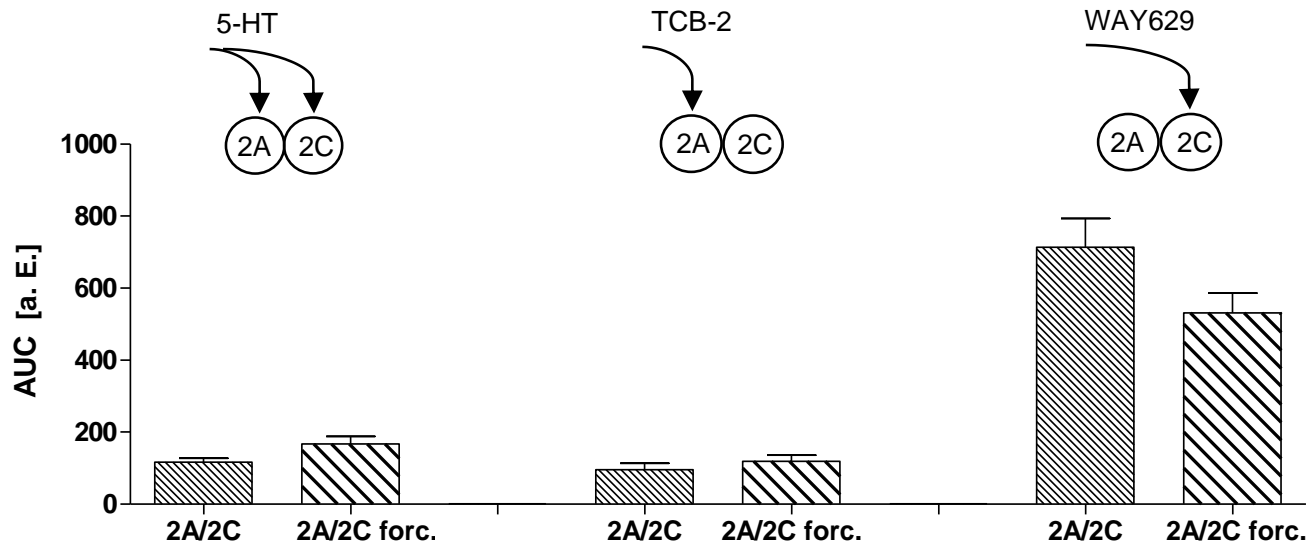

Abbildung 24: Die Diffusionskoeffizienten und Signalkurven der Rezeptoren 2A/2C. 1) Diffusionskoeffizienten der allein exprimierten Rezeptoren 2A, 2C, der ko-exprimierten $2 \mathrm{~A} / 2 \mathrm{C}$ und der forciert dimerisierten Rezeptoren 2A/2C. Es zeigen sich relativ ähnliche Werte. Lediglich der Diffusionskoeffizient der ko-exprimierten Rezeptoren ist etwas größer und weicht damit signifikant von Diffusionskoeffizient des Rezeptors $2 \mathrm{C}$ ab. 2) AUC des Signals der entsprechenden Rezeptoren nach Stimulation mit 5-HT, TCB-2 (Agonist 2A) und WAY629 Hydrochlorid (Agonist 2C). Die Signale der ko-exprimierten bzw forciert dimerisierten Rezeptoren weichen in keiner der Stimulationen signifikant voneinander ab.

\subsubsection{Dimerisierung 2A und 2C}

In der Analyse der Diffusionskoeffizienten der Rezeptoren 2A, 2C, der ko-exprimierten Rezeptoren $2 \mathrm{~A} / 2 \mathrm{C}$ und der forciert dimerisierten Rezeptoren $2 \mathrm{~A} / 2 \mathrm{C}$ zeigen sich relativ ähnliche Werte. Lediglich zwischen dem Diffusionskoeffizienten der ko-exprimierten Rezeptoren $2 \mathrm{~A} / 2 \mathrm{C}\left(\left(\mathrm{D}_{2 \mathrm{~A} / 2 \mathrm{C}}=0,0078 \pm 0,002 \mathrm{\mu m}^{2} / \mathrm{s}, \mathrm{n}=16\right)\right.$ und dem Diffusionskoeffizienten des einzeln 
exprimierten Rezeptors $2 \mathrm{C}\left(\mathrm{D}_{2 \mathrm{C}}=0,0055 \pm 0,0027 \mu \mathrm{m}^{2} / \mathrm{s}, \mathrm{n}=17\right)$ ergibt sich eine signifikante Abweichung. $\mathrm{D}_{2 \mathrm{~A} / 2 \mathrm{C}}$ ist signifikant größer als $\mathrm{D}_{2 \mathrm{C}}$ (siehe Abbildung 24 (1)).

\subsubsection{Signalgebung $2 \mathrm{~A}$ und $2 \mathrm{C}$}

Die Auswertung der Signalgebung zeigt, dass die Signale der ko-exprimierten bzw. forciert dimerisierten Rezeptoren 2A und 2C weder in der Stimulation mit 5-HT noch TCB-2 (Agonist 2A) oder WAY629 Hydrochlorid (Agonist 2C) signifikant voneinander abweichen.

Interessant ist jedoch der Vergleich mit der Signalgebung der einzelnen Rezeptoren 2A und 2C.

Die Stimulation mit dem Agonisten TCB-2 (Agonist 2A) löst sowohl für die ko-exprimierten als auch für die forciert-dimerisierten Rezeptoren 2A/2C ein im Vergleich zu dem einfach exprimierten $2 \mathrm{~A} \quad$ sehr geringes Signal aus $\left(\mathrm{AUC}_{2 \mathrm{~A}}=352 \pm 116 \mathrm{a} . \mathrm{E}, \mathrm{n}=11\right.$; $\mathrm{AUC}_{2 \mathrm{C}}=130 \pm 44$ a. E, $\quad \mathrm{n}=8 ; \quad \quad \mathrm{AUC}_{2 \mathrm{~A} / 2 \mathrm{C}}=96 \pm 63$ a. E., $\quad \mathrm{n}=13 ;$ $\mathrm{AUC}_{2 \mathrm{~A} / 2 \mathrm{C} \text { forc. }}=120 \pm 64$ a. E., $\mathrm{n}=14$; siehe Abbildung 25).

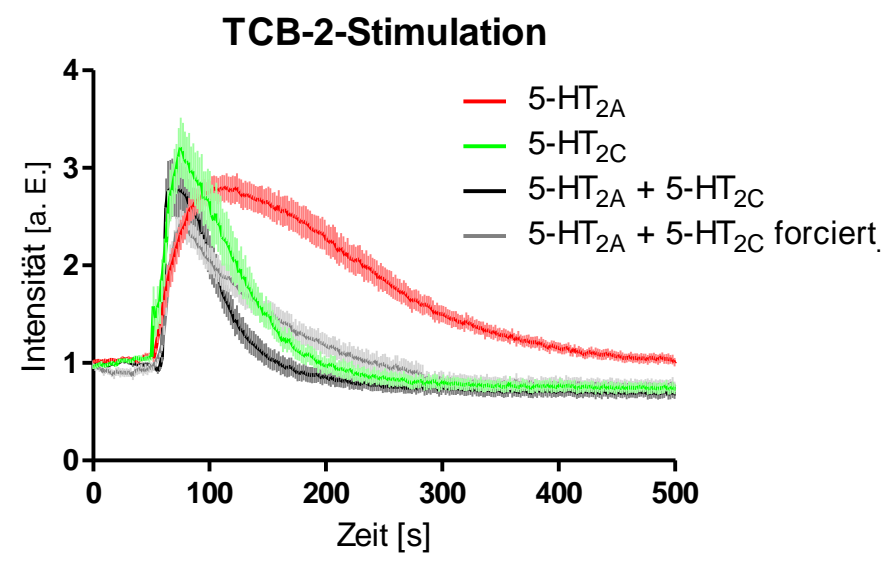

Abbildung 25: $\mathrm{Ca}^{2+}$-Signal der Rezeptoren 2A/2C im nicht forcierten und forciert dimerisierten Zustand nach Stimulation mit TCB-2. Die nicht forciert dimerisierten Rezeptoren ( $\mathrm{n}=11$ ) werden durch eine schwarze Linie und die forciert dimerisierten Rezeptoren $(n=8)$ durch eine graue Linie gezeigt. Der einfache Rezeptor $2 \mathrm{~A}$ in rot $(\mathrm{n}=13)$ und Rezeptor $2 \mathrm{C}$ in grün $(\mathrm{n}=9)$. Die Standardabwechung ist als hellerer senkrechter Balken dargestellt. Während die Signale des Rezeptors 2C und der ko-exprimierten bzw. forciert dimerisierten Rezeptoren 2A/2C eine sehr ähnliche Kinetik zeigen, fällt das Signal des Rezeptors 2A deutlich langsamer ab, sodass sich eine größere freigesetzte $\mathrm{Ca}^{2+}$-Menge (AUC) ergibt. Die AUC zwischen 35 s und 350 s wurde verglichen.

Der Vergleich der $\mathrm{Ca}^{2+}$-Kurven nach der Stimulation mit TCB-2 (Abbildung 25) zeigt sehr ähnliche Amplituden der Signale. Jedoch fällt die Kurve des Rezeptors 2A deutlich langsamer ab als die Kurven der Signale von 2C und der Rezeptorkombinationen, sodass sich für 2A eine deutlich größere freigesetzte $\mathrm{Ca}^{2+}$-Menge ergibt. Das Signal der ko-exprimierten Rezeptoren ähnelt sehr stark dem des Rezeptors 2C, während das Signal der forciert dimerisierten 
Rezeptoren ein etwas flacher abfallendes Signal und somit eine vergleichsweise größere Ähnlichkeit zu der Signalkurve des Rezeptors 2A zeigt als die ko-exprimierten Rezeptoren.

In der Stimulation mit WAY629 Hydrochlorid (Agonist 2C) zeigen die ko-exprimierten und die forciert-dimerisierten Rezeptoren 2A/2C ein starkes Signal, welches ähnlich hoch ausfällt wie das des Rezeptors 2C. An 2A wurde nur ein schwaches Signal ausgelöst $\left(\mathrm{AUC}_{2 \mathrm{~A}}=121 \pm 72\right.$ a. E, $\mathrm{n}=18 ; \mathrm{AUC}_{2 \mathrm{C}}=671 \pm 229$ a. $\mathrm{E}, \mathrm{n}=15 ; \mathrm{AUC}_{2 \mathrm{~A} / 2 \mathrm{C}}=713 \pm 278$ a. E., $\mathrm{n}=12, \mathrm{AUC}_{2 \mathrm{~A} / 2 \mathrm{C} \text { forc. }}=532 \pm 197$ a. E., $\mathrm{n}=13$; siehe Abbildung 28).

\section{WAY629-Stimulation}

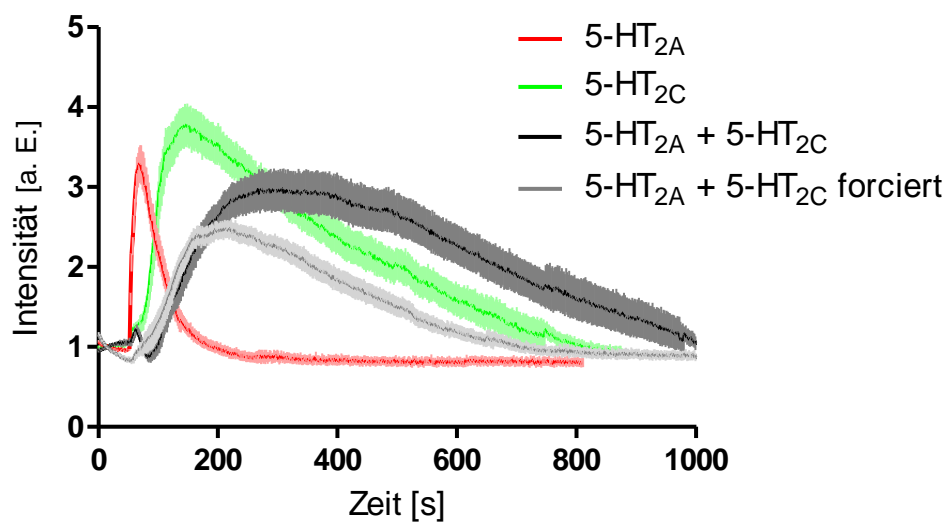

Abbildung 26: $\mathrm{Ca}^{2+}$-Signal der Rezeptoren 2A/2C im nicht forcierten und forciert dimerisierten Zustand nach Stimulation mit WAY629 Hydrochlorid. 2A ist rot dargestellt ( $\mathrm{n}=18), 2 \mathrm{C}$ grün ( $\mathrm{n}=15)$, die nicht forciert dimerisierten Rezeptoren $(n=12)$ schwarz und die forciert dimerisierten Rezeptoren $(n=13)$ grau. Die 2A-Kurve ist durch einen schnellen Anstieg und Abfall gekennzeichnet. Der Abfall des $\mathrm{Ca}^{2+}$ ist in der Signalkurve des Rezeptors 2C und der ko-exprimierten bzw. forciert dimerisierten 2A/2C deutlich flacher. Für die ko-exprimierten und forciert dimerisierten Rezeptoren zeigt sich eine sehr ähnliche Kinetik, wobei das Signal der ko-exprimierten Rezeptoren eine größere AUC aufweist. Die AUC zwischen $35 \mathrm{~s}$ und $350 \mathrm{~s}$ wurde verglichen.

In der Betrachtung der Signalkurven (siehe Abbildung 26) ist das Signal des Rezeptors 2A durch einen steilen Anstieg und Abfall gekennzeichnet. Es wird nur eine geringe $\mathrm{Ca}^{2+}$-Menge freigesetzt, während sowohl Anstieg als auch Abfall bei den ko-exprimierten und forciert dimerisierten $2 \mathrm{~A} / 2 \mathrm{C}$ deutlich flacher verlaufen. Auch der Abfall des Rezeptors 2C fällt sehr flach aus, sodass insgesamt viel $\mathrm{Ca}^{2+}$ freigesetzt wird und sich dementsprechend eine große AUC ergibt.

\subsubsection{Zusammenfassung Heterodimer $5-\mathrm{HT}_{2 \mathrm{~A} / 2 \mathrm{C}}$}

Die Diffusionskoeffizienten der ko-exprimierten und forciert dimerisierten Rezeptoren sind in etwa so groß wie die der einzeln exprimierten Rezeptoren 2A und 2C. Lediglich zwischen dem Diffusionskoeffizienten der ko-exprimierten Rezeptoren und dem Diffusionskoeffizienten von 
2C ergibt sich eine leicht signifikante Abweichung, da der Diffusionskoeffizient der ko-exprimierten Rezeptoren etwas größer ist.

In der Analyse der Signalgebung fällt besonders die Agonisten-Stimulation auf. Wird mit dem Agonisten für den Rezeptor 2A, TCB-2, stimuliert, so fallen die Signale des Rezeptors 2C sowie der ko-exprimierten als auch der forciert dimerisierten Rezeptoren $2 \mathrm{~A} / 2 \mathrm{C}$ deutlich geringer aus als das des Rezeptors 2A. Dies ist insbesondere durch den flacheren Abfall der $\mathrm{Ca}^{2+}$-Signalkurve des Rezeptors $2 \mathrm{~A}$ und die dadurch erhöhte freigesetzte $\mathrm{Ca}^{2+}$-Menge zu begründen.

Wird mit dem Agonisten für den Rezeptor 2C, WAY629 Hydrochlorid, stimuliert, so zeigt sich ein direkt umgekehrtes Bild. Die Signale des Rezeptors 2C, der ko-exprimierten und der forciert heterodimerisierten Rezeptoren 2A/2C zeigen ein starkes Signal und fallen wieder sehr ähnlich aus. Das Signal des Rezeptors 2A ist aufgrund eines schnellen Signalabfalls nach Erreichen des Peaks deutlich geringer.

Zusammengefasst deuten die Daten auf eine Heterodimerbildung der Rezeptoren 2A/2C, wobei sich das Signal des Rezeptors 2C im Dimer dominant gegenüber dem des Rezeptors 2A zeigt. Dies wird in Kapitel 4.3.2.2 diskutiert. 


\subsubsection{5-H $\mathrm{T}_{2 \mathrm{~B}}$ und $5-\mathrm{HT}_{2 \mathrm{C}}$}

1) Diffusionskoeffizient

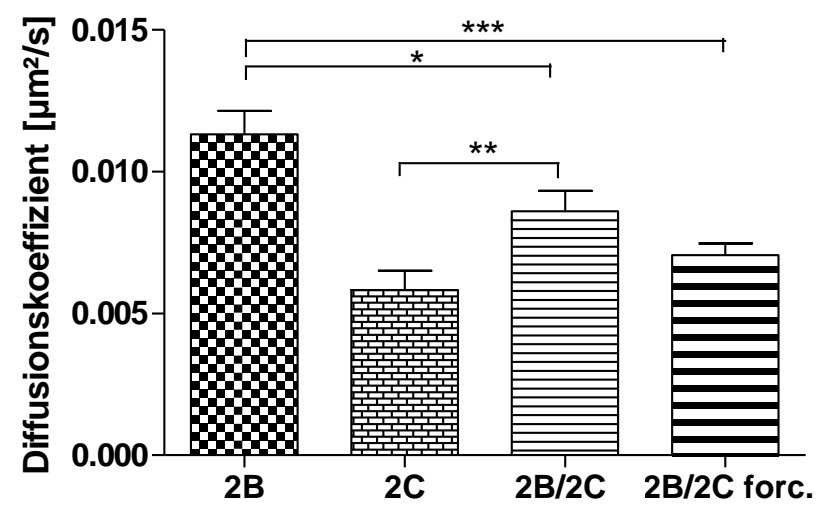

2)

Signalgebung

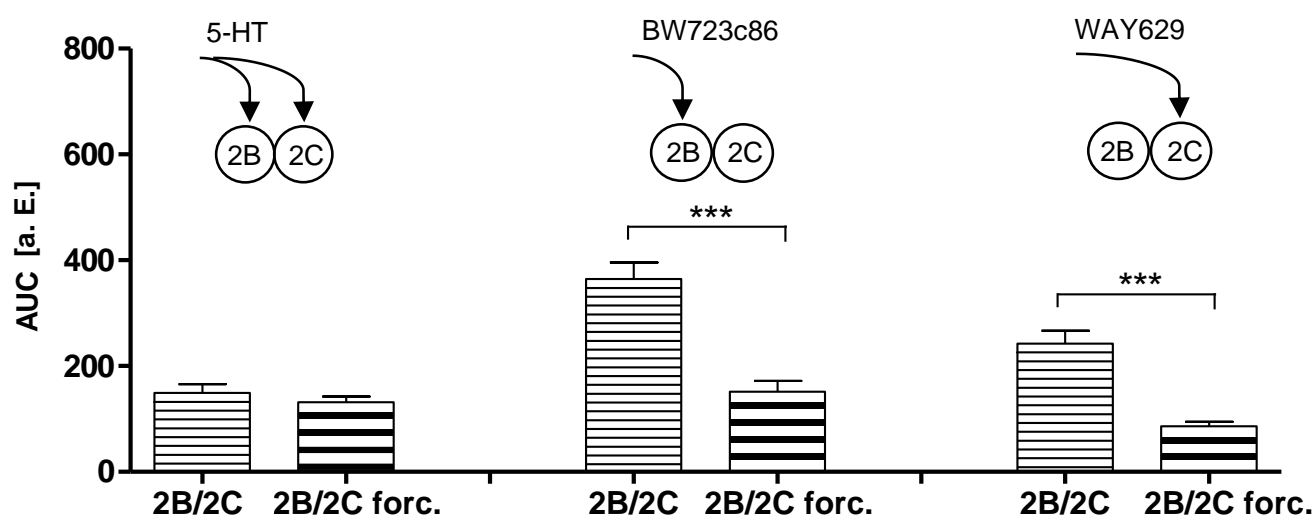

Abbildung 27: Die Diffusionskoeffizienten und Signalkurven der Rezeptoren 2B/2C. 1) Diffusionskoeffizienten der allein exprimierten Rezeptoren 2B, 2C, der ko-exprimierten Rezeptoren 2B/2C und der forciert dimerisierten Rezeptoren 2B/2C. Der Diffusionskoeffizient der ko-exprimierten Rezeptoren liegt genau zwischen den Diffusionskoeffizienten der einzelnen Rezeptoren, wobei er signifikant kleiner als $\mathrm{D}_{2 \mathrm{~B}}$ und signifikant größer als $\mathrm{D}_{2 \mathrm{C}}$ ist. Der Diffusionskoeffizient der forciert dimerisierten Rezeptoren ist geringer und weicht damit nur von $\mathrm{D}_{2 \mathrm{~B}}$ stark signifikant ab. 2) AUC des Signals der entsprechenden Rezeptoren nach Stimulation mit 5-HT, BW723c86 Hydochlorid (Agonist 2B) bzw. WAY629 Hydrochlorid (Agonist 2C). In den Stimulationen mit den Rezeptoragonisten zeigt sich ein deutliches Signal für die ko-exprimierten Rezeptoren, wobei das der forciert dimerisierten Rezeptoren konstant signifikant geringer ausfällt.

\subsubsection{Dimerisierung 2B und 2C}

Bei der Auswertung der Diffusionskoeffizienten der einfach exprimierten Rezeptoren 2B, 2C, der ko-exprimierten und der forciert dimerisierten Rezeptoren $2 \mathrm{~B} / 2 \mathrm{C}$ zeigt sich, dass sowohl der Diffusionskoeffizient der ko-exprimierten Rezeptoren 2B/2C 
$\left(\mathrm{D}_{2 \mathrm{~B} / 2 \mathrm{C}}=0,0086 \pm 0,0029 \mathrm{\mu m}^{2} / \mathrm{s}, \mathrm{n}=16\right)$ als auch der Diffusionskoeffizient der forciert heterodimerisierten Rezeptoren $\left(\mathrm{D}_{2 \mathrm{~B} / 2 \mathrm{C} \text { forc. }}=0,0070 \pm 0,001 \mathrm{\mu m}^{2} / \mathrm{s}, \quad \mathrm{n}=20\right) \quad$ zwischen den

Diffusionskoeffizienten der einzeln exprimierten Rezeptoren $2 \mathrm{~B}$ und $2 \mathrm{C}$ $\left(\mathrm{D}_{2 \mathrm{~B}}=0,0110 \pm 0,003 \mathrm{\mu m}^{2} / \mathrm{s}, \mathrm{n}=13 ; \mathrm{D}_{2 \mathrm{C}}=0,0055 \pm 0,0027 \mu \mathrm{m}^{2} / \mathrm{s}, \mathrm{n}=16\right)$ liegen. $\mathrm{D}_{2 \mathrm{~B} / 2 \mathrm{C}}$ und $\mathrm{D}_{2 \mathrm{~B} / 2 \mathrm{C} \text { forc }}$ sind dabei signifikant kleiner als $\mathrm{D}_{2 \mathrm{~B}}$. $\mathrm{D}_{2 \mathrm{~B} / 2 \mathrm{C}}$ ist außerdem signifikant größer als $\mathrm{D}_{2 \mathrm{C}}$. Dies ist bei dem forcierten Dimer $\mathrm{D}_{2 \mathrm{~B} / 2 \mathrm{C} \text { forc }}$ nicht der Fall (siehe Abbildung 27 (1)).

\subsubsection{Signalgebung $2 \mathrm{~B}$ und $2 \mathrm{C}$}

In der 5-HT-Stimulation zeigt sich für die die ko-exprimierten Rezeptoren 2B/2C ein Signal von $\mathrm{AUC}_{2 \mathrm{~B} / 2 \mathrm{C}}=149 \pm 59$ a. E. $(\mathrm{n}=13)$. Das Signal der forciert dimerisierten $2 \mathrm{~B} / 2 \mathrm{C}$ ist nicht signifikant anders $\left(\mathrm{AUC}_{2 \mathrm{~B} / 2 \mathrm{C} \text { forc. }}=132 \pm 43\right.$ a. $\left.\mathrm{E} ., \mathrm{n}=16\right)$.

In der Stimulation mit BW723c86 Hydrochlorid zeigt sich hingegen ein signifikant stärkeres Signal der ko-exprimierten Rezeptoren 2B/2C im Vergleich zu den forcierten Dimeren (BW723c86 Hydrochlorid: $\mathrm{AUC}_{2 \mathrm{~B} / 2 \mathrm{C}}=364 \pm 122$ a. E., $\mathrm{n}=15, \mathrm{AUC}_{2 \mathrm{~B} / 2 \mathrm{C} \text { forc. }}=151 \pm 75$ a. E., $\mathrm{n}=14$ ) (siehe Abbildung 27 (2)). Die Reaktionskurven sind in Abbildung 28 dargestellt. Die Amplitude der ko-exprimierten Rezeptoren fällt deutlich höher aus als die der forciert dimerisierten Rezeptoren.

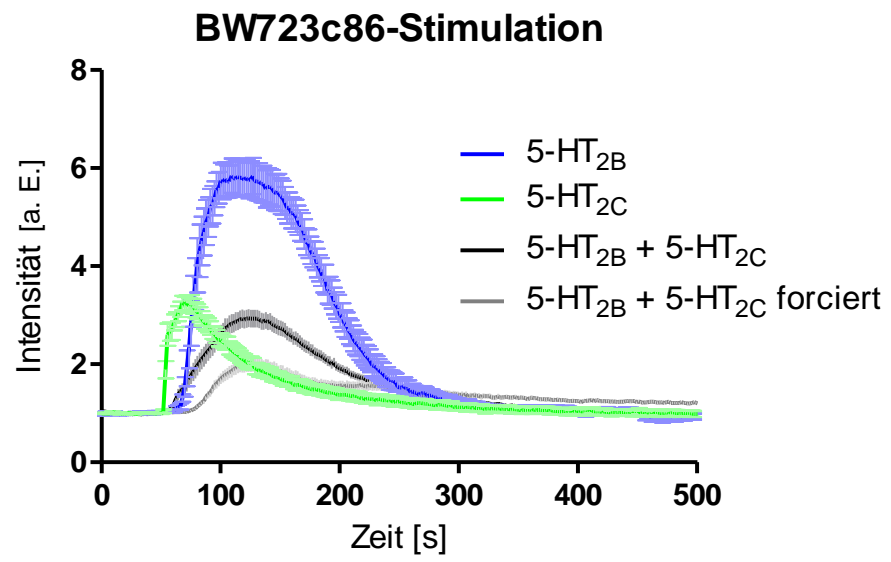

Abbildung 28: $\mathrm{Ca}^{2+}$-Signal der Rezeptoren 2B/2C im nicht forcierten und forciert dimerisierten Zustand nach Stimulation mit BW723c86 Hydrochlorid. Das Signal der nicht forciert dimerisierten Rezeptoren $(n=15)$ ist durch eine schwarze Linie dargestellt, das der forciert dimerisierten $(n=14)$ durch eine graue Linie, das des Rezeptors Rezeptors 2B ( $\mathrm{n}=18)$ blau und 2C $(\mathrm{n}=28)$ grün. Die Standardabweichung ist als hellerer senkrechter Balken dargestellt. Die Amplitude der nicht forcierten Rezeptoren fällt deutlich höher aus als die der forciert dimerisierten Rezeptoren. Die AUC zwischen 35 s und $350 \mathrm{~s}$ wurde verglichen.

Auch in der Stimulation mit WAY629 Hydrochlorid ergibt sich ein deutlich stärkeres Signal der ko-exprimierten Rezeptoren im Vergleich zu den forciert dimerisierten Rezeptoren 
$\left(\mathrm{AUC}_{2 \mathrm{~B} / 2 \mathrm{C}}=242 \pm 123\right.$ a. E., $\mathrm{n}=24, \mathrm{AUC}_{2 \mathrm{~B} / 2 \mathrm{C} \text { forc. }}=86 \pm 38$ a. E., $\left.\mathrm{n}=21\right)$. Die Reaktionskurven sind in Abbildung 29 dargestellt. Es zeigt sich, dass sowohl der Anstieg als auch der Abfall des Signals der ko-exprimierten Rezeptoren deutlich flacher ausfallen als bei der Signalkurve der forciert dimerisierten Rezeptoren, sodass sich insgesamt für die ko-exprimierten Rezeptoren eine größere AUC und damit eine größere Menge an freigesetztem $\mathrm{Ca}^{2+}$ ergeben.

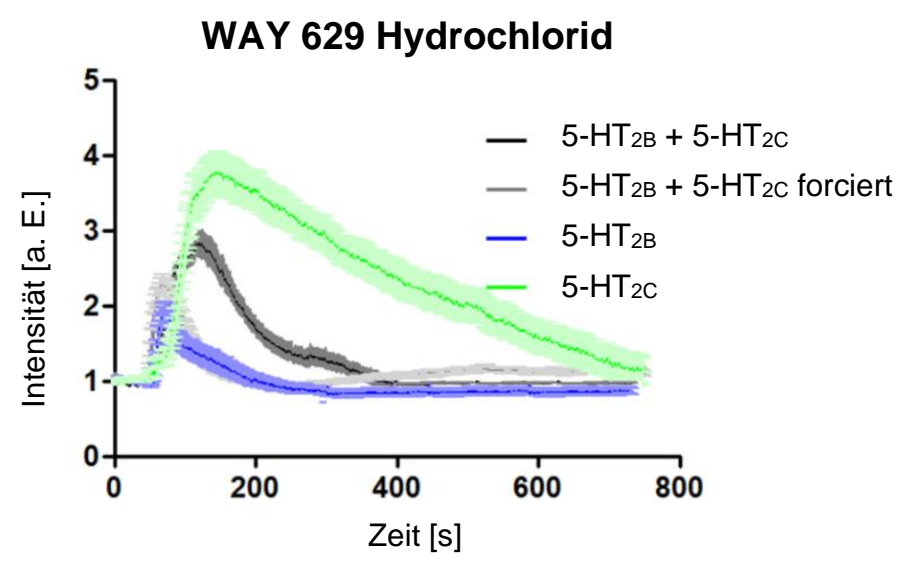

Abbildung 29: $\mathrm{Ca}^{2+}$-Signal der Rezeptoren 2B/2C im nicht forcierten und forciert dimerisierten Zustand nach Stimulation mit WAY629 Hydrochlorid. Das Signal der nicht forciert dimerisierten Rezeptoren $(\mathrm{n}=24)$ ist durch eine schwarze Linie dargestellt, das der forciert dimerisierten $(\mathrm{n}=21)$ durch eine graue Linie, das des Rezeptors Rezeptors 2B $(n=22)$ blau und 2C ( $n=15)$ grün. Die Standardabweichung ist als hellerer senkrechter Balken dargestellt. Die AUC zwischen $35 \mathrm{~s}$ und $350 \mathrm{~s}$ wurde verglichen. Der Signalanstieg und -abfall der ko-exprimierten Rezeptoren fallen flacher aus als am Signal der forcierten Rezeptoren, sodass sich einer größere AUC ergibt.

\subsubsection{Zusammenfassung Heterodimer 5- $\mathrm{HT}_{2 \mathrm{~B} / 2 \mathrm{C}}$}

Die Diffusionskoeffizienten der ko-exprimierten und forciert dimerisierten Rezeptoren sind nicht signifikant unterschiedlich und liegen zwischen denen der einzeln exprimierten Rezeptoren $2 \mathrm{~B}$ und $2 \mathrm{C}$.

In der Signalgebung ist auffällig, dass sowohl in der Agonisten-Stimulationen mit BW723c86 Hydrochlorid (Agonist 2B) als auch mit WAY629 Hydrochlorid (Agonist 2C) das Signal der forciert dimerisierten Rezeptoren deutlich unter dem der ko-exprimierten Rezeptoren liegt.

In Zusammenschau der Daten bzgl. der Diffusionskoeffizienten und der Unterschiede in der Signalgebung der Agonisten-Stimulation sprechen die vorliegenden Zahlen gegen eine Heterodimerisierung der Rezeptoren 2B/2C. Dies wird in Kapitel 4.3.2.3 ausführlich diskutiert. 


\section{$4 \quad$ Diskussion und Ausblick}

Nachdem lange angenommen wurde, dass GPCRs als einzelne Einheiten funktionieren, ist heute für viele der GPCRs bekannt, dass sie sowohl als Monomere als auch als Dimere oder Oligomere funktionieren (Pellissier et al. 2011), wobei die Dimer- bzw. Oligomerbildung noch nicht an allen GPCRs untersucht wurde. Auch die Auswirkungen der Dimerbildung auf die Signalgebung der Rezeptoren wurde bislang nur an wenigen GPCRs untersucht. In der vorliegenden Arbeit wurde eine Untergruppe der GPCRs, die Gruppe der 5-HT2-Rezeptoren, hinsichtlich ihrer Dimerbildung und deren Auswirkungen auf die Signalgebung untersucht.

Die Rezeptordimerisierung und deren Auswirkungen auf die Signalgebung wurden in dieser Arbeit mithilfe eines neuen Verfahrens analysiert. Dabei wurden die Rezeptoren mit Hilfe eines Nanobody-GFP-Konstrukts (siehe Abbildung 5 B) in eine Dimerkonstellation gezwungen und darauffolgend stimuliert. Die Kombination der Daten aus der FRAP zur Analyse der Dimerbildung, dem $\mathrm{Ca}^{2+}$-Imaging zur Messung der Signalgebung und der forcierten Dimerisierung führte zu erweiterten Interpretationsmöglichkeiten der Ergebnisse.

Die Ergebnisse zeigen uns eindeutig, dass mit dem neuen Verfahren erfolgreich Dimere erzwungen werden können. In der Auswertung wurde außerdem deutlich, dass die 5- $\mathrm{HT}_{2 \mathrm{~A} / \mathrm{B} / \mathrm{C}^{-}}$ Rezeptoren untereinander sowohl Homo- als auch Heterodimere bilden und dass dies ihre Eigenschaften bezüglich der Signalgebung beeinflusst. Im Folgenden werden die Ergebnisse der verschiedenen Rezeptorkombinationen analysiert und in Tabelle 15 als Übersichtsdarstellung zusammengefasst.

\subsection{Rezeptorexpression}

Der Nachweis, dass bei einer Ko-Expression der Rezeptoren bei halbierter DNA-Menge tatsächlich auch die halbe Rezeptormenge je Rezeptor exprimiert wird, wurde mit Hilfe der Durchflusszytometrie erbracht.

Zum einen wurde der Rezeptor 2A mit steigender cDNA-Menge transfiziert und die exprimierte Rezeptormenge im Durchflusszytometer gemessen. Es ergab sich [mindestens] bis zu der Transfektion von $2 \mu \mathrm{g}$ cDNA 2A eine proportionale Zuordnung von der cDNA-Menge zu der exprimierten Rezeptormenge (siehe Abbildung 14).

In einem weiteren Versuch wurde die Menge exprimierter Rezeptoren nach der Transfektion mit (1) $1 \mu \mathrm{g} 2 \mathrm{~A}$ cDNA und (2) $0,5 \mu \mathrm{g} 2 \mathrm{~A}+0,5 \mu \mathrm{g} 2 \mathrm{~B} \mathrm{cDNA}$ gemessen. In beiden Fällen zeigte sich die gleiche Rezeptormenge auf der Zellmembran exprimiert (siehe Abbildung 15). Da vorab die Proportionalität der transfizierten 2A-cDNA zu der exprimierten Rezeptormenge dargestellt wurde, lässt dies den Rückschluss zu, dass Rezeptor $2 \mathrm{~A}$ und $2 \mathrm{~B}$ in gleichen Teilen auf der 
Zellmembran exprimiert werden. Würde $2 \mathrm{~B}$ geringer oder stärker exprimiert werden, müsste sich auch die gesamte Rezeptormenge ändern.

Da die 5-HT 2 -Rezeptoren sich sowohl bezüglich der DNA-Größe als auch der Molekülstruktur sehr ähnlich sind (siehe Kapitel 2.2.6), kann davon ausgegangen werden, dass sich diese Ergebnisse auch auf die Expression des Rezeptors 2C übertragen lassen.

Bei einer ungleichen Verteilung der Rezeptormenge hätte sich die Auswertung der Daten insgesamt deutlich komplexer und aufwendiger dargestellt.

\subsection{Kontrolle der Dimerisierung}

Die Neigung zur Dimerbildung ist zwischen den unterschiedlichen 5- $\mathrm{HT}_{2}$-Rezeptoren verschieden stark ausgeprägt. So liegt der Rezeptor 2B beispielsweise natürlicherweise größtenteils als Monomer vor und bildet nur wenige sehr dynamische Dimere (siehe Kapitel 4.3.1). Da sich die Frage nach der Signalgebung im Dimer stellt und das Signal dieser wenigen Dimere mit den in dieser Arbeit verwendeten Methoden nicht selektiv messbar ist, musste ein Konstrukt entwickelt werden, mit welchem die Rezeptoren in Dimere gezwungen werden können. Dies wurde mithilfe rezeptorgebundenen GFPs bzw. rezeptorgebundener Anti-GFP-Nanobodys erreicht (siehe Kapitel 2.2.1).

Durch die Möglichkeit so auch die sehr dynamischen fakultativen Dimere in ein konstitutives Dimer zu zwingen, sodass die Rezeptoren größtenteils als Dimer vorliegen, konnten jedwede Einflüsse der Dimerisierung auf das Signalverhalten verdeutlicht und ggf. gemessen werden.

Die Daten aus der FRAP zur Analyse der Diffusionskoeffizienten (D) zeigen, dass die Verknüpfung der Rezeptoren mit Hilfe des GFP-Nanobody-Konstrukts erfolgreich war: Für sämtliche Kombinationen forcierter Dimere ergab sich ein D, der zwischen $0,0053^{\mu m^{2}} / \mathrm{s}$ und $0,0076 \mathrm{\mu m}^{2} / \mathrm{s}$ lag (vgl. bspw. Abbildung 19 (1)). Innerhalb der Diffusionskoeffizienten der forcierten Dimere ergaben sich keine signifikanten Abweichungen. Im Vergleich mit anderen Diffusionskoeffizienten wurde deutlich, dass die Forcierung der Dimere erfolgreich war, was sich besonders am Beispiel des Rezeptors 2B deutlich zeigt: Während sich für den einfach exprimierten Rezeptor 2B ein $\mathrm{D}_{2 \mathrm{~B}}$ von $0,0116^{\mu m^{2}} / \mathrm{s}$ ergab, lag der Diffusionskoeffizient des durch das Nanobody-GFPKonstrukt in Homodimere forcierten Rezeptors $2 \mathrm{~B}$ bei $\mathrm{D}_{2 \mathrm{~B} \text { forc. }} 0,005 \mathrm{\mu m}^{2} / \mathrm{s}$ und damit bei knapp der Hälfte des Diffusionskoeffizienten des einfach exprimierten Rezeptors. Für 2B hat sich auch im SPT gezeigt, dass der Rezeptor größtenteils als Monomer vorliegt. Es bilden sich lediglich sehr kurzzeitige, dynamische Dimere. Somit kann die Reduktion des Diffusionskoeffizienten, 
welche an den forcierten Homodimeren gezeigt wurde, durch eine effektive forcierte Dimerisierung erklärt werden.

Auch der Vergleich mit dem Diffusionskoeffizienten von 2C bestärkt die erfolgreiche forcierte Dimerisierung. Für 2C ist das Vorliegen von Homodimeren bereits nachgewiesen worden. Das simultane Vorliegen von Monomeren oder größeren Oligomeren hat sich nicht bestätigt, sodass $\mathrm{D}_{2 \mathrm{C}}$ als der Diffusionskoeffizient reiner Dimere angenommen werden kann (Herrick-Davis et al. 2004; Herrick-Davis et al. 2012). Wurde $D_{2 C}$ mit dem Diffusionskoeffizienten der forcierten Dimere verglichen, so zeigte sich in keinem Fall eine signifikante Abweichung, womit wir auch hinsichtlich der forcierten Dimere das Vorliegen reiner Dimere annehmen.

Auch die Transfektion der fluoreszenten Proteine CFP, GFP, YFP, RFP und des $\mathrm{Ca}^{2+}$-Sensors GCaMP6s in Zellen, welche einen Nanobody-gekoppelten Rezeptor exprimieren, zeigt in Abbildung 17 eindrücklich die Kopplung der Proteine an den Nanobody.

Ein großer Vorteil dieser neuen Methode der Dimer-Forcierung liegt darin, dass die Struktur des Rezeptors selbst nicht verändert wird, um das künstliche Dimer zu schaffen. Es muss lediglich ein Marker (GFP oder Nanobody) an den Rezeptor gekoppelt werden, welcher mit anderen Markern interagiert und so die Dimerisierung forciert.

Bei anderen Methoden der künstlichen Dimerisierung zeigten sich Probleme, weil die Rezeptorstruktur verändert wurde und die Rezeptoren selbst dadurch in ihrer Funktion eingeschränkt waren, sodass sie beispielsweise keine Signale mehr weiterleiteten. Dies ist z. B. bei der Methode des chemischen, cross linking beobachtet worden. Durch eine Behandlung mit $\mathrm{H}_{2} \mathrm{O}_{2}$ und den dadurch entstehenden oxidativen Stress bildeten sich intermolekulare Disulfidbrücken, wodurch die betrachteten Protein-Tyrosin-Phosphatase-Rezeptoren ihre Konformation veränderten und Dimere bildeten. Die aktiven Monomeren wurden durch die Disulfidbrücken zu Dimeren, welche jedoch inaktiv waren (Wijk et al. 2004). Durch den Einsatz von Reagenzien, welche ein chemisches, cross linking' bewirken, besteht immer die Gefahr der veränderten Stabilität und Denaturierung der Proteinstruktur (Byrne und Stites 1995).

Eine weitere Methode der künstlichen Dimerisierung stellt der Einsatz von dimeren Liganden dar, welche Rezeptoren durch ihre Bindung in eine Dimerformation bringen. Dies wurde beispielsweise für die FK506-bindenden Proteine erfolgreich angewendet. Dabei ist jedoch nicht sicher, ob die Liganden tatsächlich Monomere in eine Dimerkonstellation bringen oder vielmehr präexistente Dimere stabilisieren (Song et al. 2007). Bis dato existiert innerhalb der Gruppe der 5-HT $-\mathrm{T}_{2}$-Rezeptoren nur für den Homodimer des Rezeptors 2A ein dimerer Ligand. Dieser zeigt im Vergleich zu monomeren Liganden keine Auswirkungen auf die Signalgebung von 2A hinsichtlich einer Verstärkung oder Abschwächung des Signals (Herrick-Davis 2013). 
Dadurch dass die Rezeptoren durch all die vorab erwähnten Methoden in eine enge räumliche Nähe gebracht werden, wird ein mögliches Interaktionspotential gefördert. Bei der Auswertung der Daten muss jedoch besonders hinsichtlich der Veränderung in der Signalgebung berücksichtigt werden, dass die natürlichen Interaktionen nur gefördert und nicht forciert werden können. Gegebenenfalls ist die räumliche Nähe nicht ausreichend oder es sind andere Umgebungsund Stimulationsbedingungen nötig, damit die Rezeptoren interagieren.

\subsection{Dimerisierung und ihre Auswirkungen auf die Signalgebung}

Wenn im Folgenden die Rede davon ist, dass ein Rezeptor als Monomer oder Dimer vorliegt, so ist damit immer der größte Anteil des Rezeptors gemeint. Wird von Rezeptoren im Dimer gesprochen, so ist nicht ausgeschlossen, dass ein Teil auch als Monomer vorliegt. In der FRAP wird die Häufigkeitsverteilung in der vorliegenden Menge untersucht, sodass statistische Aussagen getroffen werden können, während einzelne Rezeptorproteine von dieser Aussage abweichen können.

Dies verdeutlich das SPT, welches am Rezeptor 2B durchgeführt wurde. Während die Daten aus der FRAP für das Vorliegen von Monomeren sprechen (siehe Kapitel 4.3.1), zeigt uns das SPT deutlich, dass durchaus Homodimere gebildet werden, auch wenn diese nur sehr dynamisch und kurzzeitig existieren. Dieses Ergebnis unterstreicht wie dynamisch eine Dimerisierung tatsächlich sein kann und dass anhand der FRAP keine absoluten Aussagen getroffen werden können. Dennoch wurden die weiteren Analysen der Dimerisierung mit der FRAP und nicht mit dem SPT durchgeführt. Der Hauptgrund dafür liegt vor allen Dingen darin, dass sich das SPT im Vergleich zu der FRAP weitaus aufwendiger in der Durchführung gestaltet.

Aufgrund des zeitlich stark begrenzten Rahmens dieser medizinischen Doktorarbeit wurde daher die Dimerisierung der Rezeptoren mit Hilfe der FRAP untersucht, welche durchaus valide Ergebnisse liefert. Die FRAP stellt eine unkomplizierte, ausreichend detaillierte und - im Vergleich zu anderen Methoden - zur Analyse des Diffusionskoeffizienten schnelle Methode dar. Das Kontrollexperiment, in welchem die FRAP an den Oberflächenproteinen CD28 und CD86 durchgeführt wurde (siehe Abbildung 18) zeigt deutlich, dass eine Differenzierung zwischen Dimeren und Monomeren möglich ist: CD28 liegt aufgrund von intermolekularen Disulfidbrücken als obligates Dimer vor (Linsley et al. 1995), während CD86 ein obligates Monomer darstellt (James et al. 2006). Beide Proteine besitzen eine Transmembrandomäne. Das Molekulargewicht von CD86 liegt über dem von CD28. Dennoch ergab sich in der FRAP für CD28 ein nur halb so großer Diffusionskoeffizient wie für CD86. Dies zeigt deutlich, dass mithilfe der FRAP zwischen Mono- und Oligomeren unterschieden werden kann (siehe 3.4.1). 
Für die FRAP war es nötig, Rezeptoren zu verwenden, welche an ein fluoreszentes Protein gekoppelt sind, das potenziell die Dimerbildung beeinträchtigen könnte. Die Auswertung der Daten hat jedoch gezeigt, dass eine Beeinträchtigung der Dimerisierung durch die gekoppelten Proteine unwahrscheinlich ist, da sich sowohl für 2A als auch $2 \mathrm{C}$ trotz der Kopplung an fluoreszente Proteine in der FRAP-Auswertung Werte ergeben haben, die für reine Homodimere sprechen. Auch muss bei der Anwendung der FRAP und ihrer Auswertung beachtet werden, dass immer nur ein Teil der Zellmembran gebleicht und ausgewertet wird. Die Existenz von sogenannten Mikrodomänen (,lipid rafts'), welche Sphingolipid-reiche Membrananteile mit einer besonderen Proteinzusammensetzung darstellen, und sich damit in ihrem Diffusionsverhalten von anderen Membrananteilen unterscheiden, wird nicht berücksichtigt (Mullineaux und Kirchhoff 2007; Simons und Sampaio 2011). Durch die Auswertung von im Schnitt n $=16$ Messwerten wird diese mögliche Verzerrung weitgehend ausgeglichen.

Die Signalgebung wurde mittels $\mathrm{Ca}^{2+}$-Imaging gemessen, also anhand der intrazellulären $\mathrm{Ca}^{2+}$ Menge nach Stimulation der GPCRs. Der $\mathrm{Ca}^{2+}$-Sensor GCaMP6s ermöglicht hierbei eine helle Fluoreszenz und sehr sensitive Messung der Veränderung der intrazellulären $\mathrm{Ca}^{2+}$-Menge (Chen et al. 2013)

Die Stimulation mit Rezeptoragonisten erlaubt weitergehende Einsichten, da sich auf diese Weise nur ein Monomer in einem Heterodimer selektiv stimulieren lässt. Dabei ist jedoch zu beachten, dass die Ergebnisse nicht direkt mit der Serotoninstimulation verglichen werden dürfen, da die Agonisten zum Teil ein anderes Signal und eine andersartige Kinetik der Signale im Vergleich zu Serotonin auslösen. Außerdem lösen die Agonisten, insbesondere der Agonist BW723c86 Hydrochlorid (Agonist 5- $\mathrm{HT}_{2 \mathrm{~B}}$ ), auch an den anderen 5- $\mathrm{HT}_{2}$-Rezeptoren Signale aus (siehe Abbildung 21), was in der Auswertung berücksichtigt werden muss. Für weitere Experimente mit den Agonisten wäre die Erstellung einer Reaktionskurve sinnvoll. So könnte die Reizschwelle des Zielrezeptors bestimmt werden und die Stimulation unterhalb der Reizschwelle für die nicht selektiv angesteuerten Rezeptoren durchgeführt werden. Da sich die Erstellung solcher Reaktionskurven jedoch sehr zeitintensiv gestaltet, wurde darauf in dieser Arbeit verzichtet.

Es sei erneut darauf hingewiesen, dass im Falle der Expression zweier verschiedener Rezeptoren nur die halbe Rezeptormenge des jeweiligen Rezeptors im Vergleich zur alleinigen Expression der Rezeptoren auf der Zelloberfläche vorliegt. Somit ergaben sich für die FRAP vergleichbare Ergebnisse, während bezüglich des $\mathrm{Ca}^{2+}$-Imagings beachtet werden muss, dass sich bei der halbierten Rezeptormenge auch das jeweilige Rezeptorsignal halbiert. Das effektive Signal ergibt sich aus der Addition der anteiligen Rezeptorsignale. 


\subsubsection{Interpretation der Ergebnisse hinsichtlich der Homodimerisierung und ihrer} Auswirkungen auf die Signalgebung

In der Auswertung der FRAP-Daten hinsichtlich der Homodimerisierung der Rezeptoren $5-\mathrm{HT}_{2 \mathrm{~A} / 2 \mathrm{~B} / 2 \mathrm{C}}$ ergaben sich deutlich unterschiedliche Diffusionskoeffizienten. Die Analyse der Ergebnisse zeigt, dass die Rezeptoren $2 \mathrm{~A}$ und $2 \mathrm{C}$ zur Homodimerbildung neigen, während 2B hauptsächlich im Monomer vorliegt. Die Daten aus dem $\mathrm{Ca}^{2+}$-Imaging unterstützen dies. Eine tabellarische Zusammenfassung ist in 4.3 .3 dargestellt.

\subsubsection{1 $5-\mathrm{HT}_{2 \mathrm{~A}}$}

Die vorliegenden Daten zeigen, dass der Rezeptor 2A als Homodimer vorliegt. Bereits von Brea et al. 2009 wurde anhand von FRET-Analysen und Immunopräzipitation die Dimerisierung untersucht, wobei Homodimere nachgewiesen werden konnten.

Der Diffusionskoeffizient ist dem der forcierten Dimere und dem des Rezeptors 2C, für welchen eine Dimerisierung bereits nachgewiesen wurde (Herrick-Davis et al. 2005), sehr ähnlich, sodass bereits aufgrund der hier erhobenen FRAP-Daten auf eine Homodimerisierung von 2A geschlossen werden kann.

Auch die Analyse der Signalgebung hinsichtlich des $\mathrm{Ca}^{2+}$-Signals spricht nicht gegen eine Homodimerisierung des Rezeptors 2A. Werden die 2A-Rezeptoren in ein Homodimer forciert, so unterscheidet sich die Signalgebung nicht von der des einfach exprimierten Rezeptors 2A. Sollte der Rezeptor physiologischerweise im Monomer vorliegen, könnte eine Forcierung der Dimerisierung eine Auswirkung auf das Signal haben.

Aufgrund der natürlichen Dimerbildung kann aus den vorliegenden Daten keine Aussage zu der Veränderung der Signalgebung im Dimer getroffen werden, da der Vergleichswert der Signalgebung im Monomer fehlt. Um zu testen ob die Rezeptoren nur im Dimer funktionieren oder im Monomer ein anderes Signal auslösen, müsste z. B. die Monomerisierung forciert werden. Wie dies möglich wäre, wird im Folgenden diskutiert.

Ein Ansatz zur Forcierung einer Monomerisierung von Rezeptoren liegt in der Beobachtung, dass beispielsweise der als Monomer vorliegende Corticotropin-releasing factor Rezeptor 2A $\left(\mathrm{CRF}_{2 \mathrm{~A}} \mathrm{R}\right)$ ein Pseudo-Signalpeptid enthält, welches seine Oligomerisierung verhindert. Signalpeptide werden in der Regel während der Rezeptorentwicklung abgespalten, jedoch verbleibt dieses Pseudo-Signalpeptid als hydrophobe Domäne am N-Terminus des GPCR und verhindert dort die Oligomerisierung der Rezeptoren (Teichmann et al. 2012). Ein Ansatz zur Forcierung der Monomerisierung wäre es somit, ein Pseudo-Signalpeptid oder andere Domänen an die Rezeptoren zu koppeln und so die Interaktion zur Oligomerisierung zu verhindern. 
In einer weiteren Studie, in welcher der Melanokortin-4-Rezeptor untersucht wurde, wurde die Rezeptordimerisierung erfolgreich durch Mutationen in den Transmembranhelices 3 und 4 sowie der intrazellulären Schleife 2 (intracellular loop 2, ICL2) verhindert und so die Monomerisierung erzwungen (Herrick-Davis et al. 2005).

Zusammenfassend zeigen die vorliegenden Studien verschiedene Möglichkeiten zur Forcierung der Monomerisierung, wobei hierfür die Koppelung weiterer Domänen oder das Einbringen von Mutationen notwendig ist, was sich aufgrund der notwendigen Vorarbeiten aufwendig gestaltet. Es wäre interessant in weiteren Arbeiten neue Ansätze zur Forcierung der Monomere zu evaluieren.

\subsubsection{2 $5-\mathrm{HT}_{2 \mathrm{~B}}$}

Der Rezeptor 2B liegt größtenteils als Monomer vor. Bei der Betrachtung des Diffusionskoeffizienten des Rezeptors 2B fällt auf, dass dieser fast doppelt so groß ist wie die Diffusionskoeffizienten der Rezeptoren 2A, 2C und der Diffusionskoeffizient des forciert dimerisierten Rezeptors 2B. Die Abweichung ist stark signifikant $(\mathrm{p} \leq 0,001)$. Aufgrund der negativen Korrelation des Diffusionskoeffizienten mit dem hydrodynamischen Durchmesser der diffundierenden Moleküle bedeutet dies einen deutlich geringeren hydrodynamischen Durchmesser und damit also beispielsweise das Vorliegen von Monomeren statt Dimeren.

Auch im SPT, welches für den 2B-Rezeptor durchgeführt wurde, zeigte sich, dass 2B hauptsächlich im Monomer vorliegt. Interessanterweise hat sich dennoch eine - wenn auch kurze und sehr dynamische - Dimerbildung der 2B-Rezeptoren gezeigt. So zeigt uns das SPT eindeutig, dass auch Rezeptoren, welche hauptsächlich und größtenteils im Monomer vorliegen, durchaus zu einer dynamischen Dimerisierung fähig sind. Diese Dimerbildung gezielt durch dimerspezifische Liganden zu stabilisieren und die Auswirkungen zu messen wäre ein interessanter weiterer Forschungsansatz (siehe Kapitel 4.1).

Da die Dimerisierung des Rezeptors 2B sehr dynamisch und kurzzeitig ist, beeinflusst sie den in der FRAP gemessenen Diffusionskoeffizienten kaum. Damit kann der Diffusionskoeffizient des Rezeptors 2B im weiteren Vergleich als Diffusionskoeffizient monomerer Rezeptoren gewertet werden.

Anhand der vorliegenden Ergebnisse wird erneut deutlich, dass die FRAP nur eine Übersicht über die breite Masse und eine Aussage über die Tendenz zur Mono- bzw. Dimerisierung erlaubt. Absolute Aussagen können nicht getroffen werden.

Auch die Signalgebung deutet darauf hin, dass der Rezeptor 2B physiologischerweise hauptsächlich als Monomer vorliegt. Im Vergleich des einfach exprimierten mit dem in ein 
Homodimer forcierten Rezeptor fällt das Signal des forciert dimerisierten Rezeptors signifikant geringer aus $(\mathrm{p} \leq 0,001)$ als das des einfach exprimierten. Ursächlich dafür könnte beispielsweise die schnellere Diffusionsgeschwindigkeit des Monomers und die damit vermehrte G-ProteinKopplung sein.

Betrachtet man die Signalkurven des forciert dimerisierten und einfach exprimierten Rezeptors 2B, so zeigt sich, dass die Kurve des einfach exprimierten Rezeptors nur einen minimal höheren Peak aufweist als die des forcierten Homodimers (siehe Abbildung 20). Auffällig ist, dass die Signalkurve des Monomers nur sehr langsam wieder absinkt und die Ausgangshelligkeit nicht wieder erreicht, wodurch die freigesetzte $\mathrm{Ca}^{2+}$-Menge (AUC) im Vergleich deutlich größer wird. Dies könnte dadurch begründet werden, dass die Stimulation an den monomeren 2B-Rezeptoren länger anhält. Jedoch muss auch die Möglichkeit einer Zellschädigung und damit ein Schaden der Rücktransporter des $\mathrm{Ca}^{2+}$ durch unphysiologisch hohe Serotonin-Konzentrationen in Betracht gezogen werden. $\mathrm{Ob}$ die größere $\mathrm{Ca}^{2+}$-Menge tatsächlich durch eine längere Aktivierung der Rezeptoren verursacht wird, sollte in weiteren Experimenten untersucht werden. Beispielsweise kann hierfür der intrazelluläre $\mathrm{IP}_{3}$-Spiegel des forcierten und nicht forciert dimerisierten $2 \mathrm{~B}$ nach Stimulation gemessen werden.

\subsubsection{5- $\mathrm{HT}_{2 \mathrm{C}}$}

Der Rezeptor 2C liegt im Homodimer vor. In den FRAP-Daten des 2C-Rezeptors zeigt sich, dass sich der $\mathrm{D}_{2 \mathrm{C}}$ nicht von dem Diffusionskoeffizienten der forcierten Dimere unterscheidet. Der $\mathrm{D}_{2 \mathrm{C}}$ ist außerdem deutlich kleiner als der $\mathrm{D}_{2 \mathrm{~B}}$, welcher das Vorliegen von hauptsächlich Monomeren widerspiegelt (siehe 4.3.1.2).

Auch in vorliegenden Studien wurde die Homodimerbildung des Rezeptors 2C bereits beschrieben (Herrick-Davis et al. 2005). Mittels fluorescence correlation spectroscopy (FCS)- und photon counting histogram (PCH)-Analysen konnte zusätzlich gezeigt werden, dass 2C nicht nur zur Homodimerisierung neigt, sondern ausschließlich in dieser Konformation vorliegt. Das simultane Vorliegen von Monomeren oder größeren Oligomeren bestätigte sich nicht (Herrick-Davis et al. 2012).

In weiteren Versuchen mit fluorescence resonance energy transfer (FRET)-Signalen wurde die Dimerbildung der 2C-Rezeptoren bereits im ER und Golgi-Apparat nachgewiesen. Die Dimere bilden sich also schon während der Rezeptor-Biogenese und nicht erst nach der Expression des Rezeptors auf der Zellmembran (Herrick-Davis et al. 2006). Auch in vivo an der apikalen Oberfläche von Zellen des Plexus choroideus konnten die Dimere des 2C-Rezeptors nachgewiesen werden (Herrick-Davis et al. 2015). Außerdem wurde die Dimerisierungsneigung in nach einer 
Agonistenstimulation und der Stimulation mit einem inversen Agonisten betrachtet. Es zeigte sich kein Einfluss auf die Dimerisierungsneigung des Rezeptors 2C (Herrick-Davis et al. 2007).

Die Analyse des hier durchgeführten $\mathrm{Ca}^{2+}$-Imagings unterstützt die Annahme einer natürlichen Dimerbildung des Rezeptors 2C, da die Signale der forcierten Homodimere sich nicht signifikant von denen der einfach exprimierten Rezeptoren unterscheiden. Ein signifikanter Unterschied würde dagegensprechen, dass die Rezeptoren bereits natürlicherweise als Dimer vorliegen.

Herrick-Davis et al. 2005 haben die Bedeutung der Dimerisierung für die Signalgebung des Rezeptors 2C durch die Inaktivierung eines der Rezeptoren im Dimer gezeigt. Wildtyp 2C-Rezeptoren wurden gemeinsam mit mutierten und dadurch inaktiven 2C-Rezeptoren exprimiert. Eine Analyse des $\mathrm{IP}_{3}$-Signals ergab, dass das Signal der Wildtyp-Rezeptoren bei Ko-Expression mit inaktiven 2C-Rezeptoren deutlich absank, obwohl vorab nachgewiesen wurde, dass die Menge der exprimierten Wildtyp-Rezeptoren auch bei der Co-Expression mit den inaktivierten Rezeptoren konstant blieb. Somit schwächte die Expression der inaktiven Rezeptoren das Signal der Wildtyp-Rezeptoren ab. Weiterhin zeigten die Daten, dass zur maximalen Aktivierung eines 2CRezeptordimers zwei Liganden notwendig sind und dass das Dimer an ein G-Protein koppelt.

Wie bereits im Falle des Rezeptors 2A kann auch für den Rezeptor 2C aufgrund der natürlichen Dimerbildung anhand der hier erhobenen Daten keine Aussage zu der Veränderung der Signalgebung im Dimer getroffen werden, da der Vergleichswert der Signalgebung im Monomer fehlt.

\subsubsection{Zusammenfassung Homodimere}

Zusammengefasst zeigen die Ergebnisse, dass sowohl der Rezeptor 2A als auch der Rezeptor 2C physiologischerweise Homodimere bilden. Die Auswirkung der Dimerisierung auf die Signalgebung kann nicht evaluiert werden, da keine Vergleichsdaten vorliegen, in denen die Rezeptoren als Monomer agieren.

Der Rezeptor 2B liegt größtenteils als Monomer vor, bildet aber fakultativ sehr dynamische Dimere. Das $\mathrm{Ca}^{2+}$-Signal der forcierten Homodimere fällt geringer aus als des einfach exprimierten Rezeptors, wobei insbesondere das langsame Absinken des $\mathrm{Ca}^{2+}$-Spiegels am einfach exprimierten Rezeptor für die dort gemessene $\mathrm{Ca}^{2+}$-Menge verantwortlich ist. Die Amplituden der $\mathrm{Ca}^{2+}$-Signale des forcierten und einfach exprimierten Rezeptors sind sich sehr ähnlich.

Die hier erhobenen Ergebnisse bestätigen bezüglich der 5-HT $\mathrm{T}_{2}$-Rezeptoren ältere Daten, in denen ein Großteil der Studien postuliert, dass die 5- $\mathrm{HT}_{1 \mathrm{~A}}, 5-\mathrm{HT}_{2 \mathrm{~A}}, 5-\mathrm{HT}_{2 \mathrm{C}}, 5-\mathrm{HT}_{4}$, und $5-\mathrm{HT}_{7}$ Rezeptoren als Homodimere vorliegen (Herrick-Davis 2013). 


\subsubsection{Interpretation der Ergebnisse hinsichtlich der Heterodimerisierung und ihrer} Auswirkungen auf die Signalgebung

Die Heterodimerisierung der 5- $\mathrm{HT}_{2}$-Rezeptoren und ihre Auswirkungen auf die Signalgebung wurden ebenfalls mittels FRAP, $\mathrm{Ca}^{2+}$-Imaging und forcierter Dimerisierung untersucht.

Anhand der Durchflusszytometrie-Experimente wurde vorab gezeigt, dass bei der Ko-Expression der gleichen DNA-Menge zweier 5-HT-Rezeptoren die gleiche Rezeptoranzahl jeder Rezeptorart exprimiert wird (siehe Kapitel 4.1). Sollten die Rezeptoren nicht miteinander interagieren, ist daher zu erwarten, dass der Diffusionskoeffizient zweier ko-exprimierter Rezeptoren zwischen den Diffusionskoeffizienten der jeweiligen allein exprimierten Rezeptoren liegt.

\subsubsection{1 $5-\mathrm{HT}_{2 \mathrm{~A} / 2 \mathrm{~B}}$}

Die Analyse der Diffusionskoeffizienten zeigt, dass die Rezeptoren 2A und 2B Heterodimere bilden. Im Vergleich zu dem Diffusionskoeffizienten des Rezeptors 2B, welcher hauptsächlich als Monomer vorliegt, ist der $\mathrm{D}_{2 \mathrm{~A} / 2 \mathrm{~B}}$ deutlich $(\mathrm{p} \leq 0,001)$ niedriger. Der $\mathrm{D}_{2 \mathrm{~A} / 2 \mathrm{~B}}$ liegt etwas über

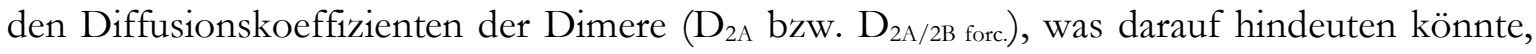
dass bei der Ko-Expression nicht alle Rezeptoren im Dimer vorliegen, jedoch ist diese Abweichung nicht signifikant.

Wird die Signalgebung in die Analyse der Dimere mit einbezogen, so zeigen sich in der Stimulation mit dem 2B-Agonisten BW723c86 Hydrochlorid Unterschiede zwischen $\mathrm{D}_{2 \mathrm{~A} / 2 \mathrm{~B}}$ und $\mathrm{D}_{2 \mathrm{~A} / 2 \mathrm{~B} \text { forc. }}$ Das Signal der forcierten Dimere fällt stärker aus als das der ko-exprimierten Rezeptoren, wobei die Abweichung mittelstark signifikant ist ( $\mathrm{p} \leq 0,01)$. Betrachtet man zusätzlich die Signalkurven, so zeigen diese eine ähnliche Reaktionskinetik der ko-exprimierten und forciert dimerisierten Rezeptoren. Sowohl die Latenzzeit als auch der Anstieg der Signalkurven sind sich sehr ähnlich. Auffällig ist jedoch, dass die Kurve des forcierten Dimers einen höheren Peak aufweist als die der ko-exprimierten Rezeptoren. Wie das stärkere Signal der forciert dimerisierten Rezeptoren zu erklären ist, lässt sich aus den vorliegenden Daten nicht schließen. Es müssten weitere Experimente durchgeführt werden, beispielsweise mit selektiveren Agonisten oder Antagonisten. Eine Möglichkeit wäre, dass die G-Protein-Bindung am Dimer effizienter ist und so mehr G-Proteine in kurzer Zeit aktiviert werden. Auch wurde eine erhöhte GDP/GTPAustauschrate bei Aktivierung eines G-Proteins durch Dimere diskutiert (Pellissier et al. 2011). Zusammengefasst zeigt sich, dass 2A und 2B heterodimerisieren. Dies wird in der FRAP eindeutig gezeigt. Der niedrige Diffusionskoeffizient ist nicht allein durch die Homodimerisierung des Rezeptors 2A begründbar. Zusätzlich zeigen sich jedoch signifikante Unterschiede zwischen 
forciert-dimerisierten und einfach ko-exprimierten Rezeptoren in der Signalgebung nach Stimulation mit dem 2B-Agonisten, welche darauf hindeuten, dass bei der Ko-Expression nicht alle Rezeptoren im Heterodimer vorliegen.

\subsubsection{2 $5-\mathrm{HT}_{2 \mathrm{~A} / 2 \mathrm{C}}$}

Die Rezeptoren 2A und 2C heterodimerisieren.

Bereits die FRAP-Daten lassen aufgrund eines niedrigen $\mathrm{D}_{2 \mathrm{~A} / 2 \mathrm{C}}$ auf eine Dimerbildung schlieBen. Da die Rezeptoren 2A und 2C natürlicherweise jeweils als Homodimere vorliegen, lässt sich anhand des $\mathrm{D}_{2 \mathrm{~A} / 2 \mathrm{C}}$ jedoch keine Aussage darüber treffen, ob der niedrige $\mathrm{D}_{2 \mathrm{~A} / 2 \mathrm{C}}$ tatsächlich durch einer Heterodimerbildung zu begründen ist. Denn sollte die Homodimerbildung der beiden Rezeptoren durch die Ko-Expression nicht gestört werden, so läge der Diffusionskoeffizient auch bei keinerlei Interaktionen zwischen den verschiedenen Rezeptoren weiterhin auf Höhe des Diffusionskoeffizienten der Homodimere.

Werden die Daten des $\mathrm{Ca}^{2+}$-Imagings in die Beurteilung der Dimerisierung mit einbezogen, so zeigen diese deutlich eine Heterodimerbildung. Insbesondere in der Agonistenstimulation wird dies deutlich. Es fällt auf, dass sowohl das Signal der ko-exprimierten als auch das der forciert dimerisierten Rezeptoren nach Stimulation mit dem Agonisten 2A im Vergleich zu der Stimulation des einfach exprimierten $2 \mathrm{~A}$ deutlich niedriger ausfällt $\left(\mathrm{AUC}_{2 \mathrm{~A}}=216 \pm 72 \mathrm{a}\right.$. E., $\mathrm{AUC}_{2 \mathrm{~A} / 2 \mathrm{C}}=59 \pm 39$ a. E., $\mathrm{AUC}_{2 \mathrm{~A} / 2 \mathrm{C} \text { forc. }}=74 \pm 39$ a. E.). Werden die Signalkurven betrachtet, so zeigt sich, dass das Signal der ko-exprimierten Rezeptoren schnell abfällt, genau wie das des Rezeptors 2C, während das Signal der forciert heterodimerisierten Rezeptoren etwas flacher abfällt. Das Signal des Rezeptors 2A fällt deutlich flacher ab, wodurch sich eine größere AUC und damit eine größere $\mathrm{Ca}^{2+}$-Menge ergeben.

Für die Stimulation mit dem Agonisten 2C zeigt sich ein ähnlicher Effekt. Die freigesetzte $\mathrm{Ca}^{2+}{ }_{-}$ Menge der Signalkurven ist in der Ko-Expression bzw. forcierten Dimerisierung fast genauso hoch wie bei der einfachen Expression des Rezeptors 2C, während das Signal des Rezeptors 2A deutlich darunter liegt. Die Signalkurven zeigen einen sehr steilen Anstieg und Abfall der 2AKurve, während die Kurven des Rezeptors 2C und an der ko-exprimierten bzw. forciert dimerisierten Rezeptoren deutlich flacher ausfallen. Wieder ähneln die Kurvenverläufe deutlich mehr der Kurve des Rezeptors 2C als der des Rezeptors 2A.

Insgesamt zeigen die Signalkurven, dass 2C bezüglich der Signalgebung den dominierenden Rezeptor darstellt, die Kurven der ko-exprimierten und forciert heterodimerisierten Rezeptoren 2A/2C ähneln diesem stark. Der Einfluss von 2A wird nur im forcierten Dimer minimal deutlich. Dies zeigt außerdem, dass das Heterodimer der favorisierte Zustand der Rezeptoren 
2A/2C bei Ko-Expression ist. Würden mehr Homodimere der Rezeptoren vorliegen, so würde das Signal des 2A-Agonisten an den ko-exprimierten Rezeptoren stärker ausfallen und mehr dem Signal des Rezeptors 2A ähneln.

Zusammengefasst zeigt die Auswertung deutlich eine Interaktion der Rezeptoren 2A/2C im Sinne einer Heterodimerbildung. Anhand der Daten aus der Agonistenstimulation wird deutlich, dass 2C der aktive Teil im Heterodimer ist und das Signal des 2A-Rezeptors unterdrückt. Dies zeigt sich besonders anhand der geringen Signale der ko-exprimierten und forciert heterodimerisierten 2A/2C nach Stimulation mit dem 2A-Agonisten TCB-2.

Die 2015 begonnenen Experimente wurden in der Zwischenzeit von Moutkine et al. 2017 bestätigt. Auch hier zeigte sich eine Dominanz des 2C-Rezeptors im Signal des 2A/2C-Heterodimer, wobei das Signal anhand des intrazellulären $\mathrm{IP}_{3}$-Levels gemessen wurde.

Die Hemmung der Signalgebung des 2A-Rezeptors durch die Dimerbildung mit 2C könnte durch eine eingeschränkten Ligandenbindung oder veränderte G-Protein-Kopplung des 2ARezeptors zu begründen sein. Das Heterodimer scheint eine Stimulation am 2C-Rezeptor zu benötigen, um ein Signal auszulösen.

\subsubsection{3 $5-\mathrm{HT}_{2 \mathrm{~B} / 2 \mathrm{C}}$}

Die Rezeptoren 2B und 2C bilden keine oder nur wenige Heterodimere.

Anhand der FRAP-Auswertung ist nicht sicher auf eine Form von Interaktion oder Heterodimerbildung zwischen den Rezeptoren 2B und 2C zu schließen. Der Diffusionskoeffizient der ko-exprimierten Rezeptoren 2B und 2C liegt genau zwischen denen der allein exprimierten Rezeptoren, was sich daraus erklären könnte, dass die Rezeptoren zum Teil Heterodimere bilden. Genauso könnte sich der Diffusionskoeffizient jedoch daraus ergeben, dass die 2B-Rezeptoren weiterhin als Monomere und die 2C-Rezeptoren als Homodimere vorliegen. Eine weitergehende Analyse, z. B. mittels SPT, wäre anzustreben, um die Fraktionen von Dimeren und Monomeren differenzieren zu können.

Betrachtet man das Signalverhalten der ko-exprimierten Rezeptoren, so ist ihr Signal in der Serotonin-Stimulation genauso groß wie das der einzeln exprimierten 2B bzw. 2C. Betrachtet man hingegen das Signal der forciert dimerisierten Rezeptoren nach der Stimulation mit Serotonin, so fällte es signifikant geringer aus als das der ko-exprimierten Rezeptoren. Auch in der Stimulation mit dem 2B-Agonisten (BW723c86 Hydrochlorid) bzw. dem 2C-Agonisten (WAY629 Hydrochlorid) fällt das Signal des forcierten Dimers sehr gering aus. Es gibt keinen dominanten Rezeptor wie in der 2A/2C-Kombination, da das Signal der co-exprimierten Rezeptoren und 
insbesondere der forciert dimerisierten Rezeptoren nach der Stimulation mit beiden Agonisten (Agonist 2B und 2C) gering ausfällt.

Der Signalreduktion am forcierten Heterodimer kann z. B. eine geringere Ligandenbindung oder eine geringere Effizienz der G-Protein-Bindung im Vergleich zu den einfach exprimierten Rezeptoren zugrunde liegen.

Zusammenfassend lässt sich aus den Daten der Schluss ziehen, dass 2B und 2C natürlicherweise kaum oder keine Heterodimere bilden, dies zeigen sowohl der Diffusionskoeffizient als auch die Signalgebung. Wird die Dimerisierung forciert, so wird die Signalgebung sowohl in der BW723c86- als auch der WAY629-Hydrochlorid-Stimulation stark gemindert im Vergleich zu dem Signal der ko-exprimierten Rezeptoren. Sollte in vivo tatsächlich eine Heterodimerisierung der Rezeptoren auftreten, so wäre es möglich, dass die Rezeptoren die Dimerisierung als Signalreduktion nutzen, beispielsweise im Falle einer übermäßigen Stimulation. 


\subsubsection{Zusammenfassung: Dimerisierung und ihr Einfluss auf die Signalgebung}

Tabelle 15: Übersicht über die Homo- und Heterodimerbildung der 5- $\mathrm{HT}_{2}$-Rezeptoren und die jeweiligen Auswirkungen der Dimerisierung auf die Signalgebung.

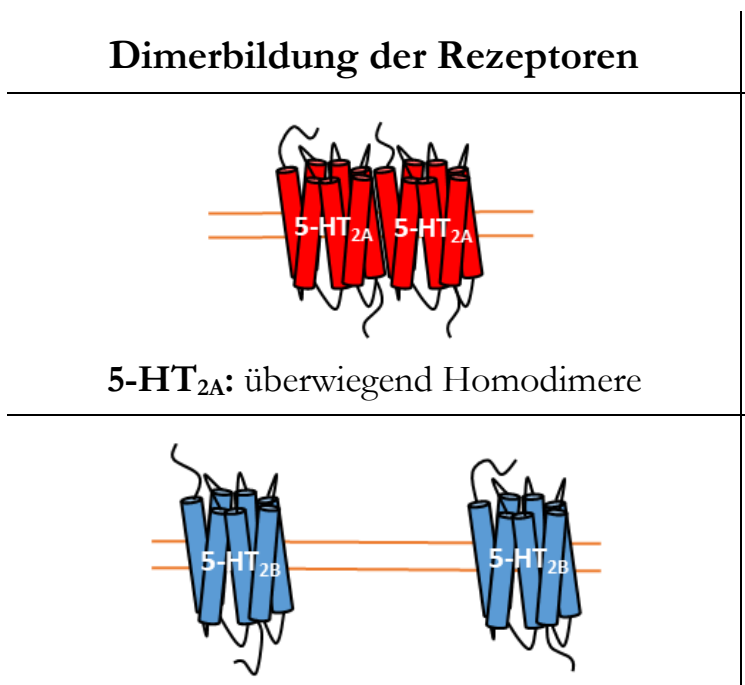

5-HT $\mathbf{T}_{2 \mathrm{~B}}$ : kurzzeitige Homodimere, überwiegend Monomere

\section{Auswirkungen auf die Signalgebung}

Die 5-HT $2 \mathrm{~A}-$ Rezeptoren zeigen eine starke, natürliche Dimerisierungsneigung. Eine weitergehende Untersuchung bezüglich der Auswirkungen auf die Signalgebung würde eine forcierte Monomerisierung erfordern.

Die nach Stimulation freigesetzte $\mathrm{Ca}^{2+}$-Menge des Rezeptors 2B ist am forcierten Homodimer geringer als am monomeren Rezeptor, während die Amplitude des $\mathrm{Ca}^{2+}$-Signals keinen deutlichen Unterschied zeigt.

Für 2C gilt dieselbe Aussage wie für 2A.

5-H $\mathbf{T}_{2 \mathbf{C}}$ : überwiegend Homodimere

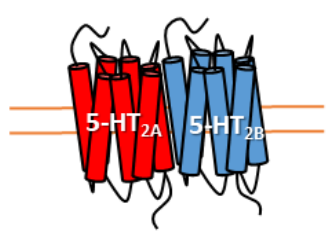

5-HT $\mathbf{T}_{2 \mathrm{~A}} / \mathbf{5 - H} \mathbf{T}_{2 \mathrm{~B}}$ : zum Teil Heterodimere

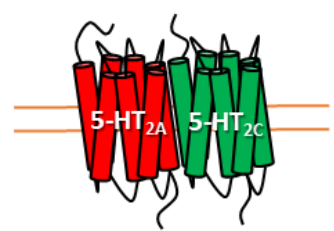

5-H'T $\mathbf{T}_{2 \mathrm{~A}}$ /5-HT $\mathbf{T}_{2 \mathrm{C}}$ : größtenteils Heterodimere

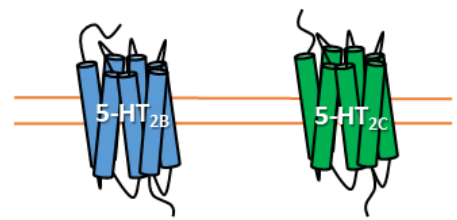

5-H'T $\mathbf{T}_{\mathbf{2 B}} / \mathbf{5 - H} \mathbf{T}_{\mathbf{2 C}}$ : keine eindeutige

Heterodimerisierung messbar
Das Signal der Rezeptoren 2A/2B wird im forcierten Dimer tendenziell verstärkt.

Die Rezeptoren 2A/2C sprechen auf einen reinen 2A-Stimulus kaum an. Für ein starkes Signal im Dimer ist ein Agonist nötig, welcher am 2C-Rezeptor angreift. Die Dimerbildung mit 2C unterdrückt das 2A-Signal.

Im forcierten Heterodimer $2 \mathrm{~B} / 2 \mathrm{C}$ ist das Signal der Rezeptoren reduziert. 


\subsection{Ausblick}

Die vorliegende Arbeit bietet einen Überblick über die Dimerisierungsneigung der Rezeptoren der 5-HT ${ }_{2}$-Gruppe (gemessen anhand der Diffusionsgeschwindigkeit) und untersucht den Einfluss der Dimerisierung auf die Signalgebung (gemessen am $\mathrm{Ca}^{2+}$-Signal). Hierfür wird zusätzlich in Form des Nanobody-GFP-Konstrukts eine neue Methode zur kontrollierten Dimerisierung der Rezeptoren eingebracht. Durch weitere Untersuchungen können die vorliegenden Daten erweitert werden.

Beispielsweise wird in den kommenden Jahren die Entwicklung der Agonisten für 5-HT-Rezeptoren fortschreiten, sodass zum einen mit selektiveren Agonisten oder zum anderen mit bivalenten Agonisten für Dimere stimuliert werden könnte. Damit könnten Auswirkungen der direkten Aktivierung eines Dimers noch besser untersucht werden. Auch die Pharmakologie würde von der Entwicklung solch bivalenter Agonisten profitieren. Durch die direkte Agonisierung bestimmter Homo- oder Heterodimere kann ein Medikament spezifischer wirken. So würden sich massiv weniger unerwünschte Arzneimittelwirkungen ergeben, womit das Medikament in noch höheren Dosierungen wirksam eingesetzt werden könnte.

Weiterhin könnte die Analyse anderer Signalwege zu neuen Erkenntnissen führen. Während in der vorliegenden Arbeit $\mathrm{Ca}^{2+}$ als Indikator für die Signalweiterleitung der Rezeptoren genutzt und in weiteren Publikationen hauptsächlich der $\mathrm{IP}_{3}$-Spiegel analysiert wurde, bieten sich auch

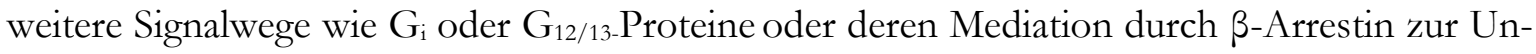
tersuchung der Signalweiterleitung der 5-HT-Rezeptoren an (Wacker et al. 2013). Auch wäre es interessant, herauszufinden wodurch die Dimerbildung der Rezeptoren deren Signalgebung beeinflusst. Mögliche Ansätze sind eine veränderte G-Protein-Bindung des Dimers oder eine erhöhte Austauschrate des GTP/GDP am gebundenen G-Protein (Pellissier et al. 2011).

Abgesehen von der Auswirkung der Dimerisierung auf die Signalgebung, welche hier im Fokus stand, können die Auswirkungen auf weitere Entwicklungsstadien der Rezeptoren untersucht werden. So kann die Dimerisierung für das Verlassen des ER, also die Ontogenese der Rezeptoren, nötig sein. Auch kann sich die Internalisierung und damit Desensibilisierung der Rezeptoren durch eine Dimerbildung ändern. Ein Rezeptor, welcher physiologischerweise nicht internalisiert wird, kann möglicherweise im Heterodimer durch den gebundenen Rezeptor internalisiert werden und andersherum (siehe Kapitel 1.4.1).

Ferner sind Auswirkungen der Bindung von Liganden auf die Dimerbildung möglich. Bisher ist bereits für den Rezeptor 5- $\mathrm{HT}_{2 \mathrm{C}}$ bekannt, dass eine Stimulation keine Auswirkungen auf seine 
Homodimerisierung hat (Herrick-Davis et al. 2005), jedoch wäre prinzipiell eine vermehrte oder verminderte Dimerbildung durch eine Ligandenbindung durchaus möglich.

Um die Dimerisierung als mögliches Target neuer pharmakologischer Ansätze zu nutzen, wäre außerdem die Identifizierung solcher Zellverbände, die verschiedene 5-HT-Rezeptoren in vivo ko-exprimieren, essenziell.

In der vorliegenden Arbeit wurden - wie bereits vorstehend genannt - nicht nur neue Erkenntnisse bezüglich der Dimerbildung der 5-HT2-Rezeptoren gewonnen. Auch wurde die Methode des Nanobody-GFP-Konstrukts zur Forcierung von Dimeren erfolgreich eingesetzt, sodass diese zur weiteren Erforschung der Rezeptordimerisierung angewendet werden kann. Für zukünftige Arbeiten wären nicht nur weitere Möglichkeiten zur forcierten Dimerisierung (siehe Kapitel 4.1), sondern auch Methoden zur Forcierung von Monomeren interessant. Bei Rezeptoren, welche ausschließlich im konstitutiven Dimer vorliegen, könnten durch die forcierte Monomerisierung eventuelle Auswirkungen der Dimerbildung gezeigt werden. Mögliche Ansätze werden bereits in Kapitel 4.3.1 diskutiert. 


\section{$5 \quad$ Zusammenfassung}

Im Rahmen der vorliegenden Arbeit wurde der Frage nach der Auswirkung der Dimerisierung auf die Signalgebung der Rezeptoren 5- $\mathrm{HT}_{2 \mathrm{~A}}, 5-\mathrm{HT}_{2 \mathrm{~B}}$ und 5- $\mathrm{HT}_{2 \mathrm{C}}$ nachgegangen.

Im ersten Schritt konnten mit Hilfe der fluorescence recovery after photobleaching (FRAP) die Diffusionskoeffizienten der einzelnen und der ko-exprimierten 5- $\mathrm{HT}_{2}$-Rezeptoren in sämtlichen Kombinationen ermittelt werden. Durch den Vergleich der Diffusionskoeffizienten zeigte sich, ob die Rezeptoren zur Homo- oder Heterodimerisierung neigen. In einem zweiten Schritt wurde durch die Messung des intrazellulären $\mathrm{Ca}^{2+}$-Spiegels und dessen Anstieg nach einer Stimulation das Signal der Rezeptoren und Rezeptorkombinationen gemessen. Die Stimulation erfolgte sowohl mit Serotonin als auch mit den Rezeptoragonisten TCB-2 (Agonist 2A), BW723c86 Hydrochlorid (Agonist 2B) und WAY629 Hydrochlorid (Agonist 2C).

Die Ergebnisse wurden anhand eines ungepaarten t-Tests mit einem Konfidenzintervall von $95 \%$ verglichen und ausgewertet. Um weitere Aussagen bezüglich der Dimerisierung und ihrer Auswirkungen auf die Signalgebung treffen zu können, wurden zusätzlich Experimente durchgeführt, in denen die Rezeptoren in reine Homo- bzw. Heterodimere forciert wurden. Die Forcierung wurde unter Verwendung eines Nanobody-Konstrukts, welches unter anderem grün fluoreszierendes Protein (GFP) bindet, erreicht. Die Daten aus diesen Experimenten konnten als Vergleichswerte genutzt werden, da sie sowohl in der FRAP-Analyse als auch im $\mathrm{Ca}^{2+}$-Imaging die Werte der reinen Dimere widerspiegeln.

Die Daten zeigen, dass sowohl 5- $\mathrm{HT}_{2 \mathrm{~A}}$ als auch 5- $\mathrm{HT}_{2 \mathrm{C}}$ als Homodimere vorliegen. 5- $\mathrm{HT}_{2 \mathrm{~B}}$ hingegen liegt größtenteils als Monomer vor und bildet nur sehr kurzzeitige, dynamische Dimere, deren $\mathrm{Ca}^{2+}$-Signal niedriger ausfällt als das der Monomere.

5- $\mathrm{HT}_{2 \mathrm{~A}}$ und $5-\mathrm{HT}_{2 \mathrm{~B}}$ bilden zum Teil Heterodimere, liegen aber auch bei einer Ko-Expression weiterhin zum Teil als Monomer bzw. Homodimer vor. Die forcierte Heterodimerisierung verstärkt das $\mathrm{Ca}^{2+}$-Signal. 5-HT $2 \mathrm{~A}$ und 5-HT $2 \mathrm{C}$ bilden Heterodimere, wobei auffällt, dass $5-\mathrm{HT}_{2 \mathrm{C}}$ die Signalgebung dominiert und das Signal des Rezeptors 5- $\mathrm{HT}_{2 \mathrm{~A}}$ unterdrückt. 5- $\mathrm{HT}_{2 \mathrm{~B}}$ und 5- $\mathrm{HT}_{2 \mathrm{C}}$ bilden kaum oder gar keine Heterodimere. Werden die beiden Rezeptoren dennoch in ein Heterodimer forciert, so ist nur noch ein sehr geringes $\mathrm{Ca}^{2+}$-Signal auslösbar.

Die Ergebnisse zeigen zum einen, dass die Verwendung eines Nanobody-GFP-Konstrukts zur Forcierung von Dimeren zuverlässig einsetzbar ist. Zum anderen wurde deutlich, dass innerhalb der Gruppe der 5-HT2-Rezeptoren sowohl Homo- als auch die Heterodimere gebildet werden und dass die Dimerisierung einen Einfluss auf die Signalgebung der Rezeptoren hat. 
Ausgehend von den im Rahmen der Doktorarbeit gewonnenen Erkenntnissen kann nun zukünftig die Dimerisierung weitergehend untersucht werden, beispielsweise mit einem Fokus auf die Entwicklungsstadien der Rezeptoren oder mit Blick auf die Rezeptorstimulation. So könnte die Dimerisierung nach weiteren Forschungen als pharmakologischer Ansatzpunkt genutzt werden. 


\section{$6 \quad$ Literaturverzeichnis}

AbdAlla S, Lother H, Quitterer U (2000): AT1-receptor heterodimers show enhanced G-protein activation and altered receptor sequestration. Nature 407, 94-98

Amano T, Richelson E, Nirenberg M (1972): Neurotransmitter synthesis by neuroblastoma clones (neuroblast differentiation-cell culture-choline acetyltransferase-acetylcholinesterase-tyrosine hydroxylase-axons-dendrites). Proc Natl Acad Sci USA 으, 258-263

Andrade R et al. (2019): 5-Hydroxytryptamine receptors (version 2019.4). IUPHAR/BPS Guide to Pharmacology. 2019(4). https://doi.org/10.2218/gtopdb/F1/2019.4; Zugriff am 15.01.2019

Axelrod D, Koppel DE, Schlessinger J, Elson E, Webb WW (1976): Mobility measurement by analysis of fluorescence photobleaching recovery kinetics. Biophys J 16, 1055-1069

Barnes NM, Sharp T (1999): A review of central 5-HT receptors and their function. Neuropharmacology $\underline{38}, 1083-1152$

Berger M, Gray JA, Roth BL (2009): The expanded biology of Serotonin. Annu Rev Med $\underline{60}$, 355-366

Berridge MJ (1984): Inositol trisphosphate and diacylglycerol as second messengers. Biochem J $\underline{220}, 345-360$

Berumen LC, Rodríguez A, Miledi R, García-Alcocer G (2012): Serotonin receptors in Hippocampus. Sci World J 2012, 1-15

Bourne HR (1997): How receptors talk to trimeric G proteins. Curr Opin Cell Biol ㅁ, 134-142

Brea J, Castro M, Giraldo J, López-Giménez JF, Padín JF, Quintián F, Cadavid MI, Vilaró MT, Mengod G, Berg KA et al. (2009): Evidence for distinct antagonist-revealed functional states of 5-Hydroxytryptamine 2A receptor homodimers. Mol Pharmacol $\underline{75}$, 1380-1391

Brink CB, Harvey BH, Bodenstein J, Venter DP, Oliver DW (2004): Recent advances in drug action and therapeutics: Relevance of novel concepts in G-protein-coupled receptor and signal transduction pharmacology. Br J Clin Pharmacol 57, 373-387

Byrne MP, Stites WE (1995): Chemically crosslinked protein dimers: stability and denaturation effects. Protein Sci 4, 2545-2558

Carli M, Kolachalam S, Aringhieri S, Rossi M, Giovannini L, Maggio R, Scarselli M (2018): Dopamine D2 receptor dimers: How can we pharmacologically target them? Curr Neuropharmacol 16, 222-230

Chalfie M, Tu Y, Euskirchen G, Ward WW, Prasher DC (1994): Green fluorescent protein as a marker for gene expression. Science 263, 802-805

Chen TW, Wardill TJ, Sun Y, Pulver SR, Renninger SL, Baohan A, Schreiter ER, Kerr RA, Orger MB, Jayaraman V et al. (2013): Ultrasensitive fluorescent proteins for imaging neuronal activity. Nature $\underline{499}, 295-300$

Davies MN, Secker A, Freitas AA, Mendao M, Timmis J, Flower DR (2007): On the hierarchical classification of G-protein-coupled receptors. Bioinformatics $\underline{23}$, 3113-3118 
Dorsch S, Klotz KN, Engelhardt S, Lohse MJ, Bünemann M (2009): Analysis of receptor oligomerization by FRAP microscopy. Nat Methods $\underline{6}, 225-230$

Ebersberger A (2002): Pathophysiologie der Migräne. Anaesthesist 51, 661-667

Edward JT (1970): Molecular volumes and the Stokes-Einstein equation. J Chem Educ 47, 261

El-Merahbi R, Löffler M, Mayer A, Sumara G (2015): The roles of peripheral serotonin in metabolic homeostasis. FEBS Lett $\underline{589}, 1728-1734$

Erspamer V (1940): Pharmakologische Studien über Enteramin. Naunyn-Schmiedebergs Arch für Exp Pathol Pharmakol 196, 343-365

Erspamer V, Asero B (1952): Identification of enteramine, the specific hormone of the enterochromaffin cell system, as 5-hydroxytryptamine. Nature 169, 800-801

Ferré S (2015): The GPCR heterotetramer: Challenging classical pharmacology. Trends Pharmacol Sci $\underline{36}, 145-152$

Fox MA, French HT, LaPorte JL, Blackler AR, Murphy DL (2010): The serotonin 5-HT(2A) receptor agonist TCB-2: a behavioral and neurophysiological analysis. Psychopharmacology (Berl) 212, 13-23

Frazer A, Hensler J: Chapter 13: Serotonin receptors. In: Siegel G, Agranoff B, Albers R, Fisher S, Uhler M (Hrsg.): Basic Neurochemistry: Molecular, Cellular, and Medical Aspects. 6. Auflage; Lippincott-Raven, Philadelphia 1999

Gershon MD, Tack J (2007): The Serotonin signaling system: From basic understanding to drug development for functional GI disorders. Gastroenterology 132, 397-414

Gibson DG, Young L, Chuang RY, Venter JC, Hutchison Iii CA, Smith HO (2009): Enzymatic assembly of DNA molecules up to several hundred kilobases. Nat Methods $\underline{6}, 343-345$

Ginés S, Hillion J, Torvinen M, Crom SL, Casadó V, Canela EI, Rondin S, Lew JY, Watson S, Zoli M et al. (2000): Dopamine D1 and adenosine A1 receptors form functionally interacting heteromeric complexes. Proc Natl Acad Sci 197, 8606-8611

Goldman N, Glei DA, Lin YH, Weinstein M (2010): The Serotonin transporter polymorphism (5-HTTLPR): Allelic variation and links with depressive symptoms. Depress Anxiety 27, 260 269

González-Maeso J, Ang R, Yuen T, Chan P, Weisstaub NV, López-Giménez JF, Zhou M, Okawa Y, Callado LF, Milligan G et al. (2008): Identification of a novel Serotonin/Glutamate receptor complex implicated in psychosis. Nature $\underline{452}, 93-97$

Guo W, Shi L, Javitch JA (2003): The fourth transmembrane segment forms the interface of the dopamine D2 receptor homodimer. J Biol Chem $\underline{278}$, 4385-4388

Gurevich VV, Gurevich EV (2008a): GPCR monomers and oligomers: it takes all kinds. Trends Neurosci $\underline{31}, 74-81$

Gurevich VV, Gurevich EV (2008b): How and why do GPCRs dimerize? Trends Pharmacol Sci $\underline{29}, 234-240$ 
Hamers-Casterman C, Atarhouch T, Muyldermans S, Robinson G, Hammers C, Songa EB, Bendahman N, Hammers R (1993): Naturally occurring antibodies devoid of light chains. Nature $\underline{363}, 446-448$

Hamm HE (1998): The many faces of G protein signaling. J Biol Chem $\underline{273}$, 669-672

Han Y, Moreira IS, Urizar E, Weinstein H, Javitch JA (2009): Allosteric communication between protomers of dopamine class A GPCR dimers modulates activation. Nat Chem Biol $\underline{5}, 688-695$

Hauser AS, Attwood MM, Rask-Andersen M, Schiöth HB, Gloriam DE (2017): Trends in GPCR drug discovery: new agents, targets and indications. Nat Rev Drug Discov $\underline{16}, 829-842$

Herrick-Davis K (2013): Functional significance of Serotonin receptor dimerization. Exp Brain Res $\underline{230}, 375-386$

Herrick-Davis K, Grinde E, Mazurkiewicz JE (2004): Biochemical and biophysical characterization of Serotonin 5-HT2C receptor homodimers on the plasma membrane of living cells. Biochemistry $\underline{43}, 13963-13971$

Herrick-Davis K, Grinde E, Harrigan TJ, Mazurkiewicz JE (2005): Inhibition of Serotonin 5Hydroxytryptamine $2 \mathrm{C}$ receptor function through heterodimerization: receptor dimers bind two molecules of ligand and one G-protein. J Biol Chem $\underline{280}$, 40144-40151

Herrick-Davis K, Weaver BA, Grinde E, Mazurkiewicz JE (2006): Serotonin 5-HT2C receptor homodimer biogenesis in the endoplasmic reticulum: real-time visualization with confocal fluorescence resonance energy transfer. J Biol Chem $\underline{281}$, 27109-27116

Herrick-Davis K, Grinde E, Weaver BA (2007): Serotonin 5-HT2C receptor homodimerization is not regulated by agonist or inverse agonist treatment. Eur J Pharmacol $\underline{568}, 45-53$

Herrick-Davis K, Grinde E, Lindsley T, Cowan A, Mazurkiewicz JE (2012): Oligomer size of the Serotonin 5-Hydroxytryptamine 2C (5-HT2C) receptor revealed by fluorescence correlation spectroscopy with photon counting histogram analysis: Evidence for homodimers without monomers or tetramers. J Biol Chem 287, 23604-23614

Herrick-Davis K, Grinde E, Lindsley T, Teitler M, Mancia F, Cowan A, Mazurkiewicz JE (2015): Native Serotonin 5-HT2C receptors are expressed as homodimers on the apical surface of choroid plexus epithelial cells. Mol Pharmacol $\underline{87}$, 660-673

Hollmann MW, Strumper D, Herroeder S, Durieux ME (2005): Receptors, G-proteins, and their interactions. Anesthesiol J Am Soc Anesthesiol 103, 1066-1078

Hoyer D, Clarke DE, Fozard JR, Hartig PR, Martin GR, Mylecharane EJ, Saxena PR, Humphrey PP (1994): International union of pharmacology classification of receptors for 5-hydroxytryptamine (Serotonin). Pharmacol Rev $\underline{46}, 157-203$

Hu GM, Mai TL, Chen CM (2017): Visualizing the GPCR network: Classification and evolution. Sci Rep 7, 15495

Hu J, Thor D, Zhou Y, Liu T, Wang Y, McMillin SM, Mistry R, Challiss RAJ, Costanzi S, Wess J (2012): Structural aspects of M-muscarinic acetylcholine receptor dimer formation and activation. FASEB J Off Publ Fed Am Soc Exp Biol 26, 604-616 
James JR, Oliveira MI, Carmo AM, Iaboni A, Davis SJ (2006): A rigorous experimental framework for detecting protein oligomerization using bioluminescence resonance energy transfer. Nat Methods $\underline{3}, 1001$

Johnston JM, Aburi M, Provasi D, Bortolato A, Urizar E, Lambert NA, Javitch JA, Filizola M (2011): Making structural sense of dimerization interfaces of delta opioid receptor homodimers. Biochemistry $\underline{50}, 1682-1690$

Kasai RS, Kusumi A (2014): Single-molecule imaging revealed dynamic GPCR dimerization. Curr Opin Cell Biol 27, 78-86

Kennett GA, Bright F, Trail B, Baxter GS, Blackburn TP (1996): Effects of the 5-HT2B receptor agonist, BW 723C86, on three rat models of anxiety. Br J Pharmacol 117, 1443-1448

Kleven MS, Assié MB, Koek W (1997): Pharmacological characterization of in vivo properties of putative mixed 5-HT1A agonist/5-HT(2A/2C) antagonist anxiolytics. II. Drug discrimination and behavioral observation studies in rats. J Pharmacol Exp Ther 282, 747-759

Kniazeff J, Bessis AS, Maurel D, Ansanay H, Prézeau L, Pin JP (2004): Closed state of both binding domains of homodimeric mGlu receptors is required for full activity. Nat Struct Mol Biol 11, 706-713

Kobilka BK (2007): G-protein coupled receptor structure and activation. Biochim Biophys Acta $\underline{1768}, 794-807$

Koppen CJ van, Jakobs KH (2004): Arrestin-independent internalization of G-protein-coupled receptors. Mol Pharmacol $\underline{66}, 365-367$

Kozasa T, Hajicek N, Chow CR, Suzuki N (2011): Signalling mechanisms of RhoGTPase regulation by the heterotrimeric G proteins G12 and G13. J Biochem (Tokyo) 150, 357-369

Kubala MH, Kovtun O, Alexandrov K, Collins BM (2010): Structural and thermodynamic analysis of the GFP: GFP-nanobody complex. Protein Sci Publ Protein Soc 19, 2389-2401

Lefkowitz RJ (1998): G Protein-coupled Receptors III. New roles for receptor kinases and $\beta$ arrestins in receptor signaling and desensitation. J Biol Chem $\underline{273}$, 18677-18680

Lin SH, Lee LT, Yang YK (2014): Serotonin and mental disorders: A concise review on molecular neuroimaging evidence. Clin Psychopharmacol Neurosci 12, 196-202

Linsley PS, Nadler SG, Bajorath J, Peach R, Leung HT, Rogers J, Bradshaw J, Stebbins M, Leytze G, Brady W et al. (1995): Binding stoichiometry of the cytotoxic T-lymphocyte-associated molecule-4 (CTLA-4): A disulfide-linked homodimer binds two CD86 molecules. J Biol Chem 270, 15417-15424

Lorén N, Hagman J, Jonasson JK, Deschout H, Bernin D, Cella-Zanacchi F, Diaspro A, McNally JG, Ameloot M, Smisdom N, et al. (2015): Fluorescence recovery after photobleaching in material and life sciences: putting theory into practice. Q Rev Biophys $\underline{48}, 323-387$

Ludwig C, Schmidt A (1868): Das Verhalten der Gase, welche mit dem Blut durch den reizbaren Säugethiermuskel strömen. In: Ludwig C (Hrsg.), Verlag von Veit und Company: Arbeiten aus der physiologischen Anstalt zu Leipzig, 1-61. Verfügbar als Reprint: Forgotten Books, London 2018 
Manzo C, Garcia-Parajo MF (2015): A review of progress in single particle tracking: from methods to biophysical insights. Rep Prog Phys $\underline{78}, 124601$

Margeta-Mitrovic M, Jan YN, Jan LY (2000): A trafficking checkpoint controls GABAB receptor heterodimerization. Neuron $27,97-106$

Martin-Gronert MS, Stocker CJ, Wargent ET, Cripps RL, Garfield AS, Jovanovic Z, D’Agostino G, Yeo GSH, Cawthorne MA, Arch JRS et al. (2016): 5-HT2A and 5-HT2C receptors as hypothalamic targets of developmental programming in male rats. Dis Model Mech $\underline{9}, 401-412$

Milligan G (2001): Oligomerisation of G-protein-coupled receptors. J Cell Sci 114, 1265-1271

Mohammad-Zadeh LF, Moses L, Gwaltney-Brant SM (2008): Serotonin: a review. J Vet Pharmacol Ther $\underline{31}, 187-199$

Moutkine I, Quentin E, Guiard BP, Maroteaux L, Doly S (2017): Heterodimers of serotonin receptor subtypes 2 are driven by 5-HT2C protomers. J Biol Chem 292, 6352-6368

Mullineaux CW, Kirchhoff H (2007): Using fluorescence recovery after photobleaching to measure lipid diffusion in membranes. Methods Mol Biol Clifton NJ 400, 267-275

Muyldermans S (2001): Single domain camel antibodies: current status. Rev Mol Biotechnol $\underline{74}$, 277-302

Muyldermans S, Atarhouch T, Saldanha J, Barbosa JA, Hamers R (1994): Sequence and structure of $\mathrm{VH}$ domain from naturally occurring camel heavy chain immunoglobulins lacking light chains. Protein Eng 7, 1129-1135

Pasqualetti M, Ori M, Castagna M, Marazziti D, Cassano GB, Nardi I (1999): Distribution and cellular localization of the serotonin type $2 \mathrm{C}$ receptor messenger RNA in human brain. Neuroscience $\underline{92}, 601-611$

Pellissier LP, Barthet G, Gaven F, Cassier E, Trinquet E, Pin JP, Marin P, Dumuis A, Bockaert J, Banères JL, Claeysen S (2011): G-protein activation by Serotonin type 4 receptor dimers. J Biol Chem 286, 9985-9997

Pompeiano M, Palacios JM, Mengod G (1994): Distribution of the serotonin 5-HT2 receptor family mRNAs: comparison between 5-HT2A and 5-HT2C receptors. Mol Brain Res $\underline{23}, 163$ 178

Rajagopal S, Shenoy SK (2018): GPCR desensitization: acute and prolonged phases. Cell Signal 41, 9-16

Rapport MM, Green AA, Page IH (1948): Serum vasoconstrictor, serotonin; isolation and characterization. J Biol Chem 176, 1243-1251

Renner U, Zeug A, Woehler A, Niebert M, Dityatev A, Dityateva G, Gorinski N, Guseva D, Abdel-Galil D, Fröhlich M et al. (2012): Heterodimerization of serotonin receptors 5-HT1A and 5-HT7 differentially regulates receptor signalling and trafficking. J Cell Sci 125, 2486-2499

Rhee SG, Choi KD (1992): Regulation of inositol phospholipid-specific phospholipase C isozymes. J Biol Chem 267, 12393-12396 
Rocheville M, Lange DC, Kumar U, Patel SC, Patel RC, Patel YC (2000): Receptors for Dopamine and Somatostatin: formation of hetero-oligomers with enhanced functional activity. Science $288,154-157$

Romano C, Yang WL, O’Malley KL (1996): Metabotropic Glutamate receptor 5 is a disulfidelinked dimer. J Biol Chem 271, 28612-28616

Sabb AL, Vogel RL, Welmaker GS, Sabalski JE, Coupet J, Dunlop J, Rosenzweig-Lipson S, Harrison B (2004): Cycloalkyl[b][1,4]benzodiazepinoindoles are agonists at the human 5-HT2C receptor. Bioorg Med Chem Lett 14, 2603-2607

Schmitt A, Mössner R, Gossmann A, Fischer IG, Gorboulev V, Murphy DL, Koepsell H, Lesch KP (2003): Organic cation transporter capable of transporting serotonin is up-regulated in serotonin transporter-deficient mice. J Neurosci Res $\underline{71}, 701-709$

Shimomura O, Johnson FH, Saiga Y (1962): Extraction, purification and properties of aequorin, a bioluminescent protein from the luminous hydromedusan, Aequorea. J Cell Comp Physiol $\underline{59}$, 223-239

Siehler S (2009): Regulation of RhoGEF proteins by G12/13-coupled receptors. Br J Pharmacol $\underline{158}, 41-49$

Simon MI, Strathmann MP, Gautam N (1991): Diversity of G proteins in signal transduction. Science 252, 802-808

Simons K, Sampaio JL (2011): Membrane organization and lipid rafts. Cold Spring Harb Perspect Biol $\underline{3}$, a004697

Sohn JW, Xu Y, Jones JE, Wickman K, Williams KW, Elmquist JK (2011): Serotonin 2C receptor activates a distinct population of arcuate pro-opiomelanocortin neurons via TRPC channels. Neuron $\underline{71}, 488-497$

Song GJ, Jones BW, Hinkle PM (2007): Dimerization of the thyrotropin-releasing hormone receptor potentiates hormone-dependent receptor phosphorylation. Proc Natl Acad Sci 104, 18303-18308

Soumpasis DM (1983): Theoretical analysis of fluorescence photobleaching recovery experiments. Biophys J 41, 95-97

Teichmann A, Rutz C, Kreuchwig A, Krause G, Wiesner B, Schülein R (2012): The pseudo signal peptide of the corticotropin-releasing factor receptor type $2 \mathrm{~A}$ prevents receptor oligomerization. J Biol Chem 287, 27265-27274

Terrillon S, Bouvier M (2004): Roles of G-protein-coupled receptor dimerization. EMBO Rep $\underline{5}, 30-34$

Tsien RY (1998): The green fluorescent protein. Annu Rev Biochem 67, 509-544

Venkatakrishnan AJ, Deupi X, Lebon G, Tate CG, Schertler GF, Babu MM (2013): Molecular signatures of G-protein-coupled receptors. Nature $\underline{494}$, 185-194

Vilardaga JP, Nikolaev VO, Lorenz K, Ferrandon S, Zhuang Z, Lohse MJ (2008): Conformational cross-talk between alpha2A-adrenergic and mu-opioid receptors controls cell signaling. Nat Chem Biol 4, 126-131 
Wacker D, Wang C, Katritch V, Han GW, Huang XP, Vardy E, McCorvy JD, Jiang Y, Chu M, Siu FY et al. (2013): Structural features for functional selectivity at Serotonin receptors. Science $\underline{340}, 615-619$

Wacker D, Stevens RC, Roth BL (2017): How ligands illuminate GPCR molecular pharmacology. Cell $\underline{170}, 414-427$

Wess J (1997): G-protein-coupled receptors: molecular mechanisms involved in receptor activation and selectivity of $\mathrm{G}$-protein recognition. FASEB J 11, 346-354

Wijk T van der, Overvoorde J, Hertog J den (2004): H2O2-induced intermolecular disulfide bond formation between receptor protein-tyrosine phosphatases. J Biol Chem $\underline{279}$, 4435544361

Woods GM, Flies AS (2019): Wild immunology—the answers are out there. Front. Immunol $\underline{10}, 126$

Xie Z, Lee SP, O’Dowd BF, George SR (1999): Serotonin 5-HT1B and 5-HT1D receptors form homodimers when expressed alone and heterodimers when co-expressed. FEBS Lett $\underline{466}$, 6367

Xue L, Sun Q, Zhao H, Rovira X, Gai S, He Q, Pin JP, Liu J, Rondard P (2019): Rearrangement of the transmembrane domain interfaces associated with the activation of a GPCR hetero-oligomer. Nat Commun $\underline{10}, 1-12$

Yadav VK, Oury F, Suda N, Liu Z-W, Gao XB, Confavreux C, Klemenhagen KC, Tanaka KF, Gingrich JA, Guo XE et al. (2009): Leptin regulation of bone mass, appetite and energy expenditure relies on its ability to inhibit serotonin synthesis in the brainstem. Cell 138, 976-989

Zhang D, Zhao Q, Wu B (2015): Structural studies of G-protein-coupled receptors. Mol Cells $\underline{38}, 836-842$

Zhang R, Xie X (2012): Tools for GPCR drug discovery. Acta Pharmacol Sin $\underline{33}$, 372-384

Zhang XC, Liu J, Jiang D (2014): Why is dimerization essential for class-C GPCR function? New insights from mGluR1 crystal structure analysis. Protein Cell $\underline{5}, 492-495$ 